\title{
Personal reflections on the multichannel cochlear implant and a view of the future
}

\author{
Graeme M. Clark, Laureate Prof Emer, AC, FAA, FRS, MS, PhD, FRCS, FRACS \\ Department of Otolaryngology, University of Melbourne, East Melbourne, Victoria 3002, Australia
}

\begin{abstract}
The multichannel cochlear implant is the first neural prosthesis to effectively and safely bring electronic technology into a direct physiological relation with the central nervous system and human consciousness. It is also the first cochlear implant to give speech understanding to tens of thousands of persons with profound deafness and spoken language to children born deaf in more than 80 countries. In so doing, it is the first major advance in research and technology to help deaf children communicate since Sign Language of the Deaf was developed at the Paris deaf school (L'Institut National de Jeunes Sourds de Paris) >200 years ago. Furthermore, biomedical research has been fundamental for ensuring that the multielectrode implant is safe as well as effective. More recent research has also shown that bilateral implants confer the benefits of binaural hearing. Future research using nanotechnology should see high-fidelity sound received, which would help deaf persons communicate in noise and enjoy music. Research should also lead to implants in ears with useful hearing.
\end{abstract}

Key words: audiology, auditory neurophysiology, auditory psychophysics, bioengineering, education of hearing impaired, multichannel cochlear implant, nanotechnology, neural prosthesis, rehabilitation, severe to profound deafness, speech science.

\section{PERSONAL REFLECTIONS}

\section{Hearing from Electrical Stimulation of Auditory Nerve}

\section{Preliminary Studies on Subjects with Hearing}

Interest in electrical methods of inducing hearing started after Alessandro Volta, who discovered the electrolytic cell, stimulated his own auditory system by connecting a battery of 30 or 40 "couples" to two metal rods, which he inserted into his ears. The sensation was momentary and lacked tonal quality [1].

Because sound is an alternating disturbance in an elastic medium, stimulating the auditory system with a direct current (DC) was later appreciated to not reproduce a satisfactory hearing sensation. Consequently, Duchene of Boulogne in 1855 [2], and later others, stimulated the ear with an alternating current. The result, however, was still not satisfactory, and only noise was produced.

Renewed interest occurred with the introduction of the thermionic valve, which enabled the auditory system to be stimulated electrically with much greater precision. This work was supported by the findings that the voltages recorded from the auditory nerve of a cat were similar in frequency and amplitude to the sounds presented to the ear, but they were still heard as noise [3].

\footnotetext{
Abbreviations: $\mathrm{ABF}=$ adaptive beamformer, $\mathrm{ACE}=$ Advanced Combination Encoder, ADRO = adaptive dynamic range optimization, AGC = automatic gain control, $\mathrm{ARC}=$ Australian Research Council, ASC = automatic sensitivity control, CIS = continuous interleaved sampling, $\mathrm{CNC}=$ consonant-nucleusconsonant, DC = direct current, DRSP = differential rate speech processor, F0 = fundamental (voicing) frequency, F1 = first formant frequency, F2 = second formant frequency, FDA = Food and Drug Administration, NIH = National Institutes of Health, NT-3 = neurotrophin 3 , PPy = polypyrrole, SNR = signal-tonoise ratio, $\mathrm{SRT}=$ speech reception threshold, TESM = transient emphasis speech processor.

Address all correspondence to Graeme M. Clark, PhD; 13 Banoon Road, Eltham, Victoria 3095, Australia; +61-94313812; fax: +61-9431-3184; Email: gclark@unimelb.edu.au or Graeme@graemeclarkfoundation.org

DOI: 10.1682/JRRD.2007.05.0064
} 
Studies then indicated that three mechanisms produce hearing when the cochlea is stimulated electrically [4-5]. First, the middle ear acts as a transducer, which obeys the "square law," and converts alterations in the strength of an electrical field into the mechanical vibrations that produce sound. The thought was that the tympanic membrane is attracted to and from the medial wall of the middle ear and that these vibrations are responsible for the hearing sensation. Second, sound was heard when the middle ear structures were absent. This finding suggests a second type of transducer that is linear. It also indicates that electrical energy converts into sound by a direct effect on the basilar membrane that then vibrates maximally at a point determined by the frequency, and these vibrations stimulate the hair cells (referred to as electrophonic hearing). Third, a crude hearing sensation was produced in patients with minimal or absent hearing that was due to direct stimulation of the auditory nerve.

\section{Preliminary Studies on Deaf Patients}

An investigation was next performed on a deaf patient [6]. The electrodes were placed on the auditory nerve that was exposed during an operation for cholesteatoma. The patient was able to detect differences in pitch in frequency increments from 100 to 1,000 pps. He was also able to distinguish certain words such as "papa," "maman," and "allô" presented as a raw speech waveform.

Another study described the results of implanting six electrodes into the modiolus of the cochlea in a patient with complete perceptive deafness [7-8]. Single stimuli produced a pitch sensation. This sensation varied according to the stimulating electrode, although where the electrode lay was not clear. The speech spectrum was separated into frequency bands, and each band was stimulated according to the characteristic "pitches" of the various electrodes. However, this method failed to result in speech understanding.

\section{Personal Research Directions from 1967-1969}

Because the results did not indicate that speech understanding was possible with electrical stimulation of the auditory nerve [7-8], I considered in 1969 that the best chance of success was to answer a series of questions elaborated in my doctor of philosophy dissertation, "Middle ear and neural mechanisms in hearing and the management of deafness" [9], and referenced in "Cochlear implants” [1,10].
These publications stated the following:

(1) Electrical stimulation of the auditory nerve could not be expected to produce hearing in patients with damage to the higher auditory centers. Many children and some adults with perceptive deafness, however, have a lesion involving the cochlea and not the higher centers, and could be helped when their deafness is severe.

(2) It would also be desirable to have clinical tests which enable patients to be selected into those most likely to benefit from the operation. Tests of speech intelligibility and the presence of recruitment are satisfactory when some residual hearing remains, but in the patients where severe or total deafness is present these methods would not be adequate. It is possible that an objective test of hearing using preliminary electrical stimulation of the cochlea could be devised.

(3) The type of electrodes used, and their method of implantation will also have to receive careful consideration as it was shown [11] that when electrodes are chronically implanted their resistance increases, and this could lead to unreliable stimulation. It was also demonstrated that when electrodes are chronically implanted in the scala tympani of cats through an incision in the round window, the surgical trauma need not cause permanent cochlear damage. The factors responsible for degeneration of the organ of Corti and auditory nerve fibers were unpredictable; however, infection was found to consistently produce widespread destruction of tissue.

(4) Not only do these technical problems require solution, but a greater understanding of the encoding of sound is desirable. As emphasized [12], the terminal auditory nerve fibers are connected to the hair cells in a complex manner, which could make it difficult for electrical stimulation to simulate sound. The relative importance of the volley and place theories in frequency coding is also relevant to the problem. If the volley theory is of great importance in coding frequency, would it be possible for different nerve fibers, conducting the same frequency information, to be stimulated in such a way that they fired in phase at stimulus rates greater than 1000 pulse/s. If this was possible, it would then have to be decided whether this 
could be done by stimulating the auditory nerve as a whole, or whether local stimulation of different groups of nerve fibers in the cochlea would be sufficient. On the other hand, if the place theory is of great importance in coding frequency, would it matter whether the electrical stimulus caused excitation of nerve fibers at the same rate as an auditory stimulus, or could the nerve fibers passing to a particular portion of the basilar membrane be stimulated without their need to fire in phase with the stimulus?

(5) If the answers to these questions indicate that stimulation of the auditory nerve fibers near their terminations in the cochlea is important, then it will be necessary to know more about the internal resistances and lines of current flow in the cochlea, and whether the electrical responses normally recorded are a reflection of the transduction of sound into nerve discharges, or directly responsible for stimulating the nerve endings.

(6) The final criterion of success will be whether the patient can hear, and understand speech. If pure tone reproduction is not perfect, meaningful speech may still be perceived if speech can be analyzed into its important components, and these used for electrical stimulation. More work is required, however, to decide which signals are of greatest importance in speech perception [9].

\section{Basic Physiological Studies to Reproduce Coding of Sound with Electrical Stimulation of Auditory Nerve}

I undertook basic physiological studies to help answer some of these questions. In particular, I assumed first that the temporal firing patterns of cells to auditory stimuli would underlie an animal's ability to perceive frequency. Second, the extent to which electrical stimuli could reproduce the response patterns should show how well frequency was perceived in implanted patients [9]. This, however, did not mean that if electrical stimuli did not reproduce the pattern, they would be unsatisfactory. Nevertheless, without any other criteria, this comparison would then be considered to provide a standard for measuring the performance of electrical stimulation in coding sound.

I undertook personal research in 1967 to answer the question, Could electrical stimulation of the auditory nerve reproduce the frequencies of speech through temporal or place coding as well as the coding of intensity?

\section{Temporal Coding of Frequency}

The temporal code for sound frequency is illustrated in Figure 1. Note the brain stem cells fire in phase with the sine waves, but Figure 2(a) shows that although they fire in phase, they do not always respond to each sine wave, because some intervals are higher multiples of the period of the sine wave. The phase-locking of the neurons can be determined by one seeing how well the intervals between nerve action potentials are synchronized to the sine wave

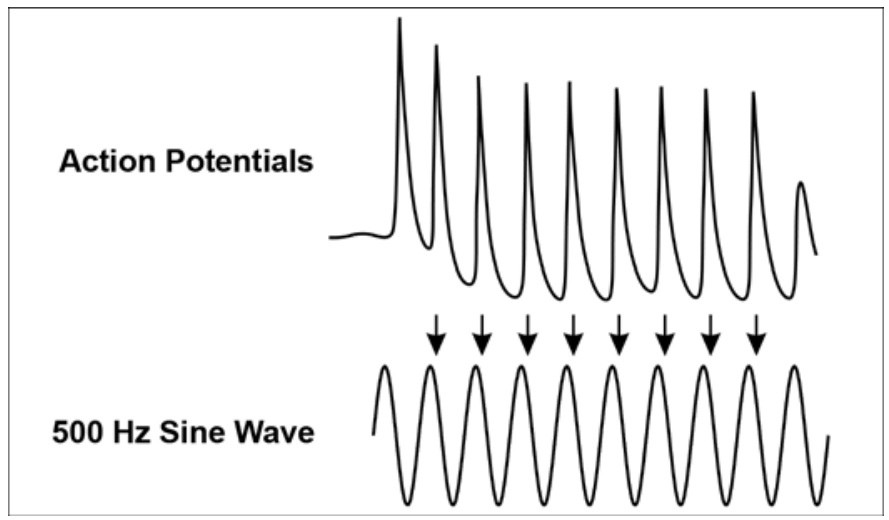

Figure 1.

Action potentials from brainstem cells (top) in superior olivary nucleus of cat to (arrows) sound frequency of $500 \mathrm{~Hz}$ sine wave (bottom). Illustration by author. Reprinted by permission of Springer Science+Business Media, (C) 2003, from Clark GM. Cochlear implants: fundamentals and applications. Berlin (Germany): Springer-Verlag; 2003. (a)

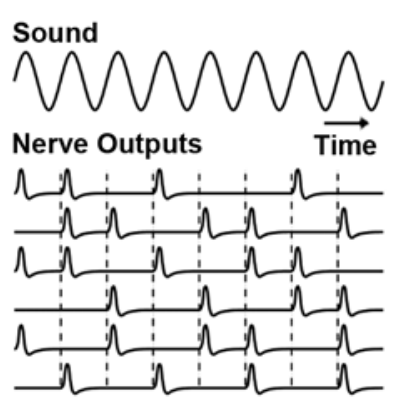

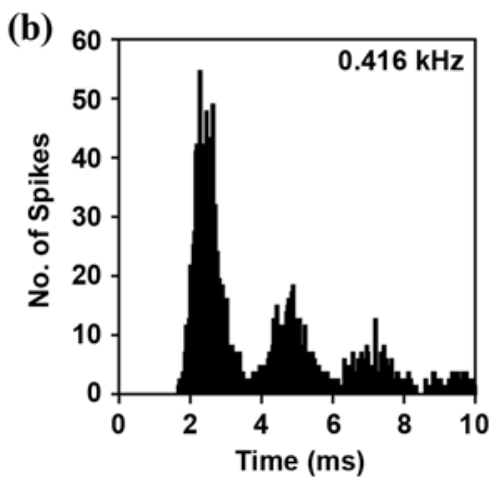

Figure 2.

(a) Phase-locking of action potentials in group of nerve fibers. (b) Interspike interval histogram of neural responses to acoustic stimulus of $0.416 \mathrm{kHz}$. Illustration by author. Reproduced by permission of Philosophical Transactions of Royal Society B from Clark GM. The multiple-channel cochlear implant: the interface between sound and the central nervous system for hearing, speech, and language in deaf people-a personal perspective. Philos Trans R Soc Lond B Biol Sci. 2006;361(1469):791-810. [PMID: 16627295] 
(Figure 2(b)). The phase-locking decreases for higher frequencies when it becomes more probabilistic or stochastic and ceases at 4.0 to $5.0 \mathrm{kHz}$ [13-14].

If the temporal coding of speech frequencies was of prime importance and could be mimicked with electrical stimulation, only a single-channel implant might be required. Single-channel implants have either transmitted the amplitude variations of the speech wave [15-17] or the voicing frequency [18] to a single electrode.

The research that I undertook in 1967 on the cat brainstem determined the extent to which neurons could follow the electrical stimulation rate of auditory nerve fibers in the cochlea without being suppressed by inhibitory mechanisms [19-20]. Recording at this level of the brain was necessary because the frequency discrimination of acoustic stimuli in the behavioral experimental animal had been shown to occur in the brainstem and not in the auditory nerve [21]. The data revealed that for brainstem neurons, electrical stimulation above 200 to 500 pps did not reproduce the same sustained firing rate or response patterns as a tone of the same frequency; this finding was most likely because electrical stimulation produced strong inhibition that suppressed neural activity. Furthermore, the firing was deterministic (i.e., tightly phase-locked to the stimulus) [19-20].

The cell responses in this study were only a small sample of the total population in the brainstem. On the other hand, field potentials are the summed electrical activity of many action potentials from a population of cells. Consequently, the auditory nerve was stimulated electrically and the field potentials recorded from electrodes that were placed within the brainstem [19-20]. The field potentials were markedly suppressed at rates from 100 to 300 pps (Figure 3) [9].

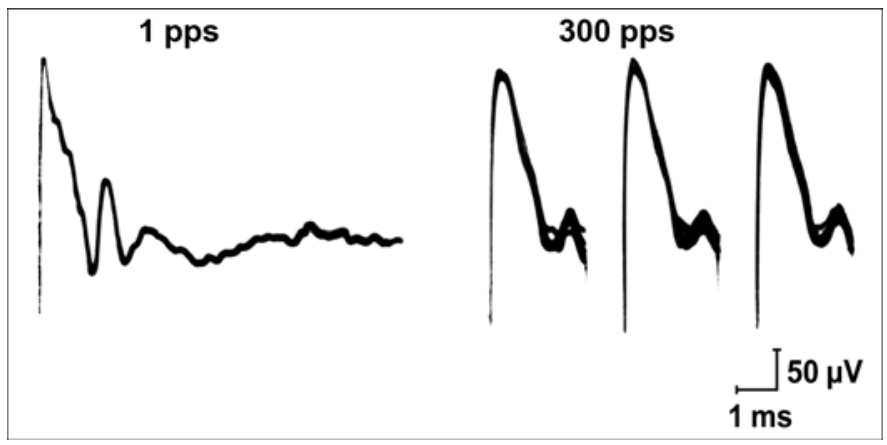

Figure 3.

Field potentials from superior olivary complex in auditory brainstem of cat for 1 and 300 pps rates of simulation of auditory nerve in cochlea. Illustration by author.
The field potential recordings from the brainstem thus showed electrical stimulation that attempted to reproduce a rate or time-period code would probably not convey adequate frequency information for a cochlear implant to help deaf patients understand the range of speech frequencies required for speech understanding, which is up to $4,000 \mathrm{~Hz}$. Consequently, local stimulation of nerve endings along different parts of the basilar membrane according to the place theory would be needed [19-20].

In addition, because 200 spikes/s was shown to be the maximum rate for an acoustic stimulus, Moxon also undertook research to determine the refractory period of auditory nerve fibers using electrical stimulation [22]. Was this limitation due to the refractoriness of the nerve fibers or mechanisms within the cochlea? The absolute refractory period of the auditory nerve fibers was found, by presentation of electrical stimuli pairs, to be only $0.5 \mathrm{~ms}$ for short bursts of stimuli and $2.0 \mathrm{~ms}$ for longer durations [22].

To ensure the brain used no processes for the perception of stimulus rate other than those reflected in unit and field potential responses, I led a series of behavioral studies on alert experimental animals from 1971 to 1975 [2325]. The research demonstrated that cats could only adequately discriminate stimulus rates of 100 and 200 pps for both electrodes at the basal (high-frequency) and apical (low-frequency) ends of the cochlea $[23,26]$. The upper limit on the rate that could be discriminated from any electrode was found to be 600 to 800 pps [24-25]. This finding was consistent with the cell and field potential data. Also significant were the low rates of excitation that could be discriminated at the high-frequency region of the cochlea; this finding indicated that rate could be coded independently from place of stimulation. In addition, studies on conditioned animals demonstrated that the detection of electrical stimuli modulated at low frequencies was the same as for glides of sound at identical low frequencies [24]. But at high modulation rates, detection was much poorer for electrical than acoustic stimuli [24]. This result indicated that rate of stimulation would not reproduce the rapid-frequency glides that are important for coding consonants and varying the place of stimulation would be required [14].

This research indicated that single-channel stimulation, which would need to rely on temporal coding, would be inadequate for speech understanding. Furthermore, later results confirmed that patients with implants were unable to discriminate differences in rate $\geq 200$ to $700 \mathrm{~Hz}$ [7-8,27-29]. 


\section{Place Coding of Frequency}

Thus it was important to know whether electrical current could be adequately localized to separate groups of auditory nerve fibers in the cochlea for place coding mid to high frequencies of speech, because these are specially relevant to understanding consonants. With place coding, as illustrated in Figure 4, sound frequencies are filtered by the basilar membrane, with the maximal displacement for the high frequencies in the basal turn moving to the apical turn for low frequencies. Place coding is preserved throughout the auditory system as seen with an orderly frequency scale for each cell's frequency of best response [30-31]. The pitch perceived should thus depend on the site of excitation in the brain [32].

To achieve place coding, Merzenich et al. first focused their research on inserting a molded electrode array in the scala tympani to fill the space [33-34], thus limiting the spread of current around it. They also showed that current

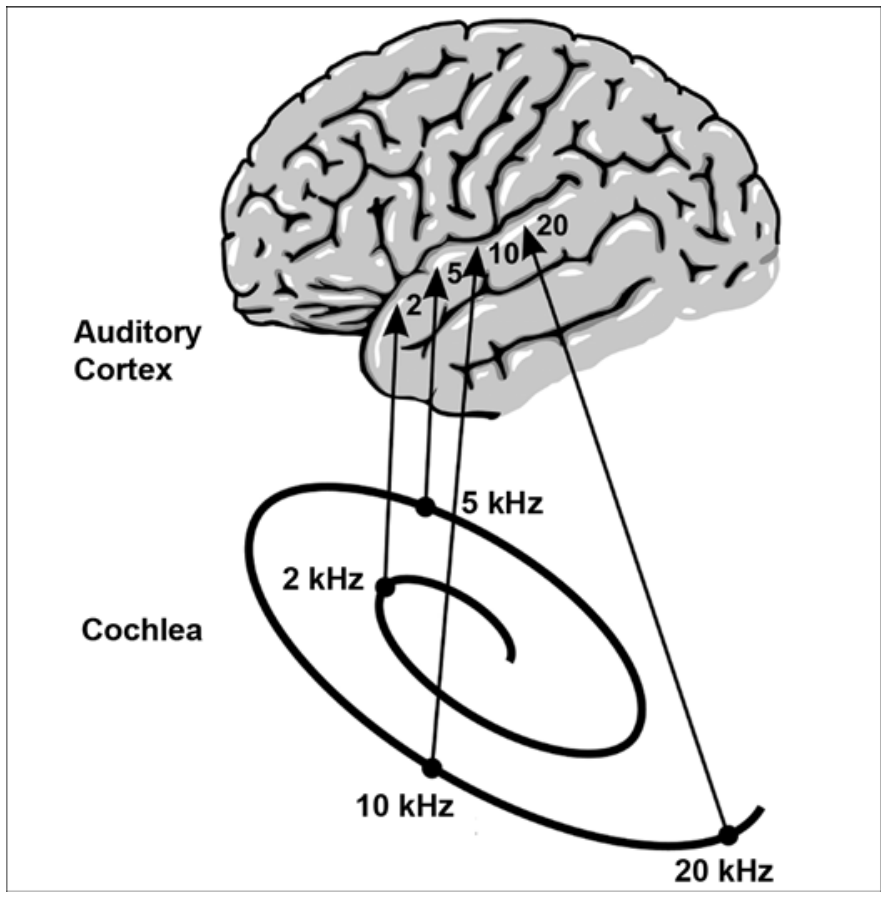

Figure 4.

Connections from regions of best frequency response in cochlea to neurons in primary auditory cortex, demonstrating how frequency scale is preserved (tonotopic organization). Intermediate centers are not shown for sake of simplicity, but tonotopic scale is preserved in each one. Illustration by author. Adapted from Clark GM. Electrical stimulation of the auditory nerve: the coding of frequency, the perception of pitch and the development of cochlear implant speech processing strategies for profoundly deaf people. Clin Exp Pharmacol Physiol. 1996;23(9):766-76. [PMID: 8911712] was best localized with bipolar stimulation of the peripheral auditory nerve fibers in the cochlea, with current flowing in a radial rather than longitudinal direction (Figure 5). The conclusions from this research on cats with hearing, however, were not readily applicable to patients with cochlear implants. Cochlear disease and anatomical variations made the precise placement of the electrode difficult under the basilar membrane for the required localized stimulation. Furthermore, research later found that a high current level was required to achieve threshold and that stimulation over the dynamic range was not always possible, because the stimulator would run out of voltage compliance [35].

On the other hand, Black and Clark's research first aimed to determine where the electrodes should be placed within the cochlea to provide the best localization of the current [36-38]. A model of tissue resistances within the cochlea [39-40] demonstrated that a current passing through the organ of Corti (which would excite peripheral auditory nerve fibers) would be localized for monopolar stimulation (Figures 5-7) [36-38,41]. As shown in Figure 7, for stimulation of the peripheral auditory nerve, the spread of current through the organ of Corti fibers falls off rapidly with distance and is thus well localized for monopolar stimulation.

The model findings were then evaluated in the experimental animal with comparisons of current distributions in the terminal auditory nerve fibers for monopolar as well as bipolar stimulation in the scala tympani (Figure 5) and between electrodes placed in the scala tympani and the scala

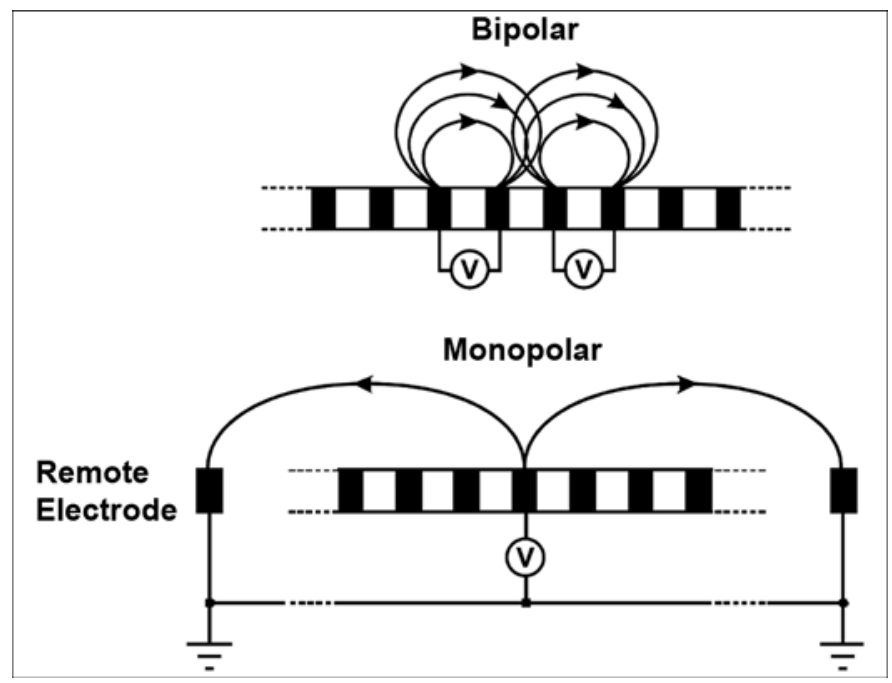

Figure 5.

Voltage (V) fields for bipolar and monopolar stimulation. Illustration by author. Adapted from Clark GM. Cochlear implants: Fundamentals and applications. Berlin (Germany): Springer-Verlag; 2003. 


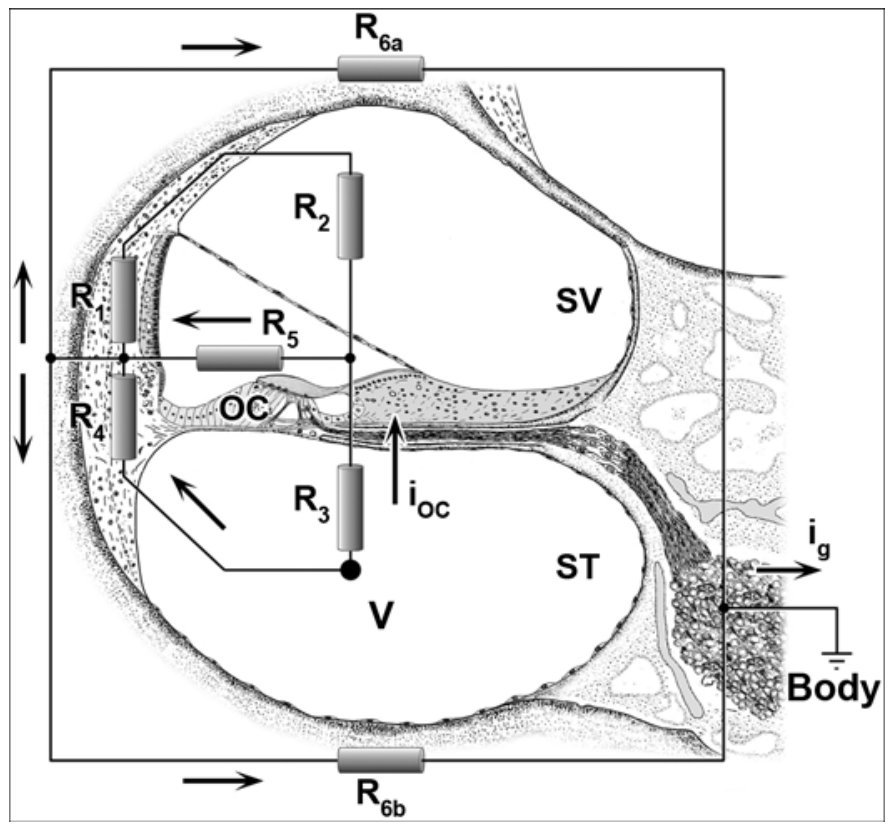

Figure 6.

Two-dimensional component of three-dimensional resistance model of cochlea. SV = scala vestibuli, $\mathrm{ST}=$ scala tympani, $\mathrm{OC}=$ organ of Corti, $\mathrm{i}_{\mathrm{OC}}=$ current through OC, $\mathrm{i}_{\mathrm{g}}=$ current to ground, $\mathrm{R}=$ resistances $1-6_{\mathrm{b}}$, $\mathrm{V}=$ voltage. Adapted from diagram by author from Black RC, Clark GM. Differential electrical excitation of the auditory nerve. J Acoust Soc Am. 1980;67(3):868-74. [PMID: 6892642]

vestibuli. As with the mathematical model at a point $14 \mathrm{~mm}$ from the round window, where the cross-sectional area of the cochlea is reduced, the length constant (a measure of current spread) became smaller, showing that current was localized for monopolar stimulation. The localization of the current with monopolar stimulation was later demonstrated to be effective in persons with implants, provided the electrodes in the scala tympani lay close to the auditory nerve fibers [41].

\section{Coding of Intensity}

The coding of sound intensity over the normal $120 \mathrm{~dB}$ intensity range may, in part, be due to the mean rate of unit firing of cochlear nerve fibers and the population of neurons excited. The dynamic ranges for fiber discharge rates were observed to be approximately $4 \mathrm{~dB}$ from threshold to maximum firing. This range is very narrow when compared with the 20 to $50 \mathrm{~dB}$ range in firing rate for sound [42-44].

\section{Electroneural Bottleneck}

These studies just mentioned, outlined in more detail by Clark [1,14], have demonstrated that even with multichannel stimulation, an electroneural "bottleneck" (Figure 8) was displayed at the interface between sound and the audi-

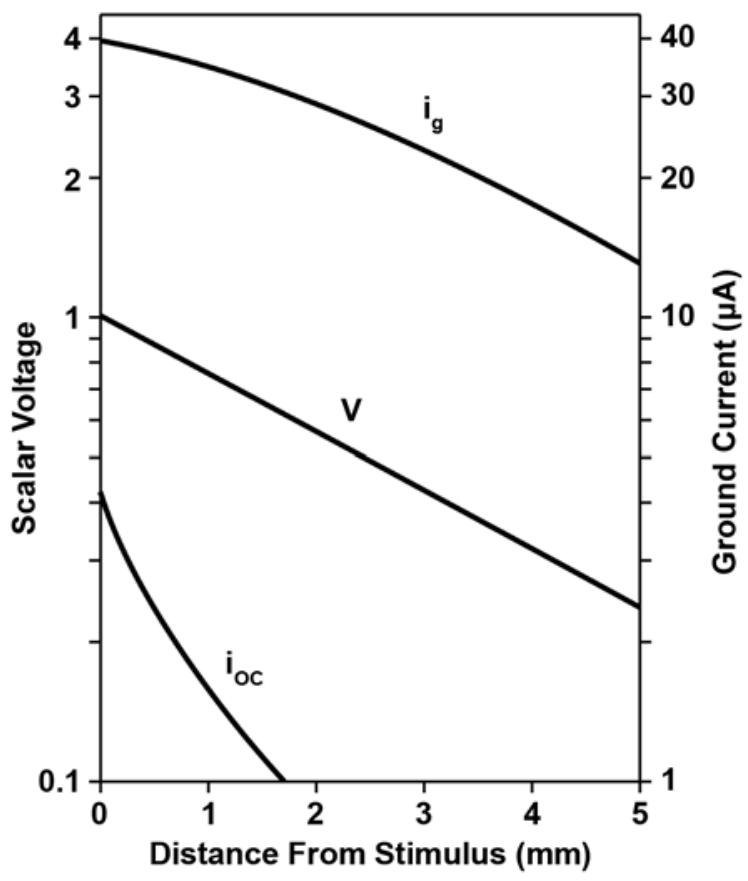

Figure 7.

Resistance model of cochlea for spread of current and voltage. $\mathrm{i}_{\mathrm{OC}}=$ current through organ of Corti, $\mathrm{i}_{\mathrm{g}}=$ ground current. Adapted from diagram by author from Black RC, Clark GM. Differential electrical excitation of the auditory nerve. J Acoust Soc Am. 1980;67(3):868-74. [PMID: 6892642]

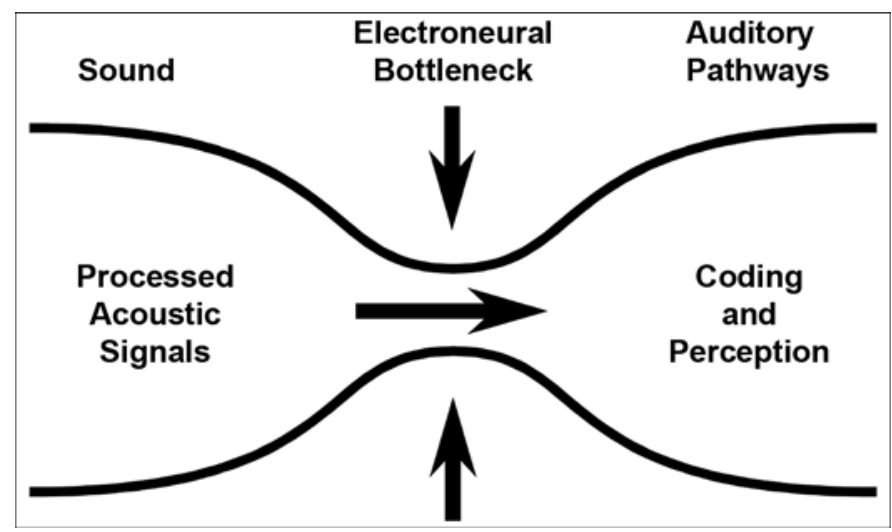

Figure 8.

Electroneural "bottleneck" with electrical stimulation of auditory nerve between sound and auditory pathways.

tory pathways, limiting the rate and place coding of frequency and intensity. Thus only certain acoustic signals could pass through for brain processing and perception. Therefore, I decided to direct research to determine which speech signals to extract and how to transmit them through the bottleneck [1,14]. 


\section{Safe Implantation of Multiple-Electrode Array into Cochlea}

The discoveries just given, however, demonstrated that before speech studies in patients, the place as well as temporal coding of frequency for electrical stimulation would need to be clarified. Place coding, in particular, required multichannel stimulation and was best achieved with electrodes placed inside the cochlea [38]. But was this safe?

\section{Surgical Trauma}

The first safety question was, Could multiple electrodes be placed safely within the scala tympani of the cochlea [36-38] without significant damage to its delicate structures and especially the auditory nerve fibers? Having commenced stapes surgery for otosclerosis in 1962, I was, as were most of my ear, nose, and throat colleagues, aware of how sensitive the cochlea was to trauma.

My research on biological safety began in 1972 [45], and it demonstrated that when multiple electrodes were inserted into the scala tympani of the cochlea through a number of holes drilled in the overlying bone, marked damage of all structures and associated loss of the auditory nerve fibers were found (Figure 9) [45]. However, further research discovered that a free-fitting electrode carrier could be passed through the round window and upward around the scala tympani with only mild histopathologic changes (Figure 9) [45-46]. An opening could also be drilled into the apical turn of the cochlea and the electrode passed downward toward the base with some but no major damage [46].

\section{Electrode Mechanical Properties}

The second question was, What were the right mechanical properties required for an electrode bundle to pass
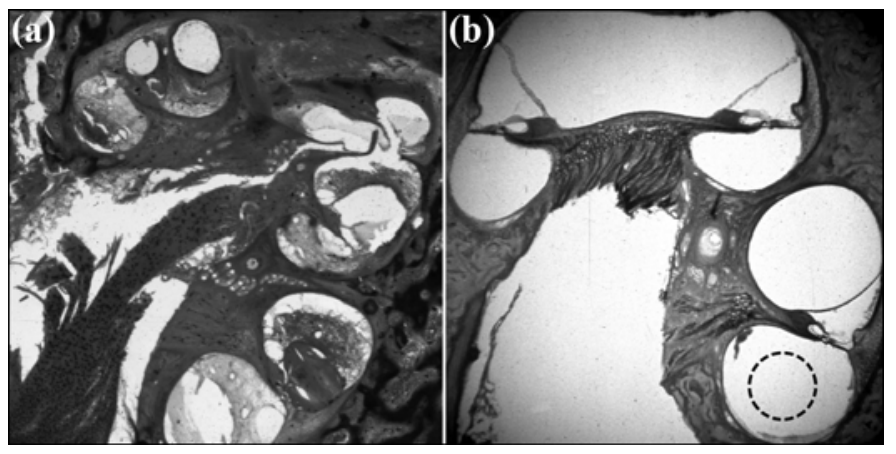

Figure 9.

(a) Cat cochlea after inserting electrodes through openings drilled in overlying bone and (b) cochlea after electrode bundle had been inserted along scala tympani by way of incision in round window membrane. upward far enough without trauma around the scala tympani and lie opposite the auditory nerves and transmit speech frequencies on a place coding basis?

The studies on the stiffness and extensibility of the materials required to achieve an adequate insertion depth were undertaken in 1975 on human temporal bones and molds of the cochlea (Figure 10) [47]. The electrode carriers were found to pass only 10 to $15 \mathrm{~mm}$ upward into the tightening spiral of scala tympani of the basal turn. But, as with the experimental animal, they passed downward easily into the widening spiral of the cochlea. Research also demonstrated that an electrode bundle inserted upward along the scala tympani would lie at the periphery of the spiral but its upward progress in the basal turn was impeded through frictional forces against the outer wall (Figure 10) [47]. The electrodes needed to be smooth to minimize the friction for easy and effective insertion and reinsertion without trauma.

However, I discovered in 1977 that by inserting blades of grass into a turban shell (Figure 11), a largescale replica of the cochlea, I could achieve an appropriate insertion depth if the electrode bundle was flexible at the tip and became increasingly stiff toward its proximal end [1]. This satisfactory insertion depth was made possible by the incremental addition of electrode wires that

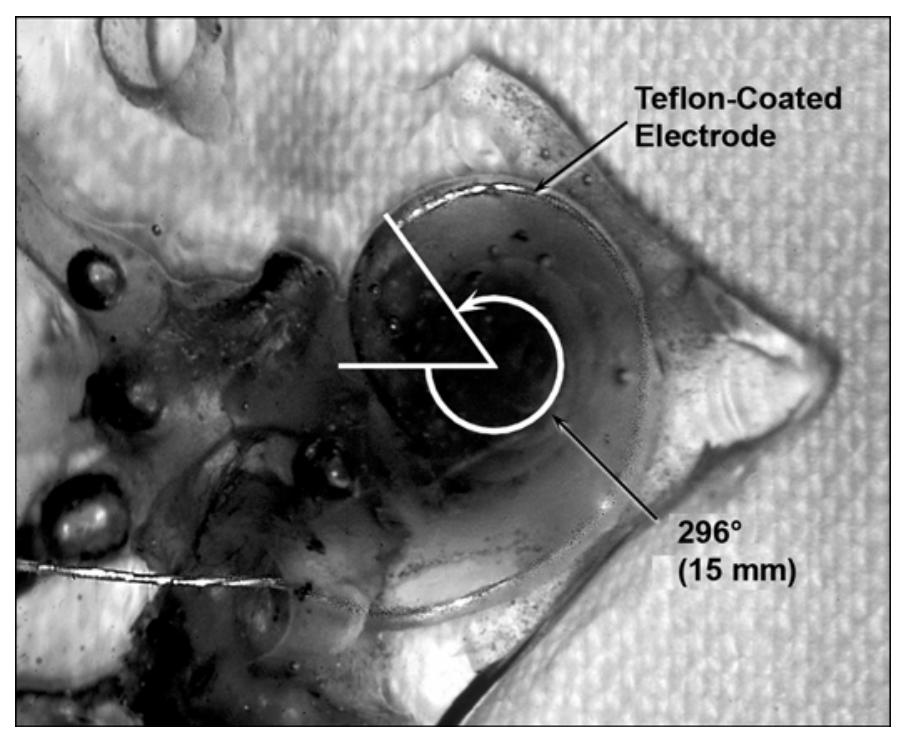

Figure 10.

Teflon-coated electrode bundle passed around (white arrow) mold of human cochlea to maximum distance of $15 \mathrm{~mm}$. Adapted from illustration by author from Clark GM, Hallworth RJ, Zdanius K. A cochlear implant electrode. J Laryngol Otol. 1975;89(8):787-92. [PMID: 1185061] 
JRRD, Volume 45, Number 5, 2008

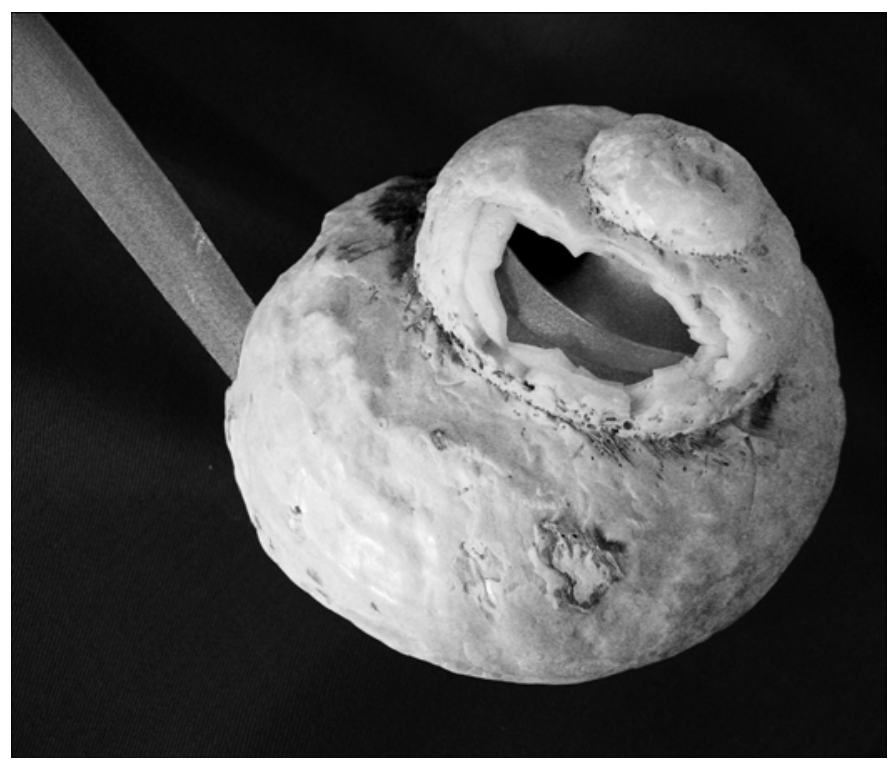

Figure 11.

Turban shell (Ninella torquata) and grass blade with graded stiffness passing around first to second turn of cochlea.

progressively stiffened the array from the tip to the base (Figure 12). This electrode with increasing stiffness could be passed around the basal turn to lie opposite the speech frequency region (Figure 13).

In 1978, circumferential electrodes were found to have the required smooth surface for minimizing friction and allowing the electrodes to pass around the basal turn [48]. With the circumferential electrodes, the array tolerated lateral displacement or rotation with the insertion. Insertions of the tapered, free-fitting array with graded stiffness

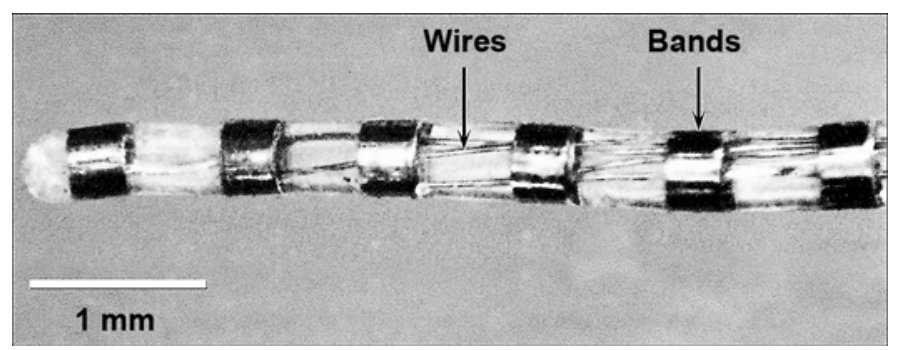

Figure 12.

Banded electrode array with incremental addition of wires to provide variable stiffness. Adapted from illustration by author from Clark GM, Blamey PJ, Brown AM, Gusby PA, Dowell RC, Franz, BKH, Pyman BC, Shepherd RK, Tong YC, Webb RL, Hirshorn MS, Kuzma J, Mecklenburg DJ, Money DK, Patrick JF, Seligman PM. The University of Melbourne-Nucleus multi-electrode cochlear implant. New York (NY): Karger; 1987. p. 38.

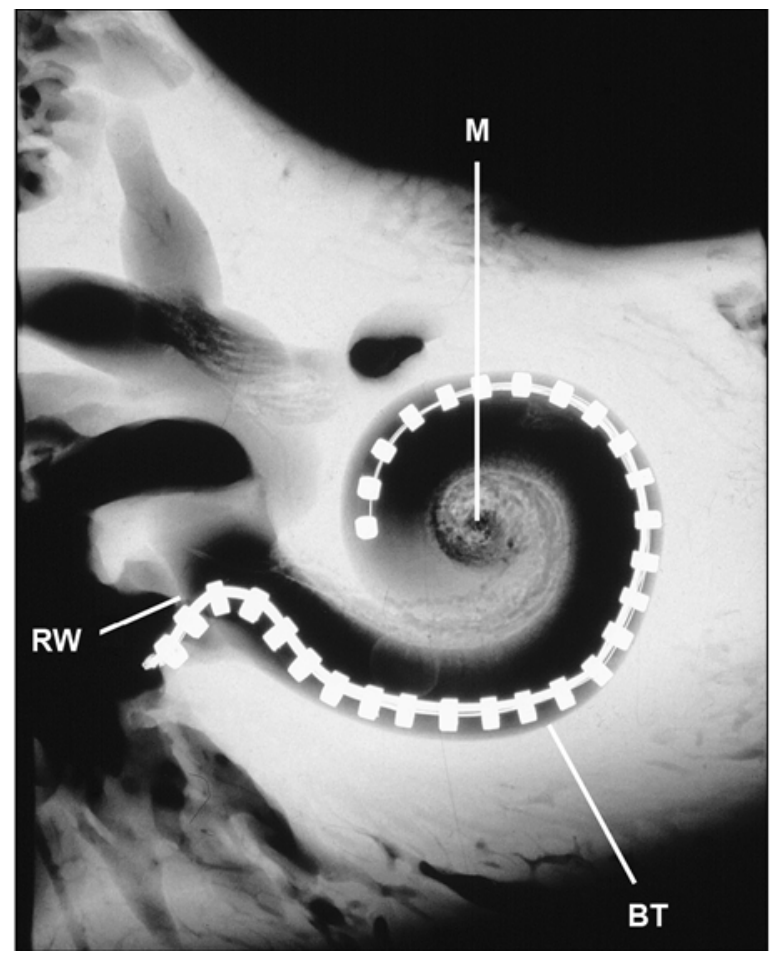

Figure 13.

Banded, free-fitting, smooth, and tapered electrode array with graded stiffness that had been passed into scala tympani of basal turn of human cochlea (BT). RW = round window (entry point to BT), $\mathrm{M}=$ modiolus in which lie spiral or auditory ganglion cells. Reprinted by permission of Springer Science+Business Media, (C) 2003, from Clark GM. Cochlear implants: Fundamentals and applications. Berlin (Germany): Springer-Verlag; 2003.

and banded electrodes were performed with minimal trauma on fresh human temporal bones [49]. Trauma could occur 7 to $13 \mathrm{~mm}$ from the round window, where the outer cochlear wall is splayed, and this directed the array at the basilar membrane. Investigations demonstrated that rotating the electrode brought the tip downward away from the membrane [50], and this procedure ensured this injury did not happen. Furthermore, research in the experimental animal indicated that the banded electrode array was not held tightly by a fibrous tissue sheath and could be removed easily and another one reinserted at a later stage, if replacement was required [51].

The mechanical properties of free-fitting arrays and their propensity to cause trauma were later studied using finite element modeling for predicting the stress-strain response of bodies for different external forces [52-53]. The model allowed contact stresses during insertion into the human cochlea to be calculated (Figure 14). The dynamics 


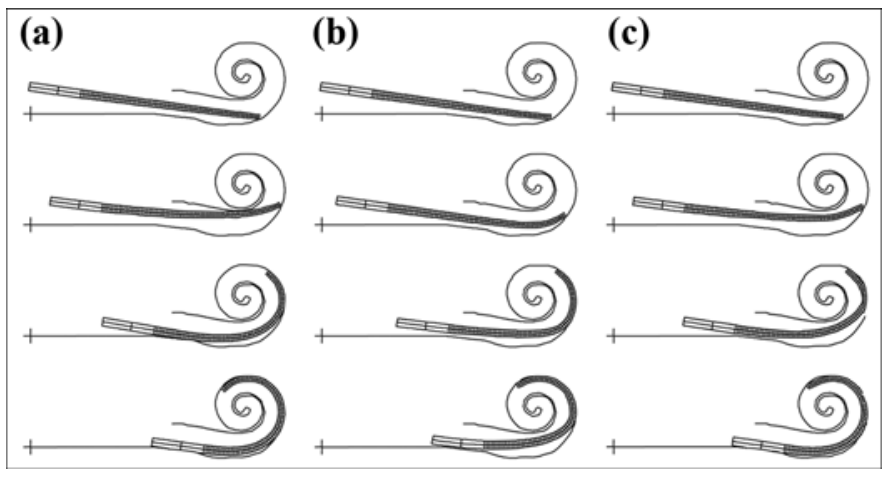

Figure 14.

Deformation of electrode array with graded stiffness when inserted into scala tympani: (a) uniform stiffness, (b) graded stiffness, and (c) uniform stiffness and soft tip. Adapted from graphic by author from Chen BK, Clark GM, Jones R. Evaluation of trajectories and contact pressures for the straight nucleus cochlear implant electrode array - a two-dimensional application of finite element analysis. Med Eng Phys. 2003;25(2):141-47. [PMID: 12538068]

of the movement of the electrode array could also be visualized. The contact pressure and its distribution along the portions of the array in apposition with the cochlea wall were predicted (Figure 15) and provided a quantitative measure of the degree of trauma that could occur during insertion. Of particular interest were the contact pressures at the tip of the array and at segments during and after insertion. The buckling stresses were high for all points along an array with uniform stiffness (design A), they were low for the electrode with graded stiffness (design B), and a marked increase was seen in the buckling stresses toward the outer end of the array with the soft tip and uniform stiffness (design C) (Figure 15). This study used a two-dimensional model and supported the free-fitting banded flexible array with graded stiffness as a good design [53]. It was later upheld with a three-dimensional model [52].

A perimodiolar precurved array was developed next to hug the modiolus and allow more localized stimulation of auditory ganglion cells and stimulation at lower thresholds. This development first began at the University of Melbourne's Australian Research Council's (ARC's) Human Communication Research Centre in 1989 and was improved by two Cooperative Research Centers (Figure 16) [1]. A stylet was found to be required to hold the precurved array straight during the insertion, but this increased the stiffness of the array and the risk of trauma $[1,52,54-55]$. Less trauma occurred if the array was
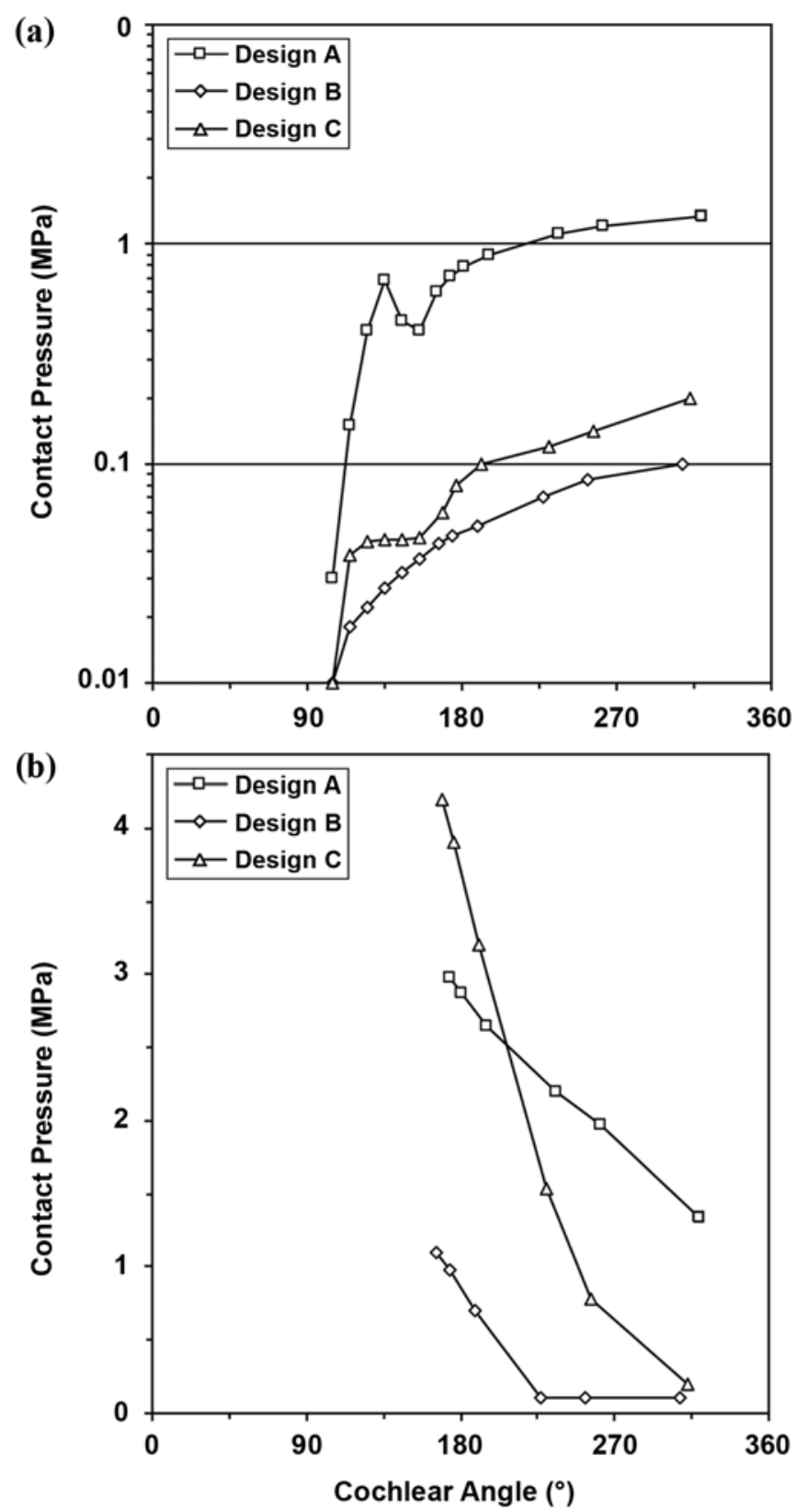

Figure 15.

(a) Contact pressures at tips of arrays. (b) Contact pressure distribution along array after insertion. Three electrode arrays: design A: uniform stiffness, design B: graded stiffness, and design C: uniform stiffness and soft tip. Adapted from graphic by author from Chen BK, Clark GM, Jones R. Evaluation of trajectories and contact pressures for the straight nucleus cochlear implant electrode array — a two-dimensional application of finite element analysis. Med Eng Phys. 2003;25(2):141-47. [PMID: 12538068]

inserted $8.5 \mathrm{~mm}$ and then advanced off the stylet [56]. Having an array with a bent [50] or soft tip [57] was an added benefit. 


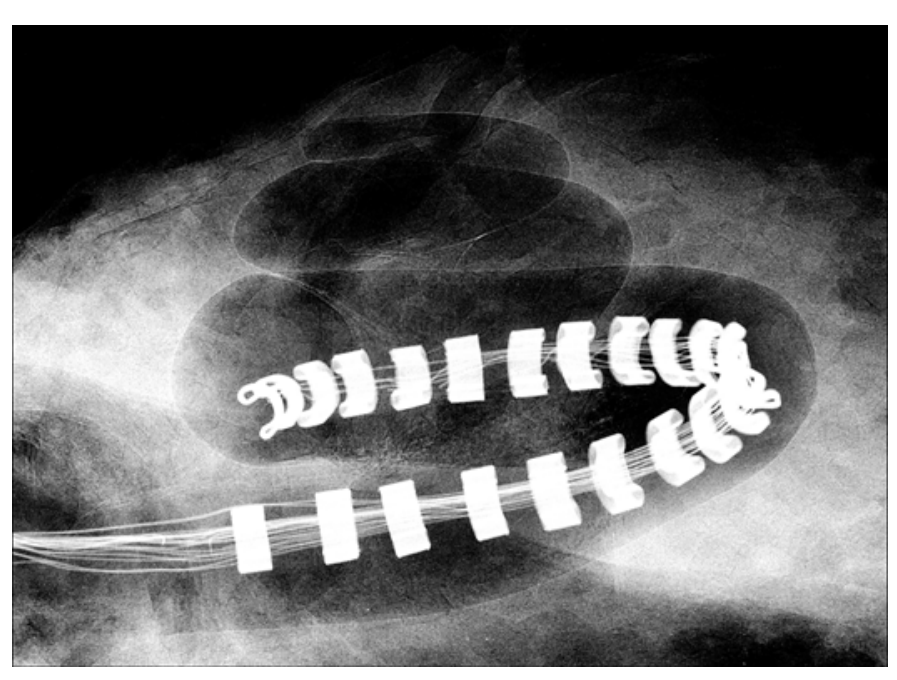

Figure 16.

Phase-contrast X-ray image of perimodiolar banded precurved array (Contour). Courtesy of $\mathrm{Xu} \mathrm{J}$ and adapted from photograph $\mathrm{Xu} \mathrm{J}$, Stevenson AW, Gao D, Tykocinski M, Lawrence D, Wilkins SW, Clark GM, Saunders E, Cowan RS. The role of radiographic phasecontrast imaging in the development of intracochlear electrode arrays. Otol Neurotol. 2001;22(6):862-68. [PMID: 11698810]

\section{Biocompatibility}

The third question was, Would candidate materials for the multiple-electrode bundle be toxic to the inner ear and auditory nerve? The late 1970s revealed a scarcity of data on the biocompatibility of materials for the electrode array and receiver-stimulator package [58-59]. The procedures used in the studies were appropriate modifications of those outlined in the U.S. Pharmacopoeia (1980): Rats were used instead of rabbits, materials were inserted under vision into the subcutaneous tissue and muscle rather than blindly through the skin, materials were left in place for 14 rather than 7 days for more clearly distinguishing between healing and inflammation, reactive and nonreactive controls were used, four to six animals were studied rather than the recommended two, and responses were graded microscopically rather than macroscopically and only when an implant pocket could be seen. An initial report [58] and a more detailed study [59] established that Silastic MDX-4-4210 (NuSil Technology; Carpinteria, California), Silastic medical adhesive type A, and platinum were biocompatible and produced little fibrous tissue reaction in the subcutaneous and muscle tissue in the rat and cat. Silastic MDX-4-4210 and fluoroethylene propylene produced little reaction in the cat cochlea. Candidate materials were further tested for cytopathic effects against embryonic cells, for systemic toxicity by intravenous and intraperitoneal injection in mice and intracutaneous irritation in rabbits, and for tissue reactions to subcutaneous and intramuscular implantation after 90 days. Our research group evaluated the assembled units by implanting them intramuscularly for 4 weeks and examining the tissue response, because the manufacturing process and working of materials could change their biocompatibility.

\section{Electrical Safety}

The fourth question was, Could the electrical currents and charges be presented at levels to minimize damage to the cochlea and auditory nerves? Charge density, charge per phase, total charge, and DC lead to neuronal damage through their effects on the capability of cellular metabolism to maintain homeostasis [60]. Electrical current can also produce an electrolytic reaction at the electrode-tissue interface with the release of toxic platinum ions [61].

Current levels and charge densities at the top of the range required to produce maximum loudness in the first patients were shown to be safe in the long-term. The charge per phase of the biphasic pulses was balanced so no residual charge produced a buildup of damaging DC.

With stimulus rates of 500 pps and the stimulus currents within a 0.5 to $0.9 \mathrm{~mA}$ range [62], no significant effect was found on spiral ganglion cell densities. Results showed that charge densities less than $32 \mu \mathrm{C} \mathrm{cm}^{-2}$ geometric/phase had no adverse effects on neurons in the cochlea and did not produce new bone growth when stimulation was performed continuously for up to 2,000 hours [63]. This density level became the upper allowable charge density for use in patients.

The response of the human cochlea and brainstem to implantation and electrical stimulation with the banded array was subsequently studied [64]. This analysis enabled the response of the cochlea to be compared with that of the experimental animal. Stimulation for 10,000 hours in the human did not lead to any observed effect on the auditory spiral ganglion cells in the cochlea or the higher brain centers.

Because high stimulus rates (800-2,000 pps) could improve speech processing, their effect on neuronal survival was subsequently examined in the experimental animal. Long-term stimulation at rates above 2,000 pps and DC levels below $0.3 \mu \mathrm{A}$ produced no significant loss of auditory ganglion cells. Thus high rates of stimulation were safe if these parameters were used. 


\section{Prevention of Inner Ear Infection}

The fifth question was, Would middle ear infection extend to the cochlea, especially around the electrode, and lead to cochlear infection and meningitis, and could this infection be prevented? Initially, in 1973-75 in the experimental animal [45-46,63], my colleagues and I showed that spontaneous middle ear infection could spread around the electrode at its entry to the cochlea and cause severe infection with marked loss of auditory neurons (spiral ganglion cells) with the risk of device-related meningitis. With these electrode insertions, no attempt to facilitate a seal occurred. Consequently, in 1977, further studies were commenced to determine how to seal the entry point [65].

First, my colleagues and I glued foreign material as disks or sleeves around the electrode to be placed at the opening into the cochlea to encourage the ingrowth of fibrous tissue into the material and so increase the path length for bacteria [65]. The materials, with and without overlying fascia and muscle autografts, were tested in the presence of experimentally induced Staphylococcus aureus and Streptococcus pyogenes infections of the middle ear. A muscle or fascia autograft around the electrode or a Teflon ${ }^{\circledR}$ felt disk was found to prevent a Staphylococcus aureus or Streptococcus pyogenes infection in the middle ear, extending to the cochlea (Figure 17) [66-67]. On the other hand, Dacron ${ }^{\circledR}$ mesh with an overlying fascial graft was associated with a strong inflammatory response and a high incidence of virulent inner ear infection. The bacteria found a home in the larger spaces in the Dacron ${ }^{\circledR}$ mesh in which to multiply, and the infection extended to the basal turn of the cochlea and along the cochlear aqueduct toward the meninges, as shown in Figure 18. It was thus not recommended as a round window seal for patients. Care was needed in the selection and design of foreign material inserted into the cochlea so that creation of a "dead space" not accessible to antibacterial agents could be avoided. On the other hand, a graft of fascia around the electrode at its entry effectively reduced the entry of infection.

To further understand how to prevent the entry of infection, other researchers and I undertook studies to determine how tissue around the electrode entry healed. Research on the penetration of horseradish peroxidase showed an increased permeability of the surrounding tissue and round window membrane over an approximately 2-week period after implantation [68]. Thereafter, the round window membrane barrier returned to normal in an additional 2 weeks. The healing time period could be vulnerable to the spread of infection from the middle ear and the development of meningitis.

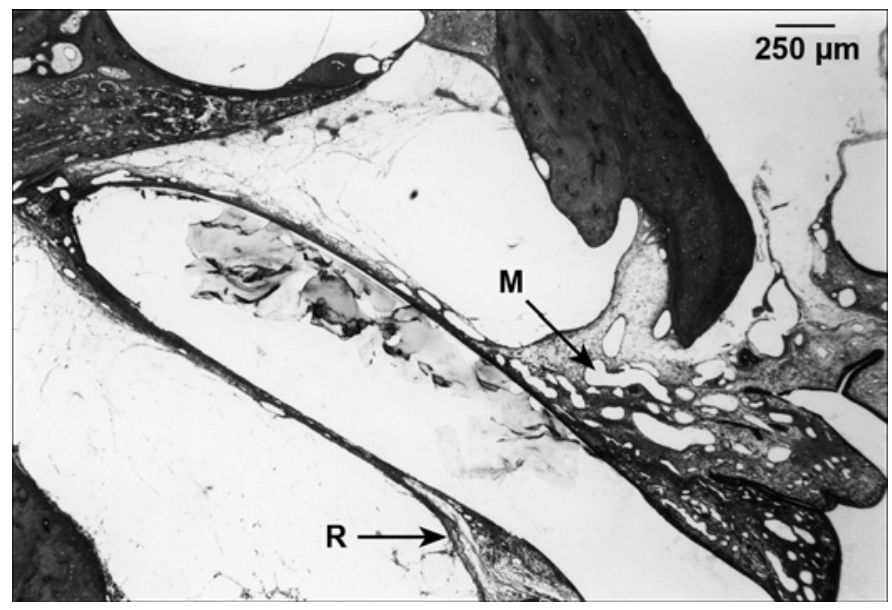

Figure 17.

Photomicrograph showing implanted cat cochlea. Fibrous tissue sheath has formed around electrode array at entry and inside scala tympani that has prevented middle ear infection extending to inner ear, thus avoiding risk of meningitis. Infection does not extend to cochlea. $\mathrm{M}=$ middle ear infection with proliferation of mucous membrane. $\mathrm{R}=$ thickened round window extending into well-formed electrode sheath. Copyright reverted to author from Clark G, Tong YC, Patrick JF. Cochlear prostheses. Edinburgh (Scotland): Churchill Livingstone; 1990.

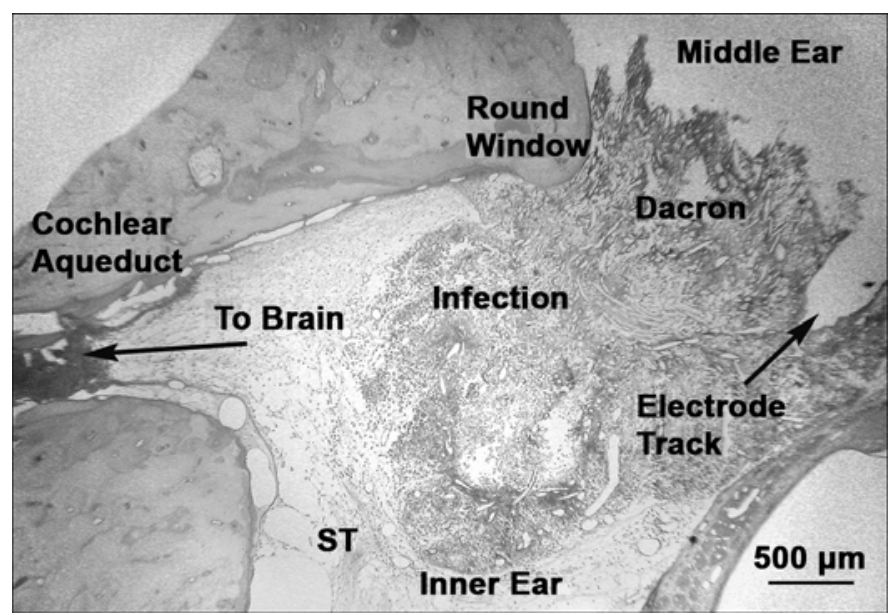

Figure 18.

Electrode seal of Dacron ${ }^{\circledR}$ mesh showing spread of Streptococcus pyogenes infection to basal turn of cochlea and extension along cochlear aqueduct that communicates with subarachnoid space and meninges. $\mathrm{ST}=$ scala tympani. Adapted from photograph by author from Clark G. Cochlear implants in children: safety as well as speech and language. Int J Pediatr Orthinolaryngol. 2003;67 Suppl 1:S7-20. [PMID: 14662167]

With middle ear infection, the round window membrane showed a marked proliferation of the connective tissue and formed protuberances of the mucous membrane and mucous cell proliferation around the electrode. 
This response of the mucous membrane was part of the body's first line of defense against bacteria, because the mucus is bacteriostatic and the cilia in the mucous membrane could sweep the bacteria away from the cochlea. In addition, studies showed that a fibrous tissue graft around the electrode bundle helped form a sheath. With the formation of a sheath, capillaries could bring phagocytic white cells to the tissue surrounding the electrode and the space between the electrode and sheath to engulf the bacteria (second line of defense). The sheath also allowed lymphocytes to penetrate the tissue and space next to the electrode and provide antibodies against the invading organisms (third line of defense) [69].

Later, when cochlear implants were discovered to be best implanted in children $<2$ years of age, research was undertaken to ensure that middle ear infections with Streptococcus pneumoniae, very common in this age group, could be prevented from extending to the inner ear and leading to meningitis.

Because a preliminary study indicated that sealing to prevent the ingress of pneumococcal infection would be important [70], research was undertaken on 21 kittens to compare different sealing techniques in their response to pneumococcal otitis media [71]. The ears were divided into those implanted with fascia or Gelfoam ${ }^{\circledR}$ seals, no seal, and unimplanted controls. Inflammation of the inner ear (labyrinthitis) was present in 44 percent of the unimplanted controls, 50 percent of the implanted ungrafted cochleas, and 6 percent of the implanted grafted (fascia and Gelfoam) cochleas. No statistically significant difference was found between the unimplanted control and the implanted cochleas. A difference, however, was seen between the implanted ungrafted and the implanted grafted cochleas but not between the use of fascia and Gelfoam. These data therefore indicated that cochlear implantation did not increase the risk of labyrinthitis following pneumococcal otitis media in normal cochleas, but incidence of infection was reduced when the entry point was grafted. Therefore, for safety, placing a fascial graft around the electrode where it enters the cochlea is important.

Further evidence for the importance of a welldeveloped electrode sheath was seen by Imani who examined its response 24 hours after a middle ear infection [72]. The findings were similar to those previously described [65]. In addition, bacteria were seen in the lymph and blood vessels of the sheath and were surrounded by polymorphonuclear and mononuclear leucocytes. This finding supported the view that the sheath reacted in a dynamic way to limit the entry of bacteria into the cochlea.
A rat model of the pathogenesis and prevention of meningitis from pneumococcal pneumoniae was next evaluated [73]. Wei et al. found that the threshold concentration of bacteria was lowest when inoculated into the cochlea compared with the middle ear and peritoneal cavity (hematogenous spread) [74]. In another study, a ciprofloxacin-coated array protected rats from meningitis by way of the hematogenous spread but only delayed the onset following middle or inner ear inoculation [75]. Finally, severe trauma to the osseous spiral lamina and modiolus due to insertion increased the risk of meningitis [76].

Clark et al. studied the response of the human cochlea to implantation and a fascial graft [64]. The entry through the round window where the electrode passed had a welldeveloped fibrous tissue sheath, which would have been effective against the spread of infection from the middle ear. A similar sheath was also seen in the temporal bones of 14 other people who had the cochlear implant [77].

The experimental results just mentioned apply only to a one-component free-fitting array, not to a two-component array. A space between two components is a conduit for infection, a home to allow pathogens to multiply, and a site to increase the pathogenicity of the organisms and reduce the ingress of antibodies and antibiotics [1].

\section{Head Growth}

The sixth question was, Would head growth in an infant cause the electrode to be withdrawn from the cochlea and would drilling a package bed affect head growth? Dahm et al. analyzed the growth of different parts of human temporal bones from birth to adulthood to determine growth changes [78]. Key findings were-

1. The distance between the sinodural angle (the site for the implant) and the round window (near the site for the electrode insertion into the cochlea) increased on average $12 \mathrm{~mm}$ from birth to adulthood, with a $5 \mathrm{~mm}$ standard deviation. Therefore, a pediatric cochlear implant should allow up to $25 \mathrm{~mm}$ of lead wire lengthening. This finding was consistent with the conclusions from radiographic studies [79].

2. The distance between the round window and the fossa incudis (floor of the mastoid antrum) did not increase with age; this result indicated that fixation of the lead wire to the fossa would be desirable. Any growth changes would be transmitted to this point rather than pulling the electrode from the round window [78].

3. Studies also showed that a redundant loop for the lead wires could lengthen even if surrounded with fibrous tissue, and furthermore, it would not need a protective sleeve [80]. 
The bed for the receiver-stimulator needed to be drilled in the mastoid and anterior segment of the occipital and parietal bones near the junction of the sutures between the mastoid, parietal, and occipital bones (asterion). In young children, this procedure was a concern because it might lead to early closure of the sutures and a skull deformity. For this reason, a study radiologically examined the head growth in the Macaque monkey after a bed for an implant was drilled in the asterion region. No effect on head growth was found over a 3- to 4-year period. The effect of drilling the sutures was also examined histologically [80]. No evidence of closure of the sutures was seen [81].

\section{Development of Fully Implantable Receiver-Stimulator}

Research to determine how to code speech could only be effectively undertaken on deaf persons. But as the behavioral studies on the experimental animal had demonstrated [82], a connection to the body should not be made with a plug and socket because of a significant risk of infection. The surgically preferred option was to transmit signals through intact skin to an implanted receiver-stimulator that would then route the stimuli to the electrodes in the cochlea (Figure 19). The receiver-stimulator was developed from 1974 to 1978 [83], with physiological design specifications provided from animal studies [84].

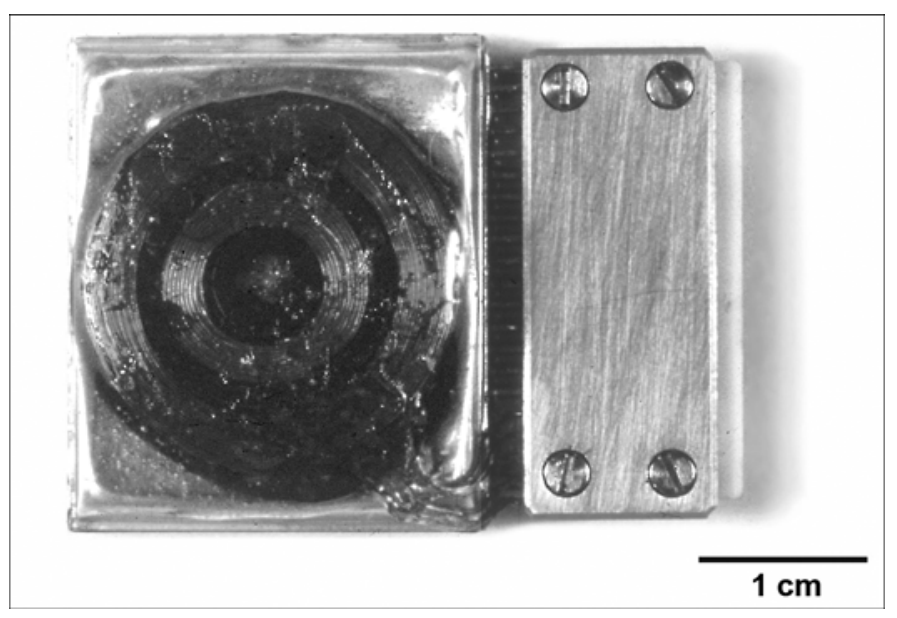

\section{Figure 19.}

University of Melbourne's multichannel receiver-stimulator implanted in first patient on August 1, 1978. Kovar container for electronics with overlying receiver coils for data and power is left; connector is right. It was removed on July 26, 1983, and replaced with Nucleus clinical trial device. Photograph by author.
A number of questions needed to be answered in developing the receiver-stimulator:

1. Should information be transmitted through the skin to the implant by infrared light shining through the eardrum, ultrasonic vibrations to the scalp, or radio waves through the overlying tissues? Studies established that an electromagnetic link was the most efficient method of data transfer [83-84].

2. Should the implant have its own batteries or receive power from outside? Because batteries would increase the size of the implant and have to be replaced periodically, radio signals were the better alternative.

3. Where should the implant be sited? It was considered best placed in the mastoid bone behind the ear, so a short lead would run to the electrodes in the cochlea and be more easily fixed in place for minimizing fractures from body movements. This placement also meant that a directional microphone could be more conveniently located above the ear to enable the person to receive a maximal speech signal while also lipreading a person face-to-face.

4. What would be the design of the receiver-stimulator electronics to allow suitable stimulus patterns to be tested? Because the stimulus data had to be transmitted through the intact skin as coded pulses on a radio wave, the choice of test stimuli had less flexibility than with a percutaneous plug and socket. Physiological, biophysical, and biological data helped set the design limits.

5. How should the electronics be packaged? The body is a very corrosive environment, and salts and enzymes could move through very fine cracks and cause electronic failure. This failure was especially likely where the wires exit the package to join the electrode bundle passing to the inner ear. A titanium/ceramic seal, as was pioneered by the pacemaker firm Telectronics in Sydney, was found to be necessary [14,59].

6 . What were the optimal dimensions of the package? These dimensions were established on the basis of anatomical dissections.

7. If the implant electronics failed and another package had to be reattached to the electrodes in the inner ear, would it need a connector and how should it be designed? A connector was used initially but was later found to be unnecessary if a failure occurred, because the banded electrode array could easily be slipped out and another inserted [59]. 
The principles underlying the electronic design of the Melbourne receiver-stimulator were elaborated in an article in 1977 [85] and a provisional patent filed in 1976 [83]. The amplitude, rate, and timing of biphasic pulses on each of 10 to 15 channels were independently controlled to stimulate an electrode array passed around the basal turn of the cochlea. The receiver-stimulator enabled frequencies to stimulate appropriate electrodes to provide 10 to 15 channels of stimulation for the place coding of frequency.

\section{Clinical Procedures}

The preoperative selection criteria were developed in 1975 and included electrical stimulation of the auditory nerve with an electrode placed in the middle ear. If pitch was perceived, the auditory nerve was considered intact [85]. A protocol was established for minimizing any risk of introducing infection during surgery [86]. The surgical procedures were created [87], as well as instruments for implanting the multichannel cochlear implant, such as the microclaw to steer the electrode bundle into and along the cochlea. The University of Melbourne's prototype receiverstimulator and electrode array were first implanted in 1978 in an adult who had had hearing before going deaf [27].

\section{Psychophysical Studies on Perception of Electrical Stimuli of Cochlear Nerve}

Once implanted, the patient underwent a series of perceptual (psychophysical) studies for determining the relation between the stimulus parameters and the sensation. Knowing what parameters could be best used for speech processing strategies was important. Another concern was learning if the physiological and behavioral predictions in the experimental animal applied to the human. In particular, I had a keen interest to see the relative importance of the place coding of frequency.

\section{Rate Pitch}

Rate of stimulation was perceived as a true pitch sensation for both apical and basal electrodes. Pitch at low rates of 50 pps corresponded to the acoustic sensation. However, at rates above approximately 200 pps, the correspondence deteriorated dramatically up to $1,000 \mathrm{~Hz}$ when it ceased [27-28]. Patients' poor ability to discriminate stimulus rates $>200$ pps was consistent with the acute physiological and behavioral animal experimental data of studies just described [19,24-26,88] and confirmed the need for multichannel stimulation to convey the important mid to high frequencies of speech. The perception of a low pitch when a high-frequency site was stimulated at low rates was also consistent with the animal data, suggesting that temporal pitch and place pitch were processed and perceived separately [14].

\section{Place Pitch}

The timbre of sound rather than the pitch was discovered to vary according to the stimulation site [27-28]. Timbre is the auditory sensation that enables a listener to judge that two sounds presented with the same loudness and pitch are dissimilar, e.g., different instruments or voices. The quality of the sound varied systematically from sharp at the high-frequency end to dull at the lowfrequency region of the cochlea. Even adjacent electrodes could be ranked correctly according to whether they were sharper or duller. At least 10 perceptually distinct channels for the place coding of speech frequencies were found.

\section{Loudness}

The 5 to $10 \mathrm{~dB}$ operating range for electrical stimulation of the auditory nerve with the banded electrodes was smaller than the 30 to $40 \mathrm{~dB}$ range for speech and the $120 \mathrm{~dB}$ range for sound, generally [27-28]. This difficulty was partly overcome, because the discriminable steps in intensity were smaller for electrical than acoustic stimulation. Thus more discriminable steps were over the narrower dynamic range for electrical stimulation.

\section{Speech Processing for Postlinguistic Deaf People}

The perception of these stimulus parameters formed the basis of speech processing strategies for speech understanding with the use of electrical stimulation. This research was first undertaken on postlinguistically deafened people (i.e., had hearing before going deaf) because they would be better able to compare sensations with those previously heard.

\section{Physiologically Based Speech Processor}

From 1977-1978, a physiologically based coding strategy [91] was developed and evaluated for determining if it was an effective method of transmitting information through the bottleneck [59]. In this case, the speech processing strategy had 10 filters because 10 stimulus channels were needed for effective communication systems [90]. The filter bandwidths were similar to the frequency response characteristics of the cochlear basilar membrane. The strategy also introduced the time delays required for 
each frequency to reach its site of maximum vibration along the basilar membrane, and it produced jitter in the stimuli that mirrored the stochastic responses of brain cells to sound. This strategy only provided very limited speech understanding because the electrical currents representing the sound energy in each frequency band overlapped, producing unpredictable variations in loudness. This discovery led to the important principle for all speech processing strategies: only nonsimultaneous stimulation should be used [59], and it was thus one of the constraints for transmitting speech information. Separating the stimuli on each channel by a short interval in time avoided the interaction of the electrical fields on each electrode, but neural integration over time could still take place.

\section{Second Formant Speech Processor}

The limitations in coding speech using the physiological model, especially through channel interaction, indicated that an alternative, more effective strategy was needed [14]. The idea of coding speech information conveying the greatest intelligibility on one or a number of electrodes, which I had previously foreshadowed, was then considered [9-10]. This idea was reinforced when the first implanted patient not only referred to the sensation on each electrode as timbre but also as a vowel. As a consequence, my research group and I then realized the vowel corresponded with the one that a person with hearing would perceive, if a similar frequency region in the inner ear were excited by a speech single formant [27-28,92]. Formant frequencies are the result of resonances in the vocal tract that amplify particular speech frequencies. Also noted was that the vowel heard could be changed with increasing or shortening the duration of the stimulus, as seen for vowels presented to subjects with hearing [27-28]. Furthermore, if pairs of electrodes were stimulated together at a constant stimulus rate, the vowel perceived would be different from that of a single electrode stimulus but depend on the relative amplitude of the two, suggesting that the central nervous system was using an averaging process for the two neural populations excited. In addition, formants are important for recognizing consonants, as illustrated in Figure 20. As shown in this figure, the direction of the frequency shifts in the second formant frequencies (F2s) is important for the intelligibility of the plosive consonants /b/, /d/, and /g/. The frequency of the burst of noise at the release of the plosive is also critical.

The ideas [27-28,92] just described led to the development of a formant extraction speech-processing strategy

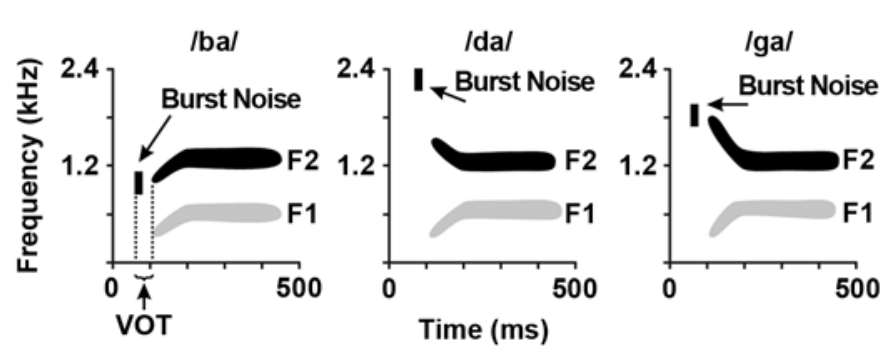

Figure 20.

First formant frequency (F1) and second formant frequency (F2) for plosives /b/, /d/, and /g/ and burst of noise produced when sound is released after vocal tract has been closed. VOT $=$ voice onset time (one of voicing cues). Reproduced by permission of Philosophical Transactions of Royal Society B from Clark GM. The multiplechannel cochlear implant: the interface between sound and the central nervous system for hearing, speech, and language in deaf people-a personal perspective. Philos Trans R Soc Lond B Biol Sci. 2006; 361(1469):791-810. [PMID: 16627295]

for electrical stimulation. F2 (range 700-2,300 Hz) was coded as place of stimulation, because rate of stimulation could not be discriminated at these higher frequencies. On the other hand, the fundamental (or voicing) frequency (F0), which is also very important for speech understanding (for example, in distinguishing between /b/, which is voiced, and $/ \mathrm{p} /$, which is unvoiced), was coded as rate of simulation proportional to F0. This coding was appropriate because voicing is low in frequency $(120-225 \mathrm{~Hz})$, and as discovered, electrical stimuli could not be discriminated at higher rates [92-96]. With unvoiced sounds, a randomized pulse rate was used; this stimulus was identified by the patient as noiselike. Rate of stimulation was retained across each of the electrodes stimulated with F2 and was consistent with the experimental animal behavioral studies $[24,26]$, which demonstrated that temporal and place coding information was processed separately. The implementation of this strategy in a hard-wired speech processor is outlined in the patent lodged in 1979 [96].

This F0/F2 strategy was first evaluated in 1978 as a software-based system on the first patient who was postlinguistically deafened. The patient's score for a closed set of six vowels was 77 percent and for eight consonants 37 percent [93,97-98]. The poorer consonant score was consistent with the fact that acoustic features other than formants are required for their recognition and needed to be transmitted. Most importantly, however, in 1979-1980, the subject improved markedly in understanding running speech when electrical stimulation was used with lipreading, compared with lipreading alone, and he was also 
able to understand some running speech with electrical stimulation alone.

These sets of results [93-95], obtained under standardized conditions, were the first clear and important demonstrations that the multichannel cochlear implant could significantly help persons with severe-to-profound deafness understand running speech and communicate in everyday situations. Furthermore, people retained their memory for speech sounds over many years and could be retrained in its use [94-95].

The F0/F2 strategy was implemented by industry (Cochlear Pty Ltd; Lane Cove, New South Wales) as a smaller speech processor. The engineering improved the sampling time of the signal. It was tested at nine centers in the United States, Germany, and Australia for the Food and Drug Administration (FDA). Its approval by the FDA established that the original data from the University of Melbourne conservatively assessed the performance of this strategy [99]. The data indicated that a number of patients were reaching a level of speech perception that allowed effective use of the device without lipreading. With the completion of the clinical trial in 1985 and followed by FDA approval of the F0/F2 strategy for multichannel stimulation, the cochlear implant was established as the first to safely restore speech understanding for adults who were postlinguistically deafened.

\section{Fixed-Filter Speech Processor}

An alternative strategy was a fixed-filter speech processor, which was investigated in 1978 at the University of Utah [100]. It had four fixed filters, and the outputs provided simultaneous monopolar analog stimulation between the electrodes in the cochlea and a remote reference on a place coding basis. Channel interaction was avoided because the electrodes were well separated spatially, limiting the number of electrodes that could be used to provide speech information. This fixed-filter strategy transmitted temporal information across the four spatial channels, but it had no voicing decision. The amplitude variations in speech were brought within the dynamic range for electrical stimulation with a compression gain amplifier. With this strategy, some vowels and consonants could be recognized. Research later reported that the same strategy provided an understanding of connected speech [101].

Another fixed-filter system was developed at the University of San Francisco and used bipolar pulsatile stimulation [102]. This type of system allowed more con- trolled excitation of nerves. The electrodes were embedded in a molded array and placed near the peripheral processes of the cochlear nerve fibers in the cochlea. Some open-set speech understanding was obtained.

\section{Psychophysical Studies on Perception of Complex Electrical Stimuli of Auditory Nerve}

Research was next undertaken to discover how the brain processed speech information and other complex sounds with electrical stimulation and how this knowledge could improve speech understanding. Speech perception with the F0/F2 strategy occurred through the integration of information along and across both temporal and spatial processing systems [98,103-111]. Furthermore, an acoustic model of multichannel electrical stimulation accurately predicted the psychophysical results and speech perception scores for formant-based speech processing strategies [104,110-111].

A varying stimulus rate was found to only discriminate over the longer duration required to convey prosody (the stress, tempo, rhythm, and intonation of speech) rather than the shorter durations of consonants, as illustrated in Figure 21. Thus using stimulation rate to differentiate between, for example, questions and statements was appropriate. Furthermore, stimulation rate was not only perceived as pitch, but in a speech context, it was also recognized as voicing [105] not only on apical lowfrequency electrodes but also on the more basal highfrequency ones. On the other hand, a change in stimulation site could be recognized over the shorter durations of consonants [105] and was thus appropriate for transmitting the frequency shifts seen in the consonants characterized as plosives (/b/, /d/, /g/, /p/, /t/, /k/) and nasals (/m/, /n/, /ng/). Furthermore, questions and statements were still recognized when variations in stimulation rate were superimposed across stimulus electrodes that transmitted shifts in formant frequencies. In addition, steady state stimuli differing in electrode position and repetition rate were characterized by two pitch components [106,112-113].

This research showed that the central auditory nervous system processed timing and spatial excitation over separate channels and that different time courses existed for the processing of the information. Our research also demonstrated that information presented to both channels could be integrated into a single perceived speech sound but with individual pitch components [106,112-113]. This capacity enabled voicing to be transmitted as a temporal code separately from speech formants or spectral 
frequencies, as would be the case with the F0/F2 speech processing strategy.

Furthermore, research showed that if two electrodes were stimulated nonsimultaneously at two separate sites along the cochlea, a sensation was experienced with two components [107-108] that was equivalent to the first formant frequency (F1) and F2 in vowels. This finding supported the development of a speech processing strategy that presented the F1 and F2 as sites of stimulation, while still coding the voicing (F0) as rate of stimulation. Although two pitch components could be distinguished, the stimulus nevertheless had only the one speechlike quality, as just discussed [28,113].

Finally, our psychophysical studies with electrical stimuli have helped show that loudness is related to the intensity of the stimulus [106] and thus the amount of electrical charge passing through the nerve membrane and the population of neurons excited. The relation between loudness and the electrical stimulus parameters is complex, but it includes the charge per pulse and the neural response rate [106].
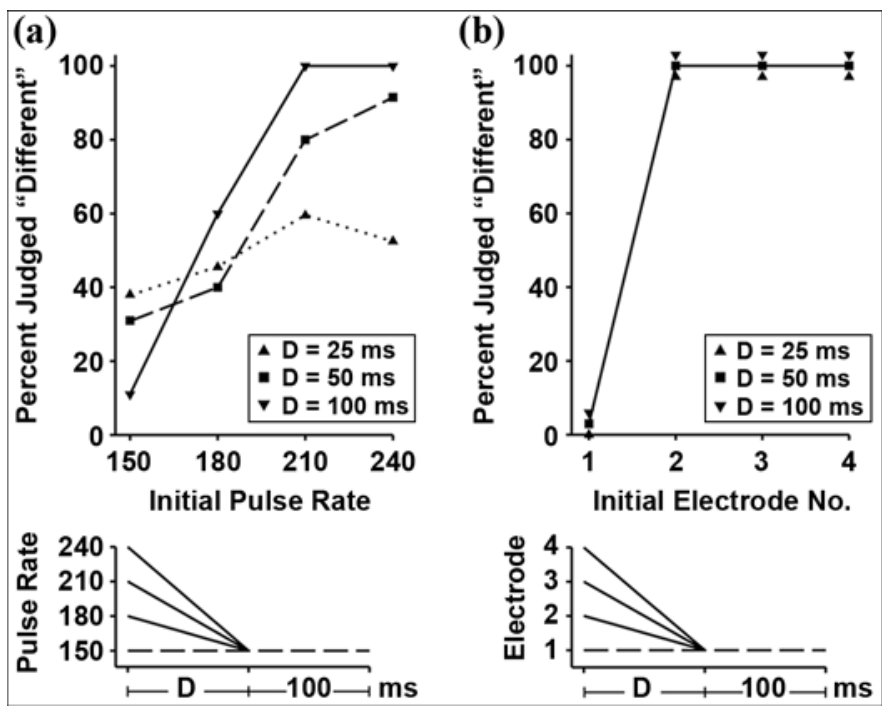

Figure 21.

(a) Top: changes in rate. (b) Top: place discrimination versus duration (D). Percentage judgments called "different" for changes in pulse rate and electrode place were compared with standard stimulus and shown for pulse rate and stimulus place trajectories. These trajectories were 25,50 , and $100 \mathrm{~ms}$ (in legend) in D. (a) Bottom: Initial pulse rates of trajectory varied from 240, 210, 180, and 150 to 150 pps. (b) Bottom: Initial electrodes of trajectory varied from electrodes 4,3 , and 2 to baseline 1 . Adapted from Tong YC, Clark GM, Blamey PJ, Busby PA, Dowell RC. Psychophysical studies for two multiple-channel cochlear implant patients. J Acoust Soc Am. 1982;71(1):153-60. [PMID: 6895638]
Acoustic Model of Electrical Stimulation in Subjects with Hearing

Before the F0/F1/F2 multichannel strategy was evaluated, it was modeled and tested using sounds to reproduce electrical stimulation in subjects with hearing. The model used seven bands of pseudorandom white noise with center frequencies corresponding to the stimulation site to represent different speech frequencies. With bands of noise, the sine waves for each frequency were removed, and voicing was simply the amplitude modulation of the noise burst at the voicing frequency.

The F0/F1/F2 strategy was first evaluated for basic perceptual tasks. The research also assessed the recognition of voicing to determine whether electrical stimulation provided fine and coarse temporal frequency information. Because the results for voicing with the acoustic model (the sine waves were removed) were comparable with the results of electrical stimulation [110], this finding suggested that electrical stimulation was only transmitting coarse temporal information but not the fine temporospatial patterns for good quality sound (Figure 22). Fine temporospatial information requires the transmission of the phase differences between the responses in individual neighboring neurons $[1,32]$.

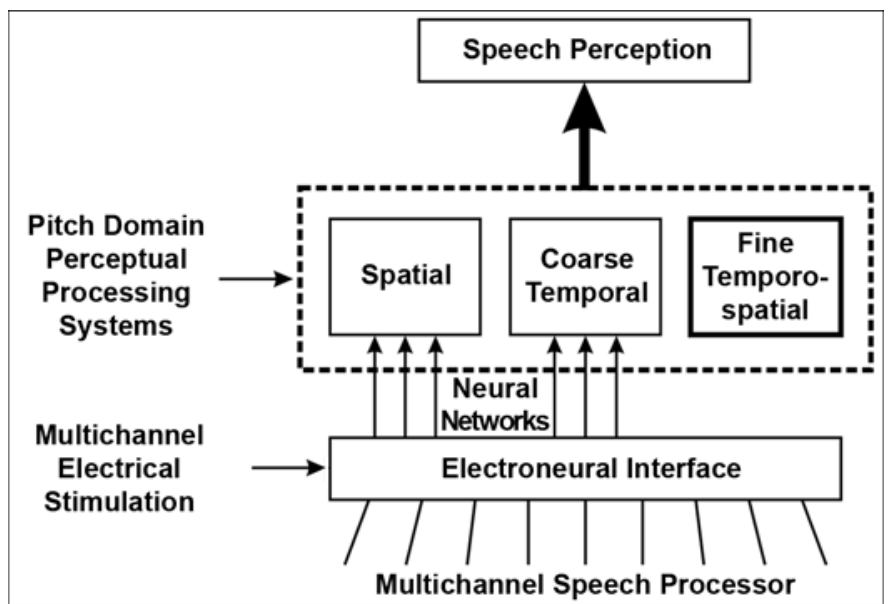

Figure 22.

Diagram of processing of frequency information and perception of pitch through central auditory spatial, temporal, and temporospatial perceptual systems. Reproduced by permission of Philosophical Transactions of Royal Society B from Clark GM. The multiplechannel cochlear implant: the interface between sound and the central nervous system for hearing, speech, and language in deaf people- $\mathrm{a}$ personal perspective. Philos Trans R Soc Lond B Biol Sci. 2006; 361(1469):791-810. [PMID: 16627295] 
The acoustic model proved quite effective in reproducing speech results obtained with the F0/F2 speech processing strategy on patients with implants. The acoustic model also predicted improved speech perception with a strategy that presented F1 as well as F2, with F0 as rate of stimulation across the stimulated electrodes (F0/F1/F2).

\section{First and Second Formant Speech Processor}

As discussed, the inaugural F0/F2 strategy gave patients with previous hearing the ability to communicate, including conversations on the telephone. However, speech perception in quiet and especially in noise was still not as good for patients with implants as it was for people with hearing. The findings on the perception of complex electrical signals [105-108] and acoustic models of electrical stimulation described earlier were important in showing that improved speech processing should be achieved by presenting additional frequency information along spatial processing channels while still retaining the temporal information across the spatial channels [110-111].

The next strategy to be investigated presented F1 and F2, along spatial processing channels, with voicing as rate of stimulation across the spatial channels (F0/F1/F2) (Figure 23). F1 was selected because speech studies on individuals with hearing had shown that both F1 and F2 were important for vowel recognition and that F1 transitions were required for voicing and identifying certain consonants. This strategy was supported by the psychophysical research that stimuli presented to two electrodes could be perceived as a two-component sensation [106108]. Furthermore, information transmission analysis for the F0/F2 and F0/F1/F2 strategies using the acoustic model [111] demonstrated improved speech perception scores with the addition of the F1 information. To overcome the problems of channel interaction, first demonstrated in the University of Melbourne's physiological speech processing strategy in 1978 [91], my research group began the policy of using nonsimultaneous (pulse separation of $0.7 \mathrm{~ms}$ ) sequential pulsatile stimulation at two different sites within the cochlea to provide F1 and F2 information. F0 was coded as rate of stimulation as with the inaugural F0/F2 strategy.

The mean open-set Central Institute of the Deaf wordin-sentence scores rose from $16(n=13)(\mathrm{F} 0 / \mathrm{F} 2)$ to 35 percent $(n=9)(\mathrm{F} 0 / \mathrm{F} 1 / \mathrm{F} 2)$ [114]. When the two-speech processing strategies were compared in background noise, the F0/F1/F2 speech processor was significantly better at a signal-to-noise ratio (SNR) of $10 \mathrm{~dB}$ [115]. Because the speech perception results and the transmission of informa-

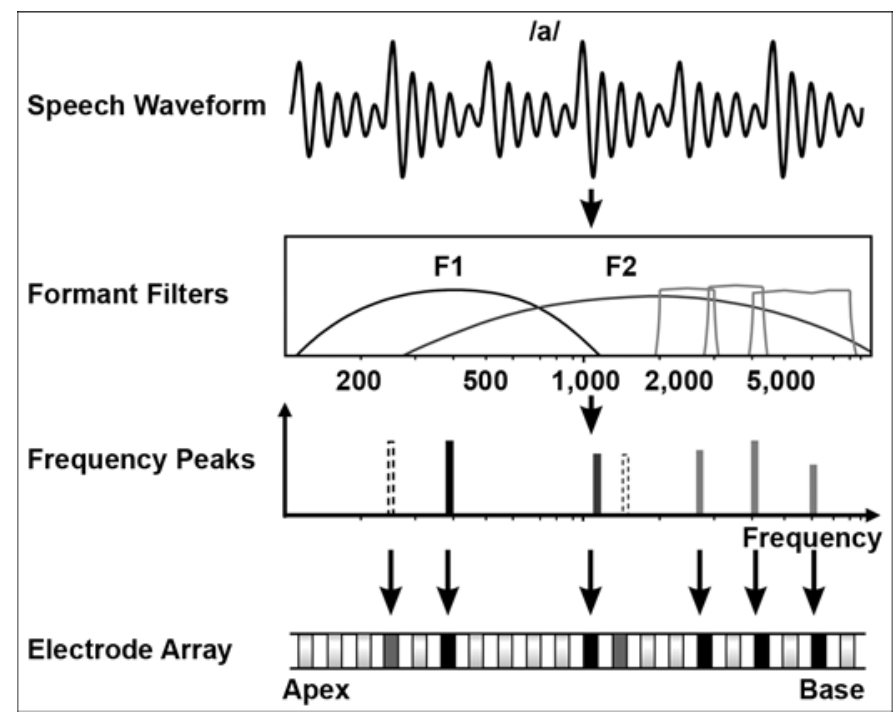

Figure 23.

First (F1) and second (F2) formant and hybrid formant/fixed-filter strategies to test speech perception $(2.0-2.8,2.8-4.0$, and $\geq 4.0 \mathrm{kHz})$.

tion with vowels and consonants for electrical stimulation using the F0/F1/F2 processor were similar to those obtained for the acoustic model, the similarity confirmed the predictive value of the model. The U.S. FDA approved the F0/F1/ F2 speech processor in May 1986 for postlinguistically deafened adults, and a number of studies confirmed that speech perception was significantly better than for the F0/ F2 strategy [1].

\section{Hybrid Formant/Fixed-Filter Speech Processor (MULTIPEAK)}

Both the formant-based and fixed-filter strategies just described had limitations [92-95,101-102,111,114], especially for consonant recognition and hearing speech in noise. Consonants that carry much of the high-frequency information, for example, fricatives such as /s/ and / / [59], were noted to have lower scores, and because of their importance for speech understanding, a second modification of the formant strategy was developed that presented the energy from high-frequency fixed bands in the third formant frequency region (2.0-2.8, 2.8-4.0, and $\geq 4.0 \mathrm{kHz}$ ), as well as F1 and F2, as a stimulation site (Figure 23). Voicing was transmitted as rate of stimulation across the spatial processing channels. It was therefore a hybrid formant/fixedfilter (MULTIPEAK) selection strategy.

When the F0/F1/F2 and hybrid formant/fixed-filter strategies were compared [116], a significant improvement was seen with open-set word in sentences for the 
hybrid strategy both in quiet and background noise [116]. Furthermore, a randomized prospective study by Cohen et al. [117] showed speech perception scores were greatly improved for the hybrid formant/fixed-filter strategy than for a six-fixed-filter strategy developed commercially as Ineraid (Richards Medical Company; Memphis, Tennessee) [117-118]. The hybrid formant/fixed-filter system was approved by the FDA on October 11, 1989, for speech understanding in deaf adults who previously had hearing.

\section{Fixed-Filter Speech Processor: Constant High Stimulus Rate}

An alternative fixed-filter system was developed in which the outputs from a number of bandpass filters were presented to electrodes nonsimultaneously as interleaved pulses to reduce channel interaction [119]. A fixed-filter scheme then evolved (continuous interleaved sampling [CIS]) that used constant rate of stimulation for avoiding channel interaction and at a higher rate than previous strategies for representing voicing better [120]. Voicing was transmitted as amplitude variations in the speech wave across the channels. This strategy improved open-set speech scores compared with the other fixed-filter schemes.

\section{Fixed-Filter Maxima Speech Processor: Constant Low Stimulus Rate}

An improvement in speech processing was found with a strategy that selected the six maximal outputs from a bank of 16 and later 20 fixed filters [121], rather than formant energy peaks, and presented this information to the brain along spatial processing channels (Figure 24) [122]. The pattern of speech frequencies was well represented for those in the F1 region (Figure 25), and the frequencies were easier to extract than formant peaks in the presence of noise. Furthermore, the outputs of each filter were presented to the electrodes at a constant rate, because the study by Tong et al. had shown that, with a constant stimulus rate, the amplitude variations in speech could transmit the coarse temporal information required for voicing across the spatial channels [123-124].

This maximal filter output strategy gave better open-set word results in quiet and in noise than the hybrid formant/ fixed-filter strategy [125-126]. This strategy developed by industry had 20 filters and stimulated at a constant rate of approximately 180 to 300 pps per channel and was referred to as "SPEAK" [125-126].

The results for SPEAK [127] were the same or better than CIS [128] for comparable groups of patients. This finding was interesting because again it suggested the impor-

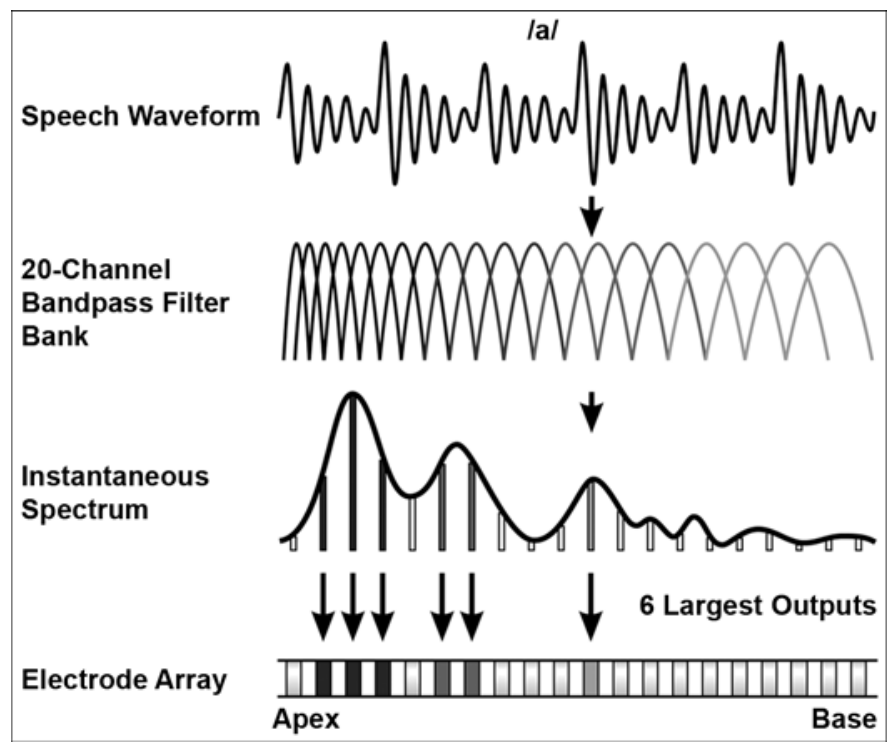

Figure 24.

Fixed-filter maxima strategy showing six spectral maxima from 20 bandpass filters. Adapted from Clark GM. Cochlear implants. Diseases of the ear. 6th ed. Ludman H, Wright T, editors. London: Edward Arnold; 1998. p. 149-163.

tance of a spectral pattern of frequencies similar to that of speech (well represented with this strategy).

\section{Fixed-Filter Maxima Speech Processor: High Stimulus Rate}

Because high stimulus rates could better sample voicing and reproduce noisy signals more accurately, the fixed-filter maxima strategy was used at high rates of 800 to 1,600 pps and referred to as the Advanced Combination Encoder (ACE) (Cochlear Pty Ltd; Lane Cove, New South Wales). But before high stimulation rates were used, a series of studies on the experimental animal was undertaken to ensure that these rates would be safe [129130]. An improvement in speech perception was seen for some patients when high rates (i.e., $800-1,600$ pps rather than 250 pps) were used [131] (Figure 26). This finding suggested that differences in performance may be due to the responsiveness of neurons to temporal information. Therefore, one strategy is not appropriate for all.

\section{Differential Rate Speech Processor}

Because the fixed-filter maxima strategy at high stimulus rates (Cochlear Pty Ltd-ACE) showed variable results, with some people performing best at a low rate of $250 \mathrm{pps}$ and others at 800 pps, together with David Grayden, I 

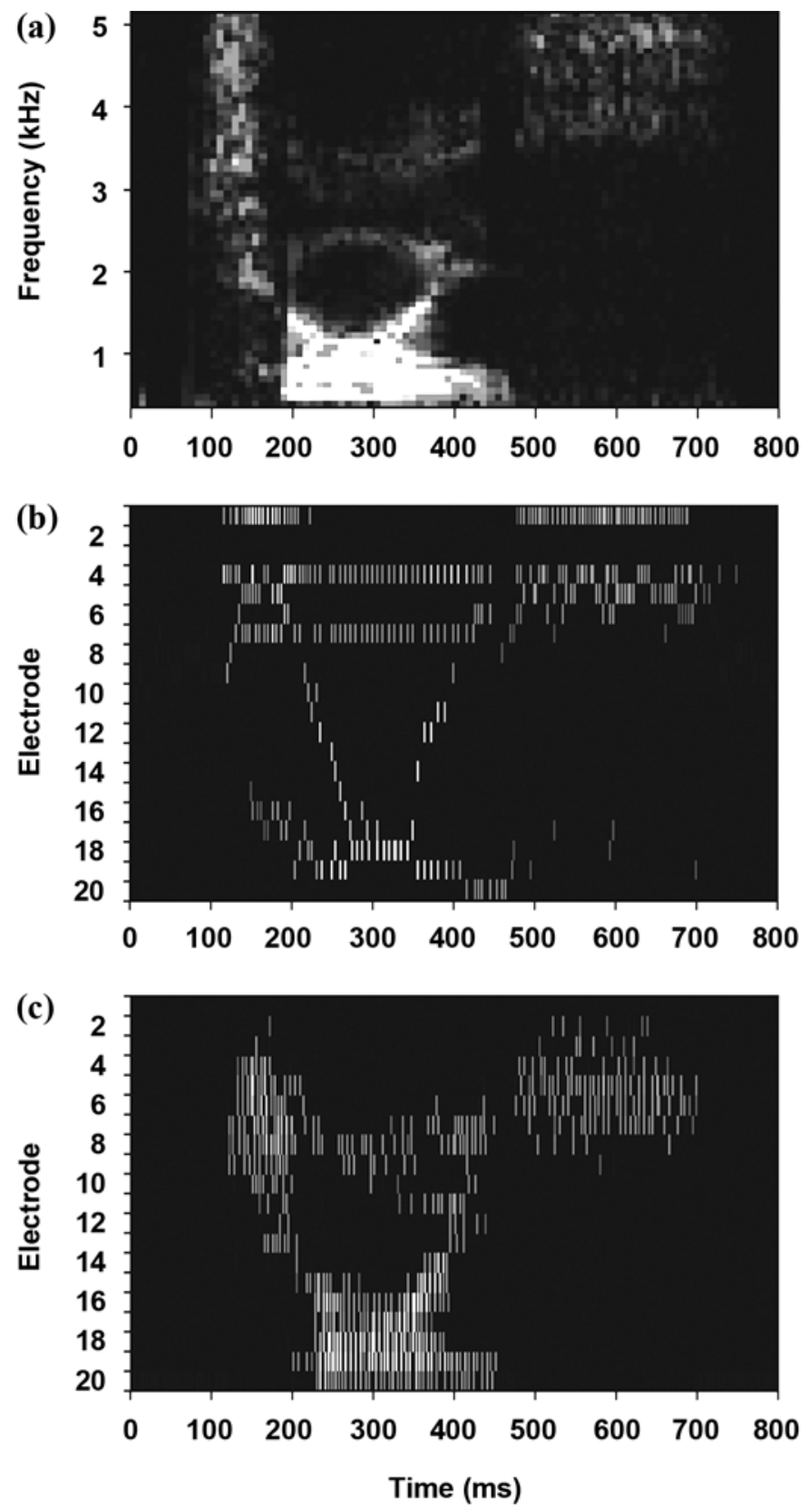

Figure 25.

(a) Spectrogram plot of frequency versus time for word "choice" with intensity at each frequency indicated by brightness. (b) MULTIPEAK: electrode representations (electrodograms) for "choice” using first and second formants and high-frequency fixed filter. (c) SPEAK: fixedfilter maxima strategy. (Note these are spatial representations of speech signal and do not show temporal processing.) Reproduced by permission of Philosophical Transactions of Royal Society B from Clark GM. The multiple-channel cochlear implant: the interface between sound and the central nervous system for hearing, speech, and language in deaf people-a personal perspective. Philos Trans R Soc Lond B Biol Sci. 2006;361(1469):791-810. [PMID: 16627295]

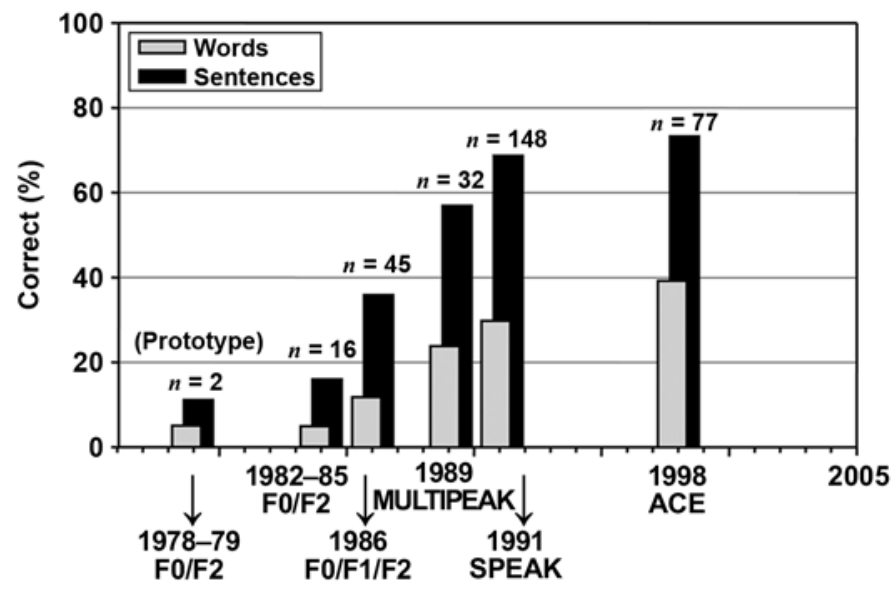

Figure 26.

Open-set word and sentence scores for extraction of first (F1) and second (F2) formants (F0/F1/F2 processor), addition of high fixed-filter outputs (MULTIPEAK), and then finally six to eight maximal filter outputs at low rates (SPEAK) and high rates (Advanced Combination Encoder $[\mathrm{ACE}])$. All frequencies were coded on place basis. F0 = fundamental (voicing) frequency. Reproduced by permission of Philosophical Transactions of Royal Society B from Clark GM. The multiple-channel cochlear implant: the interface between sound and the central nervous system for hearing, speech, and language in deaf people-a personal perspective. Philos Trans R Soc Lond B Biol Sci. 2006;361(1469):791-810. [PMID: 16627295]

performed research to understand why this variance occurred and how it could lead to a more advanced strategy. First, research was undertaken to determine how rate affected the recognition of phonemes [132-134]. An information transmission analysis showed a trend for manner of articulation to be better perceived for high rates and place of articulation for low rates. Better manner of articulation could be expected for sibilants at high stimulation rates because they cause the nerves to fire in a random fashion (Figure 27) like noisy acoustic signals. With the other manner features (nasal, continuants, and voicing), higher stimulation rates more accurately represent the speech envelope.

Place of articulation, however, was better perceived with a low stimulation rate. Studies suggest that at a high rate, the response patterns at the edge of a population of excited fibers would transmit poorer place information, because of a less clear-cut distinction between excited and nonexcited fibers [135].

A differential rate speech processor (DRSP), a speech processing strategy that provides manner of articulation at high stimulation rates and place of articulation at low rates, was developed and is illustrated in Figure 27 [134]. This DRSP selects place information that is usually 
(a)

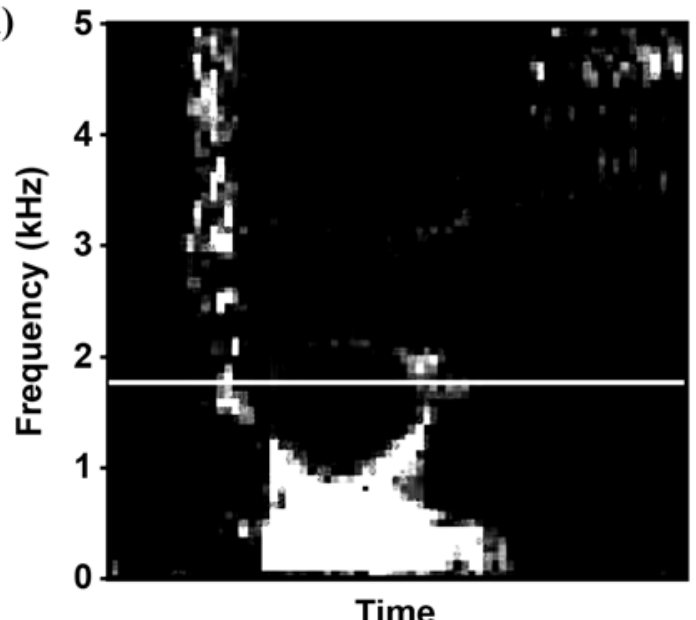

(b)

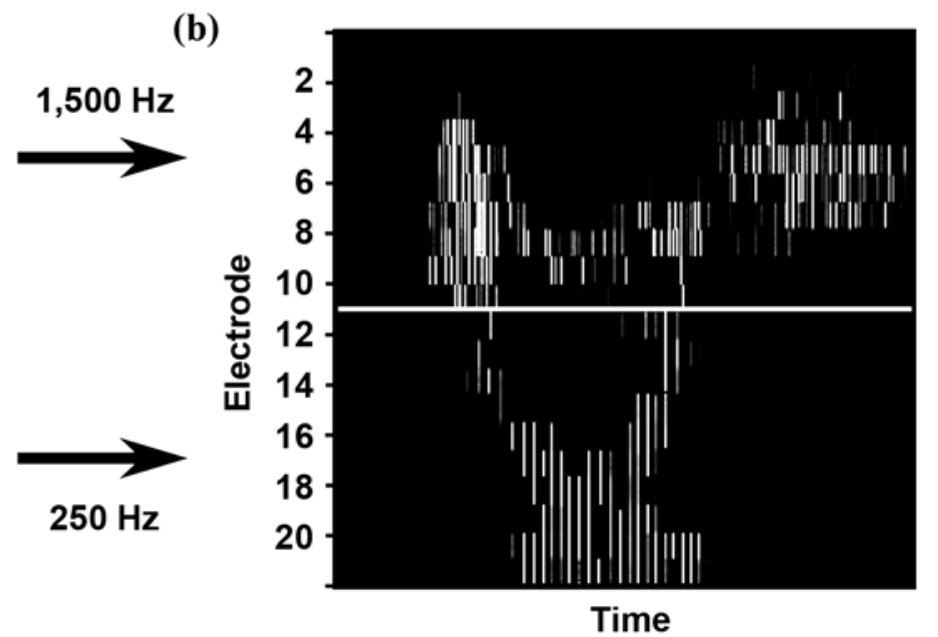

Figure 27.

Differential rate speech processor. (a) Spectrogram: low frequencies that predominately represent place information are coded on electrodes in upper-basal turn at low stimulus rates. (b) Electrodogram: high frequencies that predominantly represent manner are coded on lower-basal electrodes at high stimulus rates. Sources: Grayden DB, Clark GM. The effect of rate stimulation of the auditory nerve on phoneme recognition. In: Barlow M, editor. Proceedings of the Eighth Australian International Conference on Speech Science and Technology; 2000 Dec 4-7; Canberra, Australia. Canberra (Australia): Australian Speech Science and Technology Association. p. 356-61; and Clark GM. Editorial. Cochlear implants: climbing new mountains. The Graham Fraser Memorial Lecture 2001. Cochlear Implants Int. 2001;2(2):75-97. Reproduced by permission of John Wiley \& Sons, Limited, (c) 2001.

within the low-frequency range and presents it at low stimulation rates. Manner of articulation that is usually in the higher frequency range is presented at a high stimulation rate. This strategy has been evaluated and was found to be a compromise between fixed low- and high-rate strategies that can perform equal to or better than either of these strategies for most subjects [136].

\section{Transient Emphasis Speech Processor}

Speech perception in quiet and noise has been improved with a strategy called transient emphasis speech processor (TESM) that selects important cues and emphasizes them [131,137], for example, the transient cues for the recognition of plosive consonants (Figure 28). The amplitude, frequency, and duration of these segments were probably not being adequately extracted, and their perception could have been obscured by temporal and spatial masking.

Support for this concept came first from physiological studies by Clark et al. [24] and the psychophysical studies by Tong et al. [105] that showed how the frequency transients of speech were coded by electrical stimulation. Second, the acoustic study by Kennedy et al. [138] on listeners with hearing impairment demonstrated that an increase in the intensity of consonants in relation to vowels improved the perception of some consonants in a vowel consonant environment [139].

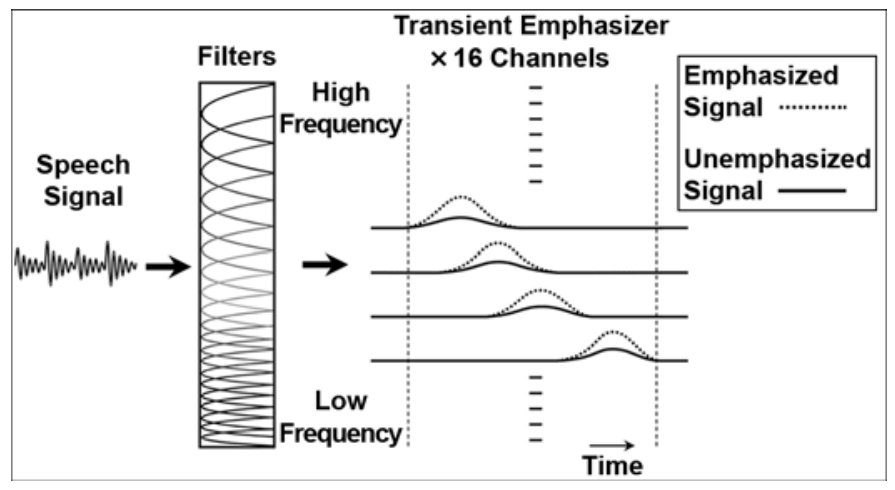

Figure 28.

Transient emphasis strategy showing amplification of outputs from four speech filters over short duration. Sources: Vandali AE, Harrison JM, Huigen JM, Plant K, Clark GM. Multichannel cochlear implant speech processing: further variations of the spectral maxima sound processor strategy. Ann Otol Rhinol Laryngol Suppl. 1995;166:37881 [PMID: 7668714]; and Clark GM. Editorial. Cochlear implants: climbing new mountains. The Graham Fraser Memorial Lecture 2001. Cochlear Implants Int. 2001;2(2):75-97. Reproduced by permission of John Wiley \& Sons Limited, (c) 2001.

The TESM strategy was first evaluated on four subjects at a $+5 \mathrm{~dB}$ SNR and compared with the fixed-filter maxima. A significant improvement was found with the TESM strategy in these four subjects for open-set wordin-sentence perception in noise, but not for words, consonants, or vowels in quiet [131]. 
Because the strategy could have been overemphasizing the onset of long duration cues, such as vowel formants, it was modified to emphasize the rapid changes accompanying short duration signals (5-50 ms) [137]. A study on eight Nucleus 22 patients found that the consonant-nucleusconsonant (CNC) open-set word, sentence, and closed-set consonant and vowel scores were all improved [137]. These data indicate the importance of representing the spectral and temporal information over short durations in speech coding strategies.

\section{Preprocessing of Speech}

As can be seen in Figure 26, the graph of open-set speech scores, with the University of Melbourne's formant and spectral selection schemes, shows a stepwise increase over 20 years from 5 to 40 percent for words and 18 to 75 percent for sentences. However, plateauing is inevitable because of electrodes providing a limited interface with the auditory nervous system. Nevertheless, preprocessing has helped and will continue to provide a clearer signal and give better hearing of speech, especially in noise.

\section{Automatic Gain and Sensitivity Control}

The speech processors discussed have automatic gain control (AGC) to keep speech intensity variations within the dynamic range. When the intensity of the signal rises, the compression is increased (attack time) and the gain reduced, and when the intensity of the speech signal falls, compression and gain are reversed.

The gain also needs to be adjusted through an automatic sensitivity control (ASC). If the background noise is above a certain level, the ASC will reduce the gain and vice versa if the background noise is too low.

\section{Adaptive Dynamic Range Optimization}

Adaptive dynamic range optimization (ADRO) is a mathematical routine that has been developed to more accurately fit the dynamic range for sound intensities in each frequency band into the dynamic range for each electrode [140-141]. It applies a set of rules to control the output level. An audibility rule specifies that the output level should be greater than a fixed level between threshold and maximum comfort level at least 70 percent of the time. The discomfort rule specifies that the output level should be below maximum comfort level at least 90 percent of the time [141-143]. ADRO's mode of operation is illustrated in the diagram in Figure 29. With speech, the preemphasis and AGC in the standard speech processor
(Figure 29(a)) reduce the intensity range of all the frequencies. As a result, limited dynamic range is available for electrical stimulation on many of the electrodes. On the other hand, with ADRO (Figure 29(b)), less compression of the speech frequencies and greater dynamic range on all stimulating electrodes are shown.

\section{Adaptive Beamformer}

Speech perception in noise can be improved with the Griffiths/Jim adaptive beamformer (ABF) [144]. The principles of the ABF are shown in Figure $\mathbf{3 0}$ for a situation in which speech arrives from the front and noise from one side. The signals from the microphones at each ear are sent to an addition and subtraction unit. The output from the addition unit contains speech plus added noise (Noise 1), and the output from the subtraction unit has removed speech and subtracted noise (Noise 2). In

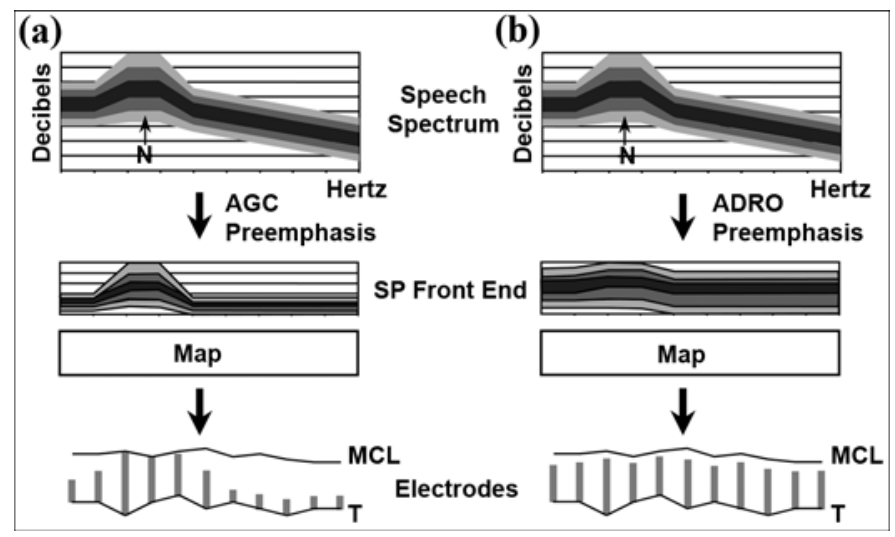

Figure 29.

Frequency to electrode mapping, in presence of noise $(\mathrm{N})$, for standard (a) speech processor (SP) of present cochlear implant and (b) SP with adaptive dynamic range optimization (ADRO). Top graphs: intensities of speech frequencies with added N, middle: intensity outputs of SPs after preemphasis and automatic gain control or ADRO, and bottom: relative current levels mapped to electrodes on array. AGC = automatic gain control, $\mathrm{MCL}=$ maximum comfortable level, $\mathrm{T}=$ threshold . Sources: Clark GM. Editorial. Cochlear implants: climbing new mountains. The Graham Fraser Memorial Lecture 2001. Cochlear Implants Int. 2001;2(2):75-97; and Martin LFA, James C, Blamey PJ, MacFarlane D, Swanson B, Just Y, Galvin KL. Adaptive dynamic range optimisation for cochlear implants. Aust J Audiol. 2000;22 Suppl:64; and Martin LFA, Blamey PJ, James C, Galvin KL, MacFarlane D. Adaptive range of optimisation for hearing aids. In: Barlow M, Rose P, editors. Proceedings of the Eighth Australian International Conference on Speech Science and Technology; 2000 Dec 4-7; Canberra, Australia. Canberra (Australia): Australian Speech Science and Technology Association, Inc; 2001. p. 373-78. Reproduced by permission of John Wiley \& Sons, Limited, (c) 2001. 


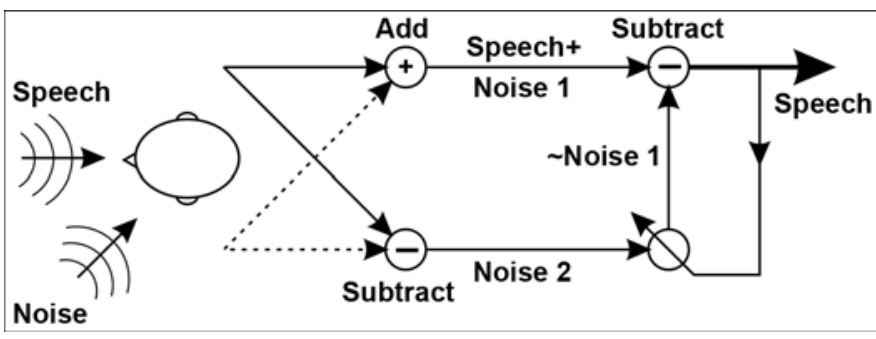

Figure 30.

Principles of operation of Griffiths/Jim adaptive beamformer, which improves speech perception in noise. Illustrations from Van Hoesel RJ, Clark GM. Evaluation of a portable two-microphone adaptive beamforming speech processor with cochlear implant patients. J Acoust Soc Am. 1995;97(4):2498-2503. [PMID: 7714267]

the next stage, the two signals are then subtracted and an adaptive filter is used to adjust noise to approximately zero, with output relatively free of noise. With this arrangement, the processor effectively uses the two microphones to form a beam directly in front of the subject and attempts to reject sounds not falling within it.

Dual microphones and an ABF have been used for improving the recognition of speech in noise for persons with cochlear implants [144-145]. A study was undertaken on four patients tested for speech perception at $0 \mathrm{~dB}$ SNR, with the signal directly in front of the patients and the noise at $90^{\circ}$ to the left [144]. The results showed hearing in noise dramatically improved for the ABF strategy when compared with a strategy that simply added the two microphone signals together (sum). A mean open-set sentence test score for the $\mathrm{ABF}$ was 43 percent and 9 percent for the control at a very difficult ( $0 \mathrm{~dB}) \mathrm{SNR}$.

Further development is required to make this $\mathrm{ABF}$ more robust in multispeaker and reverberant conditions. This development is being achieved with an $\mathrm{ABF}$ that reduces background noise from the surrounding environment [57].

\section{Bilateral Cochlear Implants and Bimodal Hearing}

Once the benefit of a cochlear implant in one ear was established $[99,146]$, research commenced to determine the value of bilateral implants [147-148], particularly speech understanding in the presence of background noise. Furthermore, comparisons of speech perception for multielectrode implants and hearing aids on children showed that a multichannel implant for a profound hearing loss gave comparable results with that of a hearing aid in a child with a severe hearing loss [149-150]. This finding led to studies on adults and children with an implant in the worse ear and a hearing aid in the better ear (bimodal hearing) [151].
With bilateral implants and bimodal hearing, the aim was to reproduce the benefits of two ears. These benefits are-

1. The ability to localize the direction of a sound (because of differences in the intensity and the time of arrival and phase of the sound at each ear).

2. Hearing speech in noise in each ear due to central neural mechanisms that partially remove the noise, but not the signal (squelch effect or binaural release from masking).

3. Hearing speech on one side with competing noise in the opposite ear (the head shadow effect).

4. Loudness summation.

Psychophysical studies on subjects with bilateral implants who use headphones showed that interaural intensity differences could be readily used for good sound localization but not so for temporal differences. However, ensuring that equivalent sites in each ear were excited was also important [147,152-154]. Furthermore, when sound localization was tested with a series of freefield speakers, the average detection was $15.5^{\circ}$ compared with $1^{\circ}$ to $2^{\circ}$ for normal hearing. When the cues were isolated, the interaural temporal differences for electrical stimulation were similar for sound at $50 \mathrm{pps}(150 \mu \mathrm{s})$ but not at higher rates [155]. The average interaural intensity difference perceived was $0.3 \mathrm{~dB}$ for electrical stimulation; this was approximately three times that for acute hearing.

To investigate the head shadow as well as the "squelch" effect, presenting the noise separated in space from speech was necessary. The head acts as an acoustic barrier that attenuates the signal on the far side of the head compared with the near side. The effect is greater for high frequencies and is approximately $7 \mathrm{~dB}$ in the speech frequency range. The squelch effect leads to improved understanding of speech in noise because of central neural mechanisms that compare the signals at each ear and partially remove the noise but not the signal [14].

The first study on binaural implants, in which the speech signal and noise were spatially separated, was undertaken by van Hoesel and Clark $[1,156]$. The SNR was determined for the reception of speech with the speech and noise presented at $45^{\circ}$ toward each ear [156]. The speech reception threshold was determined for only the better ear with speech to the better ear and noise to the worse ear or speech to the worse ear and noise to the better ear. A significant improvement in speech intelligibility was observed for binaural listening for the better 
ear alone when the noise was on the same side as the better ear and the signal was on the contralateral side. When signal and noise locations were reversed, the binaural performance was similar to the better monaural side alone. The results show that binaural implantation can improve performance for speech in noise when signal and noise are spatially distinct and positioned such that the head orientation can be used to improve the SNR at one of the two ears [156].

In a later study [155], the noise and sound were first presented together from directly in front and speech scores were determined for monaural and binaural hearing. The noise was then moved opposite the left or right ear and the SNRs adjusted to return the speech perception scores to those for the frontal presentation. The results showed a very significant head shadow effect of 4 to $5 \mathrm{~dB}$. A possible squelch effect of 1 to $2 \mathrm{~dB}$ resulted on one side [1].

With bimodal stimulation, a number of patients could fuse acoustic stimulation in one ear with electrical stimuli in the other ear, with speech understanding improving overall in both quiet and noise [113,151,156]. Loudness summation seen for acoustic stimulation in one ear and electrical in the other needed to be controlled in the bimodal presentation of speech. Ching et al. also reported significant benefits for sound localization and hearing speech in the presence of spatially separated noise [157].

\section{Multichannel Cochlear Implant for Children Born Deaf or Deafened Early in Life}

After multichannel formant speech processing was proven to restore significant speech understanding in adults who had hearing before going deaf $[97,99]$, the next main question was, Would people born deaf or deafened early in life (prelinguistically deafened) also achieve the same level of speech understanding? If the brain neural connectivity had been optimized by prior exposure to sound for speech understanding in adults, could the right connectivity still occur if no prior exposure to sound had existed and they were subjected to electrically coded signals?

\section{Speech Perception}

Initial studies on two adults who were deafened early in life and used Sign Language of the Deaf (a system of signs that has its own grammar and is not related to spoken English) found they had poor speech understanding with electrical stimulation. This poor understanding was associated with an inability to discriminate rate and site of stimulation. They, however, had comparable abilities for discriminating current level with those of adults who had hearing before going deaf [158].

Therefore, we (researchers of these past studies) postulated that results with electrical stimulation in people born deaf would be better in children rather than in adults who had been born deaf or were prelinguistically deafened, because brain plasticity would allow them to develop rate and place discrimination and adapt to the speech processing strategies. For that reason, in 1985 and 1986, three children with ages decreasing from 14 to 5 years and who were prelinguistically deafened received a multichannel cochlear implant [89,159]. Because the youngest child had significant openset speech scores for electrical stimulation, other children were then operated on in the University of Melbourne's clinic. After a training regime was developed, five children from the clinic (aged 6-14 years) out of a group of nine were reported to have substantial open-set speech recognition for monosyllabic words scored as phonemes (range 30\%-72\%) and sentences scored as key words (range 26\%-74\%) [160162]. The children who did not achieve open-set speech recognition were implanted during adolescence after a long duration of profound deafness. The children who obtained open-set speech understanding, in particular, also improved in language [161-162].

These clinical reports were the first that established that severely and profoundly deafened children born deaf or prelinguistically deafened could achieve open-set speech understanding and then spoken language using electrical stimulation alone [89,160-161]. They used the F0/F1/F2 and hybrid formant/fixed-filter speech processing strategies. In addition, a number of children who were operated on at $\leq 5$ years of age achieved benefits similar to adults who had hearing before going deaf.

The good results obtained from the Melbourne clinic [160-162] led to the start of a clinical trial in the United States for the FDA that commenced in 1987 [163]. The results for 80 children from the international trial of the F0/ F1/F2 and hybrid formant/fixed-filter speech processing strategies were presented to the FDA. One June 27, 1990, the multichannel cochlear implant that used these strategies was approved by the FDA as safe and effective for children $\geq 2$ years, making this cochlear implant the first to be approved by any international health regulatory body. Thus it became the first major advance in helping severely to profoundly deafened children communicate since Sign Language of the Deaf was developed at the Paris deaf school (L'Institut National de Jeunes Sourds de Paris) $>200$ years ago. 
The results for 91 children born deaf and 51 deafened after birth were compared. The open-set scores for those deafened after birth were better than for those born deaf, but the closed-set results were comparable. Although the data suggested that prior exposure to sound was more important than electrical stimulation alone for optimal speech processing, the ages of the children at implantation, duration of deafness, and other factors had not been considered in the comparison.

Another series of studies found that the longer the hearing loss, the poorer the speech perception [164]. This result suggested that a critical period of plasticity existed for developing brain connections, and early surgical intervention was indicated. This hypothesis has been supported in a recent study on children who received the cochlear implant at $\leq 12$ months of age. They had language comprehension and expression comparable with their hearing peers, and their results were better than for a group of children who received the implant between 12 and 24 months of age [165].

\section{Psychophysics}

Concurrent research was undertaken on prelinguistically deafened children that determined the development of perception skills of importance for speech understanding. Busby and Clark showed that with prelinguistically deafened children, the discrimination of electrode place was worse if the period of hearing loss was long or the child was implanted at an older age [166]. The data suggested that exposure to sound or electrical stimulation during the "plastic" phase of brain development would be required for this perceptual skill to develop. In addition, the better the discrimination of electrode place in the apical turn, the better the closed-set speech perception score.

The ability to discriminate place of stimulation varying over time was also an important skill for postlinguistically deafened adults in understanding the dynamically changing speech signal [105], and for this reason, it was also studied in prelinguistically deafened children [167]. The prelinguistically deafened children were less successful than postlinguistically deafened adults in discriminating electrode place trajectories, and this finding correlated with speech perception scores. Our research also found that the discrimination of place trajectories had developed in children by 3 years of age.

In addition, we considered that the ability of children to rank electrode pitch monotonically with the electrode place of stimulation (rather than discriminate electrode place) was an important determinant for speech percep- tion. The speech scores in children with implants with and without the ability to rank electrode pitch correctly are shown in Figure 31 [166-168]. One can see that not all children who could rank electrode pitch (58\%) had good speech perception results of $\geq 30$ percent. This finding suggests that the development of neural connectivity for place discrimination or pitch ranking is not the only factor for learning speech. Other factors could be temporal processing or the development of language.

\section{Spoken Language}

To achieve the best speech results for severely to profoundly deafened children with multichannel cochlear implants, the research showed the necessity for early diagnosis and implantation. Early diagnosis can be achieved with a screening program for all births and objective testing of hearing thresholds with, for example, the steady state method for recording auditory evoked-brain potentials first reported by Rickards and Clark [169] and Stapells et al. [170].

Once the hearing loss is diagnosed, an early intervention program should develop receptive and expressive language. This program will require the child to be educated to maximally use hearing with the cochlear implant. The auditory-verbal method is specially suited for this. The use of minimal visual cues with the auditory-verbal method is supported by physiological studies that have

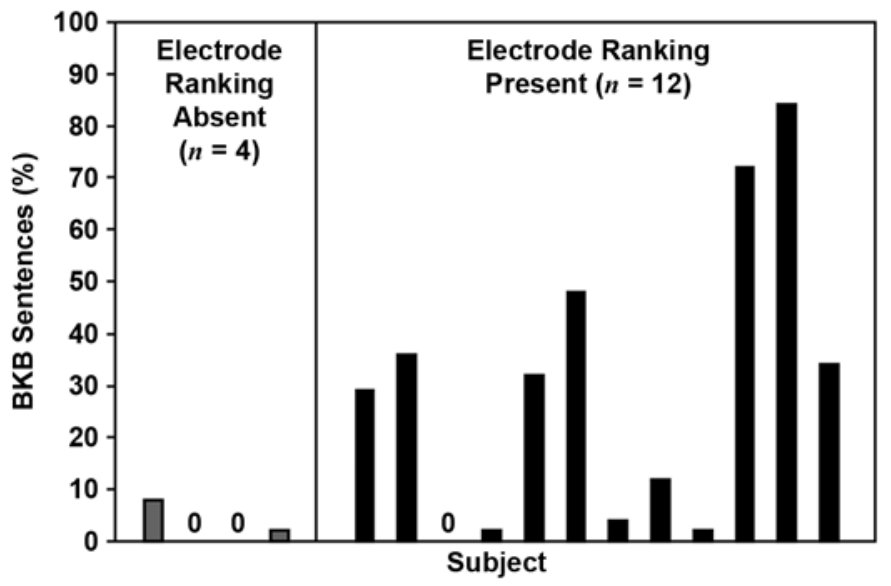

Figure 31.

Electrode ranking according to whether pitch changed monotonically with electrode. Electrode ranking for pitch versus word scores for BenchKowal-Bamford (BKB) open-set sentences for electrical stimulation alone on 16 children using cochlear implants. Calculated from data from Busby PA, Clark GM. Electrode discrimination by early-deafened subjects using the cochlear limited multiple-electrode cochlear implant. Ear Hear. 2000;21(4):291-304. [PMID: 10981605] 
shown that in deaf animals, an overdominance of visual inputs to the auditory cortex that lead to an incorrect balance between the auditory and visual systems needs to be corrected.

The relative contributions from the two sensory systems were studied in a speech coding context with the use of the McGurk effect [168,171-172]. The McGurk effect occurs when the lip movements for a speech signal are formed independently and are not necessarily the ones that accompany the auditory signal. For example, we may hear the signal for /ba/, but the lips show /ga/, as illustrated in Figure 32. That combination can lead to a fusion response and the perception of /da/ or /tha/. On the other hand, if an auditory /ga/ is presented and then combined with a visual /ba/, a combination response of /bga/ results (Figure 32).

The response may be due to the importance of information from one modality relative to the ambiguity of the other information source. So, if an adult cannot perceive auditory speech sounds clearly, the sounds are ambiguous and then information from visual speech cues becomes more important. Thus a McGurk effect indicates the weighting of auditory and visual stimuli by the individual, relative to the degree of clarity contained within the signal. Fusion responses also suggest that the cortex is

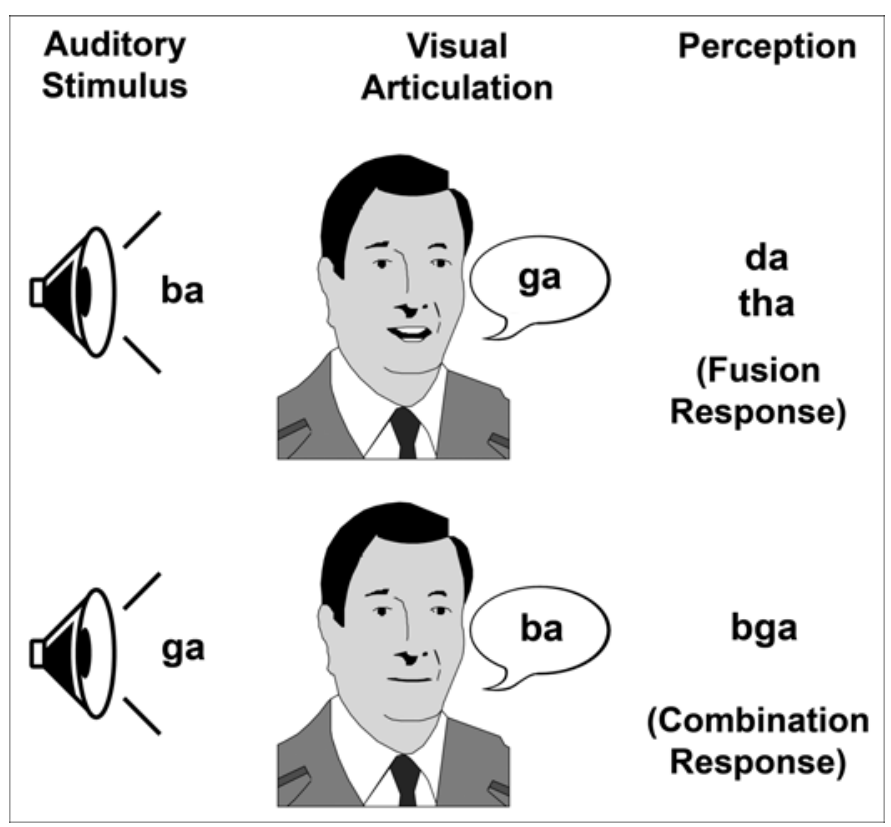

Figure 32.

McGurk effect: auditory and visual speech information is presented separately. capable of integrating auditory and visual stimuli, a skill that is possibly underused prior to cochlear implantation.

The McGurk effect is seen in children with hearing and with implants. If children with hearing are tested with an acoustic stimulus in which the frequency transitions are shifted progressively from low rising to high falling as for the recognition of F2, the percept will change from /ba/ to / da/ to /ga/, as shown in Figure 33(a) [171-172]. When the rising frequency transition becomes flat (stimulus 3), a central probability processor cannot determine whether the signal is a /ba/ or /da/, but with a falling frequency transition, a rate of fall (stimulus 7) exists in which the probability detector cannot distinguish between /da/ and /ga/. In Figure 33(b), the acoustic signals are accompanied by a visual /ba/. The visual /ba/ is a clear signal; therefore, the more indistinct differences in the acoustic cues for /ba/ and /da/ for stimulus 3 are weighted in favor of $/ \mathrm{ba} /$ and are statistically significant as indicated by the stars (in the graph). In Figure 33(c) on the other hand, with a visual /ga/, the cues are weighted in favor of $/ \mathrm{da}$ / because the visual signal for /ga/ may be more like /da/ than /ba/. This evidence indicates the McGurk fusion effect.

The same stimuli were presented to children of the same age and nonverbal intelligence who had implants. The results are shown in Figure 34 [172]. Acoustically, more confusion exists between the /da/ and /ga/ sounds, which is probably due to reduced ability to process these higher frequency transitions. Nevertheless, when the visual /ba/ is given (Figure 34(b)), more /ba/ responses occur because the signal is more distinct than the auditory signals for /da/ and /ga/. A dominant visual effect appeared to be more pronounced for children with implants than for children with hearing. In addition, with the visual /ga/, the central processor had a stronger bias for the visual signal than for sound. These data suggest that in deafness with limited auditory experience, the cortex is capable of appropriately integrating auditory and visual signals, but more practice is needed to take advantage of plasticity for establishing the right balance between vision and audition.

The results have important implications for habilitation. First, they show that a visual bias exists in integrating information in children with implants; however, a higher level function for fusion of auditory and visual information is present as in children with hearing. The visual bias could be used positively when the distinct and easy-to-read /ba/ is combined with the auditory signal for /ba/ and be helpful in training. On the other hand, if the auditory signals for /ba/, /da/, and /ga/ are not strong and 
(a)

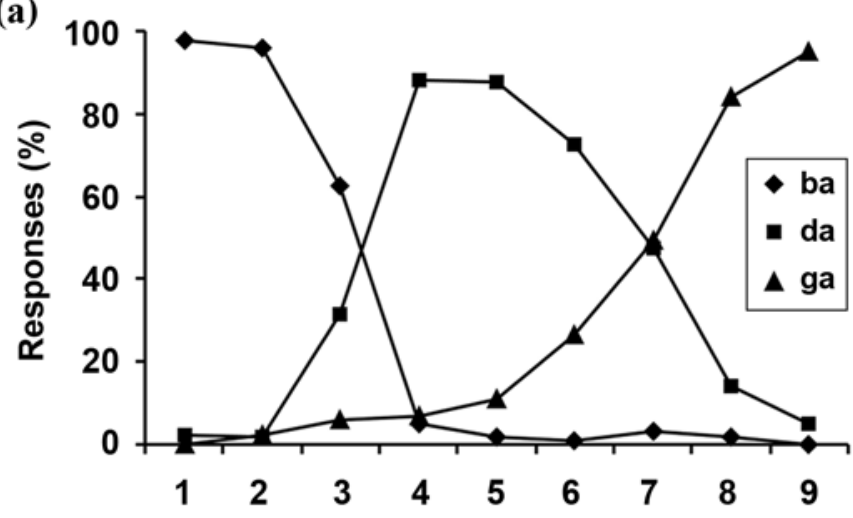

(b)

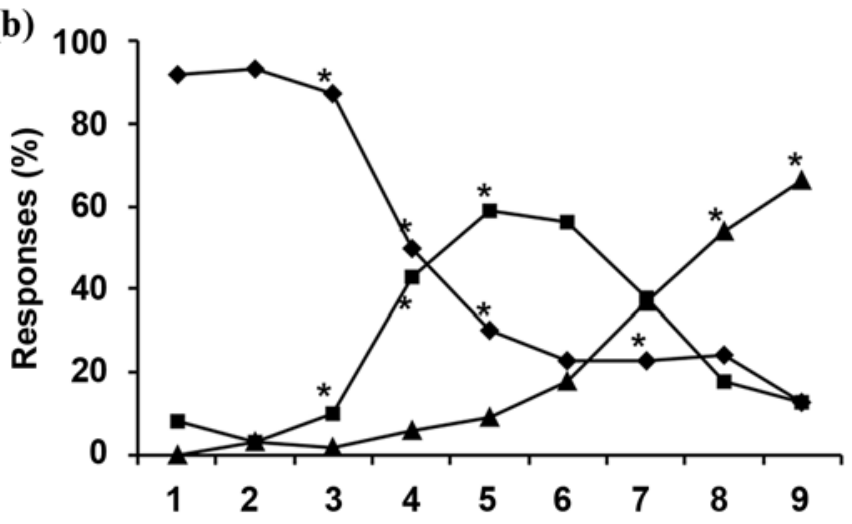

(c)

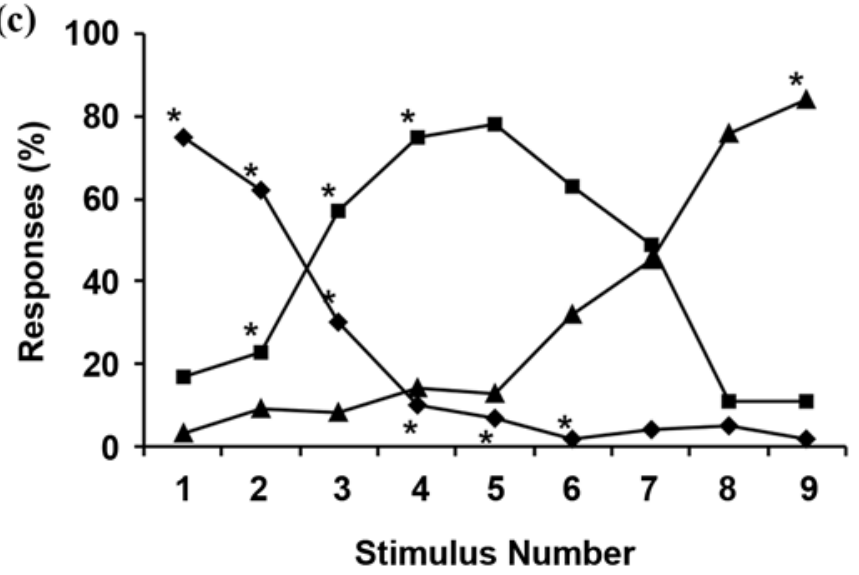

Figure 33.

Consonant recognition for electrical place transitions in children with implants. (a) Auditory alone, (b) with visual /ba/, and (c) with visual /ga/. Stars $(*)$ indicate statistical significance. Reprinted by permission of Springer Science+Business Media, (C) 2003, from Surowiecki V, Grayden DB, Dowell RC, Clark GM, Maruff P. The role of visual cues in the auditory perception of synthetic stimuli by children using a cochlear implant and children with normal hearing. In: Bow C, editor. Proceedings of the 9th Australian International Conference on Speech Science and Technology; 2002 Dec 14; Melbourne, Australia. Melbourne (Australia): Australian Speech Science and Technology Association Inc; 2002.
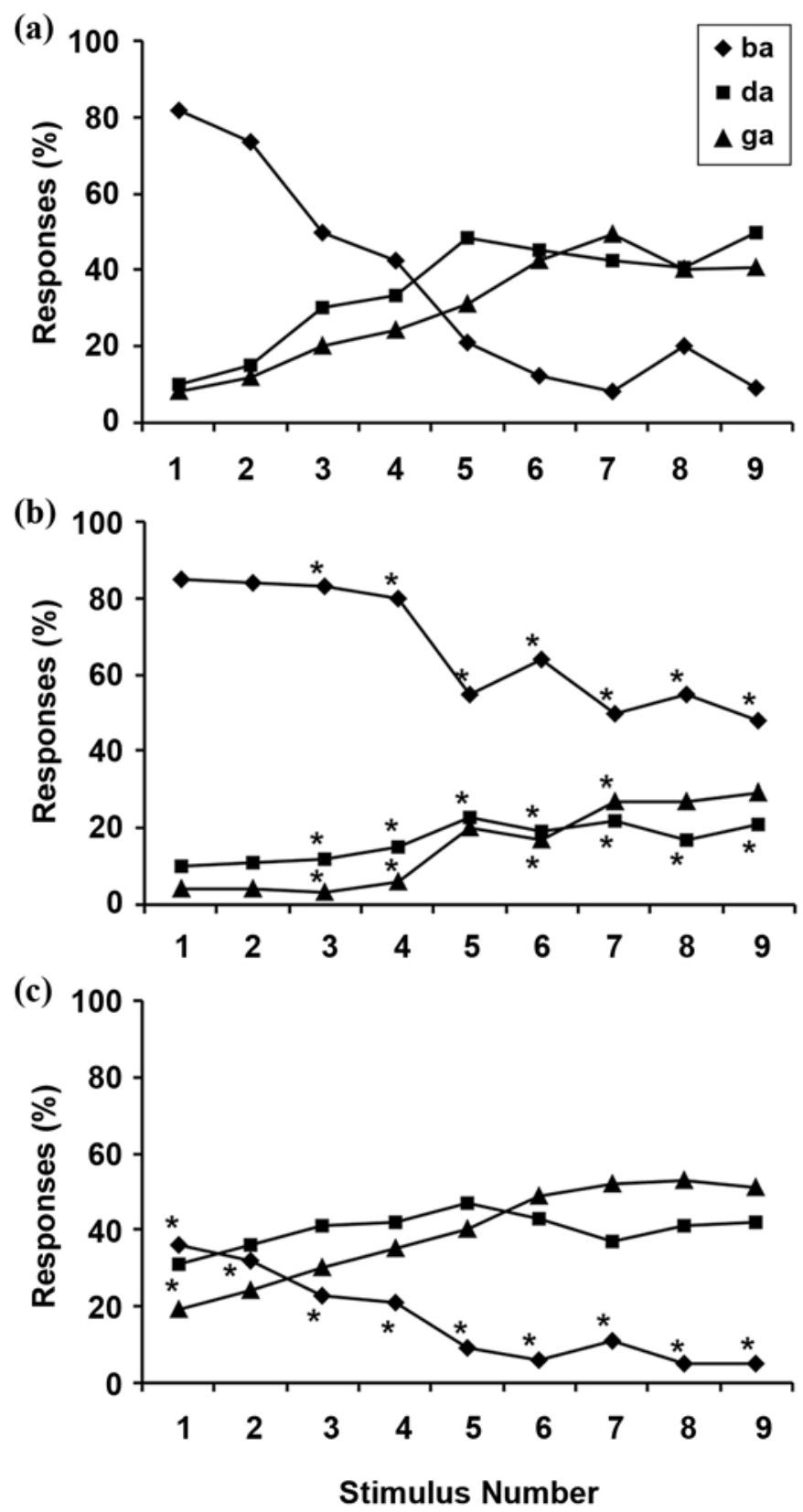

Figure 34.

Consonant recognition for acoustic frequency transitions in children with hearing. (a) Auditory alone, (b) with visual /ba/, and (c) with visual /ga/. Stars $(*)$ indicate statistical significance. Reprinted by permission of Springer Science+Business Media, (C) 2003, from Surowiecki V, Grayden DB, Dowell RC, Clark GM, Maruff P. The role of visual cues in the auditory perception of synthetic stimuli by children using a cochlear implant and children with normal hearing. In: Bow C, editor. Proceedings of the 9th Australian International Conference on Speech Science and Technology; 2002 Dec 14; Melbourne, Australia. Melbourne (Australia): Australian Speech Science and Technology Association Inc; 2002. 
unambiguous, then fusion with lipreading will not produce an effective result. This result means that either specific auditory verbal training for any auditory distinctions should be carried out or implant speech processing should make the transitions, for example, between /da/ and /ga/, more distinct [1]. A speech processing strategy that emphasizes transitions is the TESM (discussed on p. 671-72).

An excellent example of the benefit of auditory-verbal education provided by a regular primary school named Mount View, in Melbourne, Australia, is shown in Figure 35, where the mean growth in language years is plotted against chronological age. Deaf students are in the classrooms with hearing children, but additional help is provided from a teacher of the deaf when needed. In 40 percent of the children, most have good or excellent receptive language, while most of the others have language comparable with that expected for aided children with a severe hearing loss.

\section{VIEW OF FUTURE}

\section{High-Fidelity Hearing}

Speech perception in quiet with present cochlear implants has reached a plateau (Figure 26) [14]. Furthermore, speech perception in noise is significantly worse than for persons with hearing [1]. In addition, with bilateral implants, as distinct from two hearing ears, only a small squelch effect exists to assist hearing in noise, probably because of inadequate fine temporospatial coding. For music, the recognition of melody with temporal coding is restricted to 800 pps [173-174], and the quality is described as poor.

In studying how electrical stimulation could achieve high-fidelity hearing, I have assumed this process could be accomplished through a more accurate reproduction of the coding of frequency. Psychophysical and acoustic modeling research has demonstrated that the perception of pitch with place and coarse temporal processing is good but fine temporospatial processing is unsatisfactory [14,32].

With regard to the fine temporospatial firing patterns, I reported that although the interspike intervals for electrical and acoustic stimulations were different at low frequencies (up to $400 \mathrm{~Hz}$ ), the discrimination of pitch was similar at these frequencies [32]. A stimulus rate of $400 \mathrm{pps}$, referenced in a 1999 study [175] and seen in Figure 36 [176], had a deterministic firing pattern (tightly phase-locked), and for a $400 \mathrm{~Hz}$ sound, the firing pattern had a stochastic or

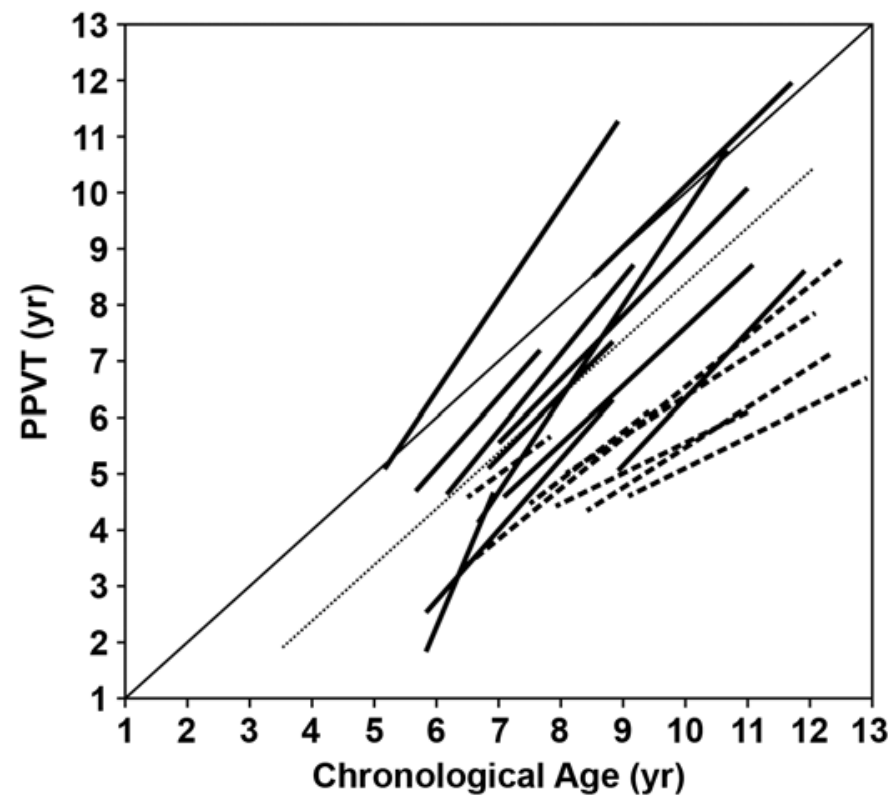

Figure 35.

Receptive vocabulary growth with equivalent language age versus chronological age. PPVT = Peabody Picture Vocabulary Test. Courtesy of J. Sarant and M. Dann, University of Melbourne.

probabilistic pattern. On the other hand, at mid-frequencies of $800 \mathrm{~Hz}$, the interspike interval patterns were similar for acoustic and electrical stimulation, but pitch discrimination was much poorer for electrical stimulation. One possible explanation was that neuronal firing for sound was correlated across small groups of neurons because of phase differences, as a result of the traveling wave along the basilar membrane, as illustrated in Figure 37, and this pattern was not reproduced with electrical stimulation. Higher rates of electrical stimulation, e.g., frequencies of 1,200 and $1,800 \mathrm{pps}$, have only very limited capacity to follow in time with the stimuli because the stimuli occur in the refractory period (Figure 38) [177].

The fine patterns of responses are due to neighboring fibers [178] reproducing the phase changes seen from sound waves traveling along the basilar membrane (Figures 37 and 39) [179-181], but they do not occur for an electrical stimulus. With the traveling wave, there are (1) longitudinal wave motion due to the rapid transit of the wave to the point of maximal vibration (much like the tsunami passing across the ocean) and (2) lateral wave motion at the point of maximal vibration (like the tsunami reaching the shore) (Figure 39).

Furthermore, modeling and physiological studies have shown that the input to neurons in the brainstem from a 

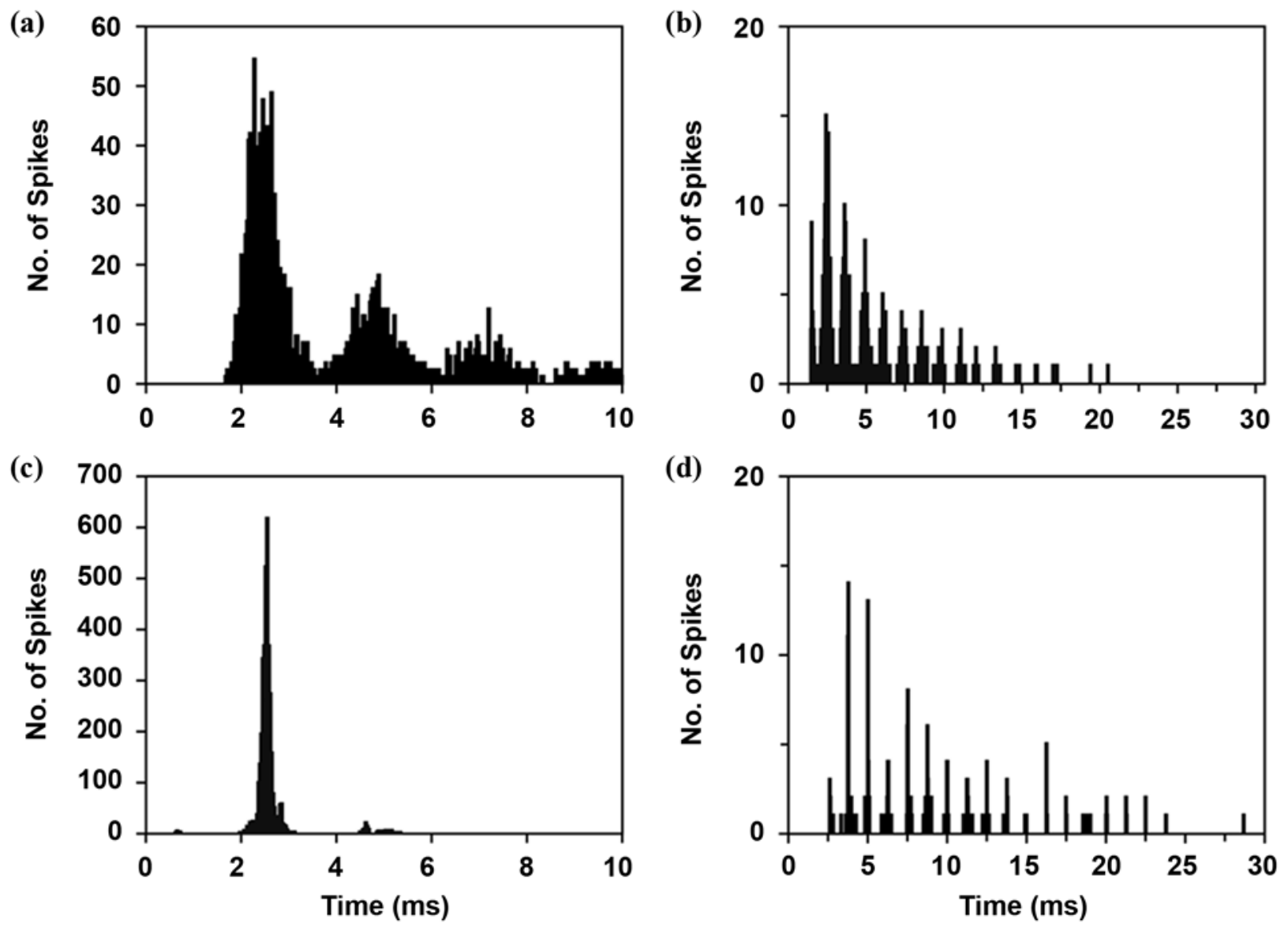

Figure 36.

Extracellular interspike histograms from globular bushy cells in anteroventral cochlear nucleus for acoustic stimulation at (a) 416 and (b) $834 \mathrm{~Hz}$ and electrical stimulation at (c) 400 and (d) 800 pps. Graphs by author. Adapted from Clark GM. Research advances for cochlear implants. Auris Nasus Larynx. 1998;25(1):73-87. [PMID: 9512798]

localized rather than a widespread region of the cochlea leads to a more synchronized output from the brainstem nuclei [182-183]. Thus phase variations around the region of maximal vibration on the basilar membrane can be processed (Figures 37 and 39). This fine temporospatial pattern of response cannot be reproduced with present electrical stimuli because the current spread is more widespread. In addition, electrical stimulation could more easily stimulate the inhibitory side inputs to a cell.

Thus for improving frequency coding, electrical stimulation will need to reproduce the fine temporospatial pattern of responses for transmitting phase. The temporospatial pattern will not only require an increased density of electrodes, as illustrated in Figure 40 [182], but the preservation of the auditory neurons (Figure 41) [184]. In addition, our studies have shown the auditory peripheral processes from spiral ganglion cells can be preserved after deafness with the installation of neurotrophin 3 (NT-3) and brain-derived neurotrophic factor [178], and this preservation is facilitated through combined electrical stimulation [185]. Furthermore, neurotrophins can cause peripheral processes to resprout from the spiral ganglion cells when the neurotrophins are administered during an early phase of degeneration [178].

To determine the most effective method for delivering neurotrophins to the cochlea, Richardson et al. studied the diffusion of radioiodine (NT-3) instilled into the scala tympani and found that ${ }^{125}$ I-labeled NT-3 reached all the turns of the cochlea after only 24 hours but the density of the signal varied for different structures in each turn of the cochlea [186]. For example, a strong signal was found in the endosteum of the scala tympani and basilar membrane 
(Figure 42), and its relative density was greatest in the basal turn. However, the signal was weak amongst the spiral ganglion cells but strong around Rosenthal's canal (Figure 42). Similarly, a weak signal was found in the peripheral auditory nerve region in the osseous spiral lamina. Although the weak signal in the auditory neuron region indicated a low concentration of neurotrophin, it was sufficient to preserve and regenerate the neurons. Many tyrosine protein kinase $\mathrm{C}$ and p75 receptors are on the cells and p75 receptors are on the peripheral processes for NT-3. The small proportion of NT-3 reaching the spiral canal and the spiral lamina indicates that the perfusion of neurotrophins into the scala tympani with a Micropump (UMP2, World Precision Instruments, Inc; Sarasota, Florida) is very inefficient.

Because the research just discussed showed the delivery of a nerve growth factor into the cochlea with a Micropump was inefficient, its localized release from a polymer in the scala tympani was a better option. Polypyrrole (PPy) is the polymer of choice. In the reduced state, PPy is neutral, and via hydrophobic interactions, proteins are likely to interact with the polymer backbone. However, if electrons are removed by oxidation, the polymer backbone becomes positively charged and more hydrophilic NT-3 interactions (these changes in polymer properties are likely to diminish any polymer) and result in electrically controlled (highly localized) release (Figure 43).

This array could be placed beneath the basilar membrane as shown in Figure $\mathbf{4 4}$ to preserve and stimulate the peripheral nerve fibers or next to the modiolus to stimulate the spiral ganglion cells. The placement of these electrodes would be with a perimodiolar array, as shown in Figure 45. A cochlear implant electrode array and polymer would release neurotrophins to minimize the loss of peripheral processes or ganglion cells that occur after a hearing loss or with trauma associated with an electrode insertion. The neurons would then be available for fine temporospatial patterns for more ideal frequency coding.

The fine temporospatial stimulus patterns and localized release of neurotrophins could be improved with the development of a composite array with carbon nanotubes. Research in the ARC Centre of Excellence for Electromaterials Science (Canberra, Australia) is showing that carbon nanotubes can be used to deliver neurotrophins and electrical charge to neurons. Carbon nanotubes are made of a one-molecule layer of graphite and are 1,000 times smaller than a human hair. They have extraordinary

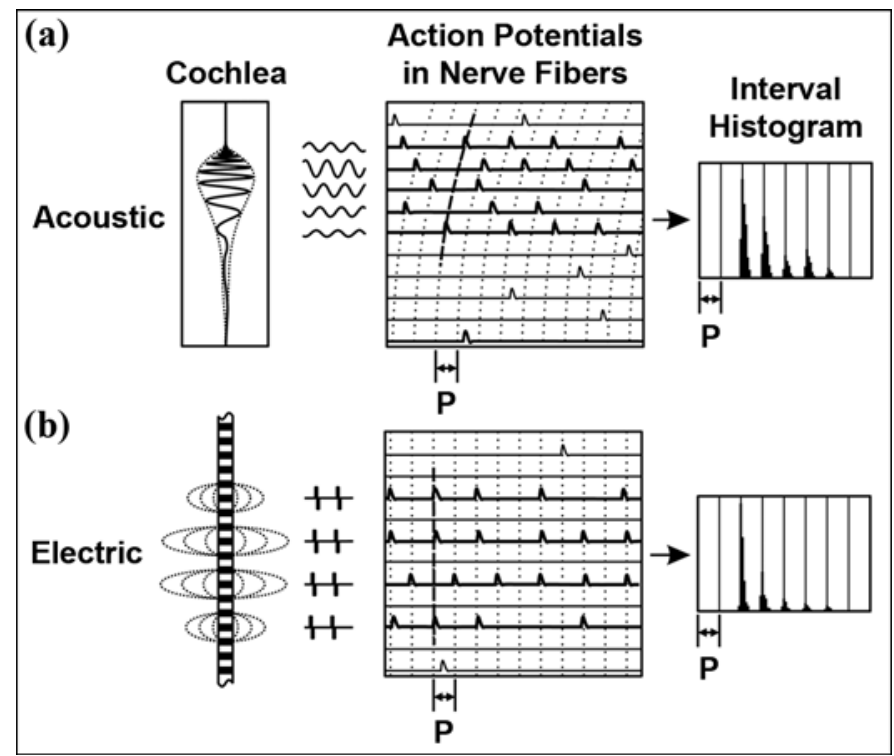

Figure 37.

(a) Left: Basilar membrane traveling wave for sound, center: phaselocking of nerve responses in small population of neurons showing delays from sound passing along basilar membrane, and right: interspike interval histogram of response to sound. (b) Left: electrical fields for multiple-electrode stimulation, center: phase-locking of nerve responses in small population of neurons, and right: interspike interval histogram of response to electrical stimulations. $\mathrm{P}=$ period of sound wave. Source: Clark GM. Editorial. Cochlear implants: climbing new mountains. The Graham Fraser Memorial Lecture 2001. Cochlear Implants Int. 2001;2(2):75-97. Reproduced by permission of John Wiley \& Sons Limited, (c) 2001.

strength and are 50 times stronger than steel. Their capability to conduct electricity is similar to that of platinum. They are fabricated by heating them to become gaseous in an inert atmosphere and then condensed with a metal catalyst in a second furnace.

The carbon nanotubes, shown in Figure 46, can be used in bundles for stimulation. The PPy with neurotrophin incorporated can be deposited on the surface of the nanotubes or around them (Figure 46(a)). This greatly increased surface area facilitates the uptake and release of neurotrophins better than flat surfaces. Furthermore, the carbon nanotubes can be deposited onto substrates for patterned electrical stimulation of nerves and localized release of trophic factors (Figure 46(b)).

\section{Electroacoustic Hearing}

Another new challenge is called electroacoustic hearing. It involves implanting ears with residual low-frequency hearing and preserving that hearing, vibrating the basilar 
(a)

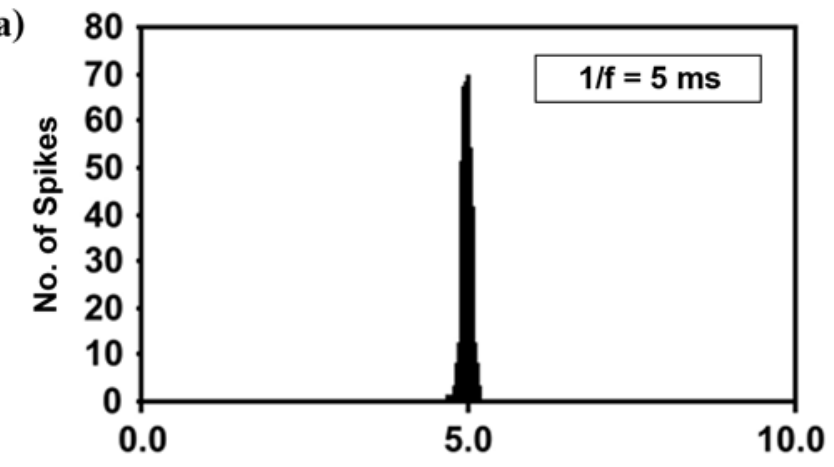

(b)

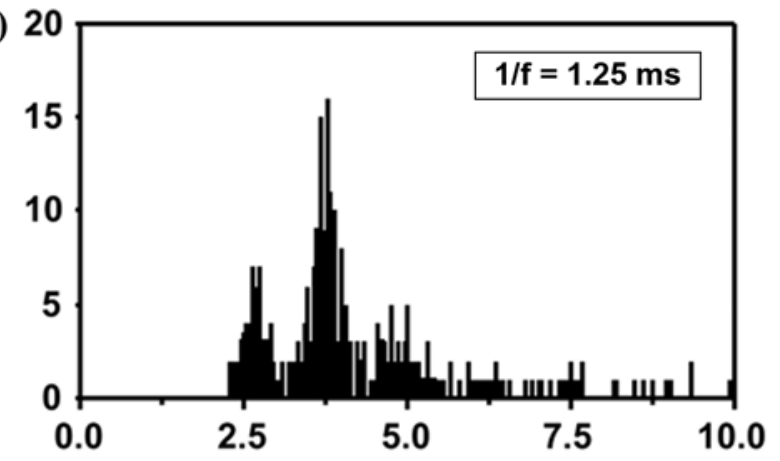

(c)

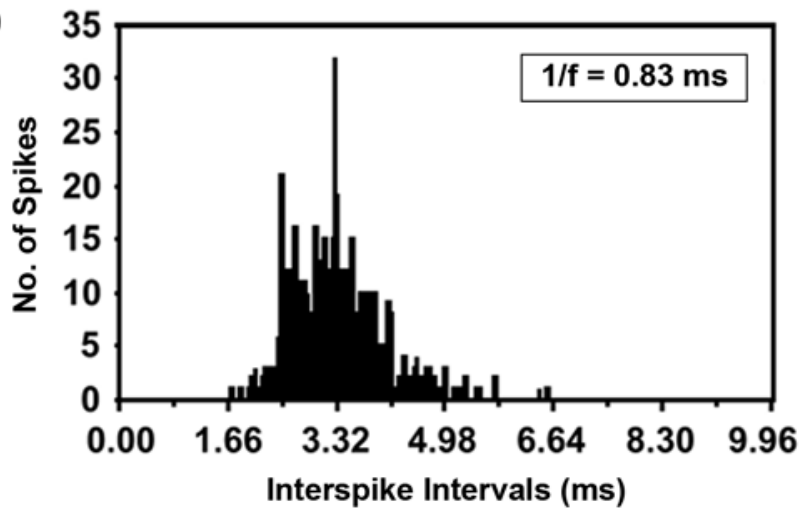

(d)

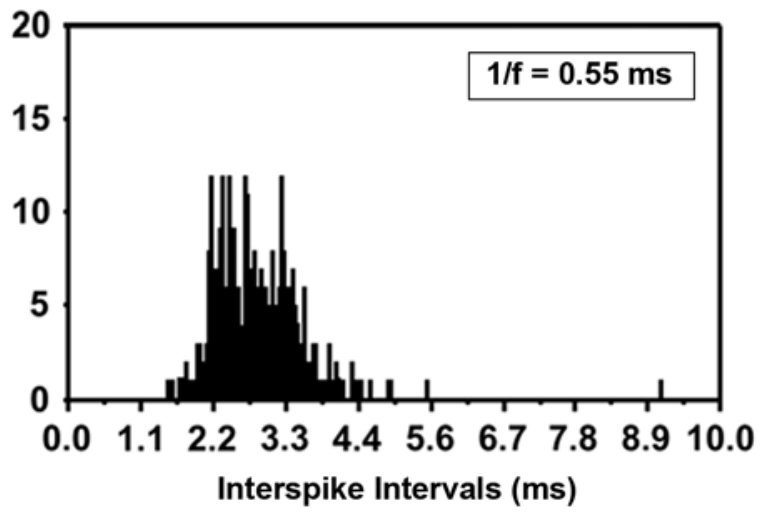

Figure 38.

Intracellular interspike histograms from globular bushy cells in anteroventral cochlear nucleus for increasingly higher rates of electrical stimulation: (a) 200, (b) 800, (c) 1,200, and (d) 1,800 pps. Broken line indicates absolute refractory period. $\mathrm{f}=$ frequency. Data analyzed by Paolini and Clark in The effect of pulsatile intracochlear electrical stimulation on intracellularly recorded cochlear nucleus neurons. In: Clark GM, editor. Cochlear implants. XVI World Congress of Otorhinolaryngology Head and Neck Surgery; 1997 Mar 2-7, Sydney, Australia. Bologna (Italy): Monduzzi Editore; 1997. p. 119-24. Reprinted by permission of Springer Science+Business Media, @ 2003.

membrane to excite the residual hair cells, and electrically stimulating the nerves that transmit the higher frequencies.

\section{Pathophysiology}

The concept of combined sensory hair cell excitation and electrical stimulation of auditory nerves is illustrated in Figure 47. Hair cell excitation may occur with either a hearing aid or electrophonic hearing. Electrophonic hearing occurs when electrical stimulation causes the outer hair cells to contract. This action leads to a traveling wave propagating along the basilar membrane to the site of maximal vibration. A hearing aid and electrophonic hearing both need to provide the low frequencies and the implant the mid to high frequencies of speech, with direct electrical stimulation.

In the lower half of Figure 47, syllable recognition has been plotted against cutoff frequency. Note the rapid increase in intelligibility from 1,000 to $2,000 \mathrm{~Hz}$. In addi- tion, the low frequencies are very important for melodies and integrating the speech signal from two ears in the presence of background noise.

Before patients with residual hearing were implanted, an earlier study on the experimental animal reported that an electrode array could be inserted very carefully through the round window membrane with only a $10 \mathrm{~dB}$ fall in thresholds (Figure 48) [187]. However, when a traumatic insertion occurred, the thresholds were generally elevated by 40 to $60 \mathrm{~dB}$. Furthermore, the study showed that the latency of the derived responses to clicks was the same before and after implantation, indicating that the frequency place basilar membrane mechanics were largely undisturbed [187].

Studies were next carried out in the experimental animal on the relation between cochlear pathology postimplantation and residual hearing. Research showed that factors such as trauma, infection, or just implantation 


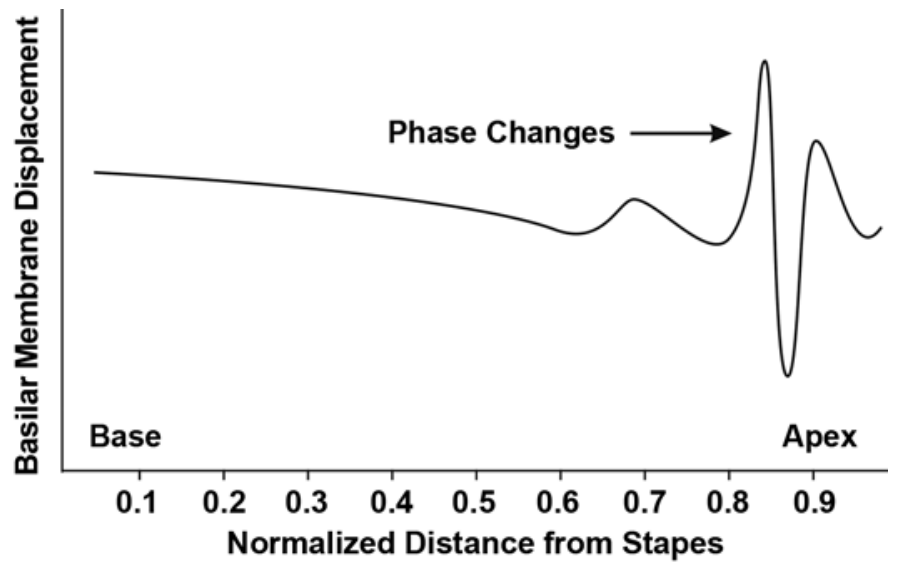

Figure 39.

Sound wave generated from cochlear model and traveling along basilar membrane. Sources: Neely ST, Kim DO. A model for active elements in cochlear biomechanics. J Acoust Soc Am. 1986;79(5): 1472-80 [PMID: 3711446]; and Au D, Bruce I, Irlicht L, Clark GM. Cross-fiber interspike interval probability distribution in acoustic stimulation: a computer modeling study. Ann Otol Rhinol Laryngol Suppl. 1995;166:346-49 [PMID: 7668700]. Reproduced by permission of John Wiley \& Sons, (c) 2001.

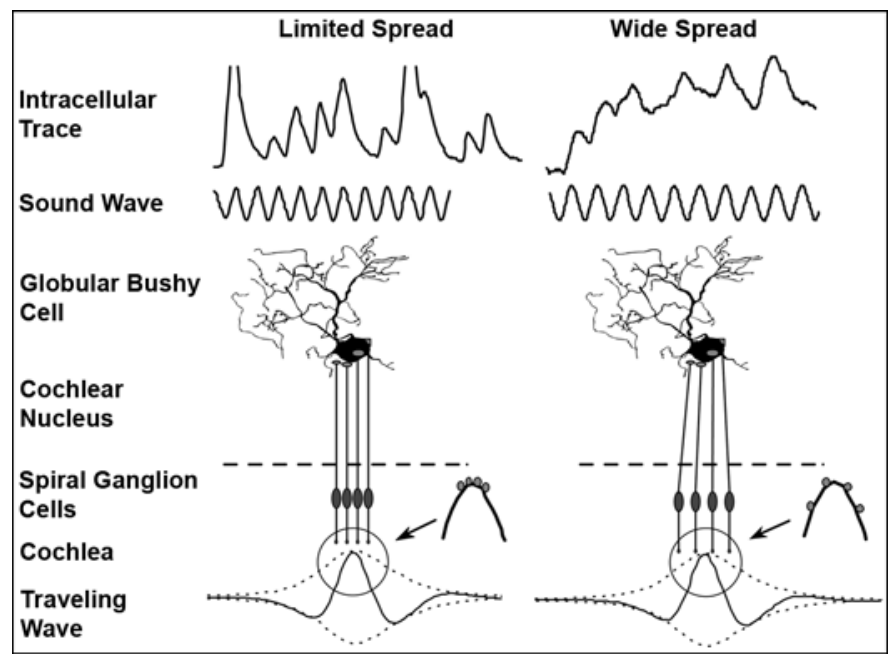

Figure 40.

Effect of spread (limited and wide) of excitation of basilar membrane on processing of phase information in first stage of auditory brain processing (globular bushy cells in consonant nucleus). Courtesy of AG Paolini.

would cause fibrous tissue and bone in the scala tympani and be associated with hair cell loss [188]. Also noted was that if the electrode abutted the basilar membrane or if significant fibrous tissue or bone in the scala tympani dampened the basilar membrane vibration, the hearing threshold would elevate. The correlation between new

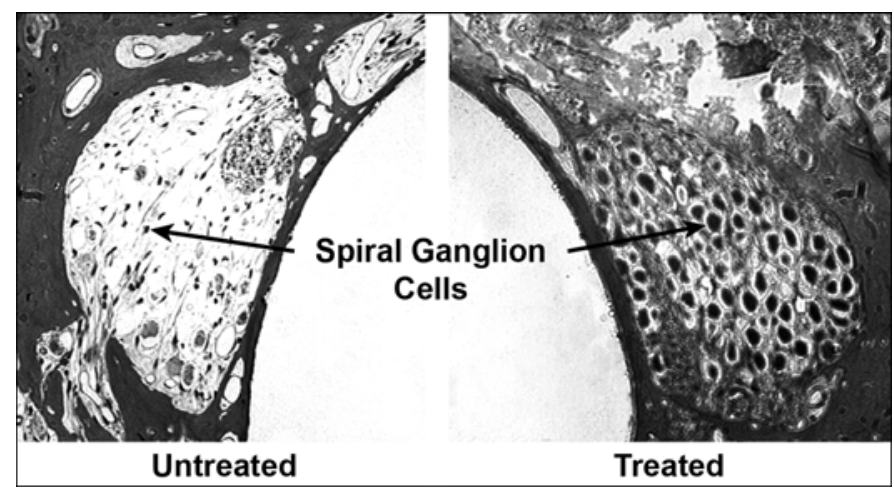

Figure 41.

Spiral ganglion cells in one of guinea pigs in study 5 weeks after systemic administration of ototoxic drugs. Right scala tympani was infused with brain-derived neurotrophic factor for 4 weeks (treated), and left was control side (untreated). Source: Marzella PL, Clark GM, Shepherd RK, Bartlett PF, Kilpatrick TJ. Synergy between TGF-beta 3 and NT-3 to promote the survival of spiral ganglia neurons in vitro. Neurosci Lett. 1998;240(2):77-80 [PMID: 9486476]. Reproduced by permission of John Wiley \& Sons Limited, (c) 2001.

bone and fibrous tissue in the scala tympani and hearing loss was confirmed [189]. This study also suggested that fibrous tissue and bone formation are due to an endosteal response caused by changes in the local cochlear microenvironment.

Then, a long-term study on 26 ears found that all cochleas had an increase in click-evoked auditory brainstem response thresholds for the first 4 weeks. In 46 percent, the thresholds returned to within $15 \mathrm{~dB}$ of the preimplant level. A long-term moderate loss was seen in 31 percent, and a severe loss was seen in 23 percent. In 27 percent of the ears, a moderate-to-severe inflammatory response was found that was most likely due to infection of the middle ear [130].

These results stress the importance of better understanding the cochlear histopathologic response before a widespread implanting of ears with residual hearing. Otherwise, a significant number of people could lose their hearing. With clinical research trials, great care is required to ensure sterility during surgery, prepare an adequate seal at the electrode entry point, avoid trauma to the cochlea, and manage middle ear infection rigorously.

\section{Hybrid Speech Processing}

For implanting deaf patients with residual hearing, Cochlear Ltd (changed from Cochlear Pty Ltd) along with Dr. Bruce Gantz (Department of Otolaryngology, University of Iowa) developed a short $10 \mathrm{~mm}$ array to minimize trauma to the cochlea and thus reduce the risk of hearing 

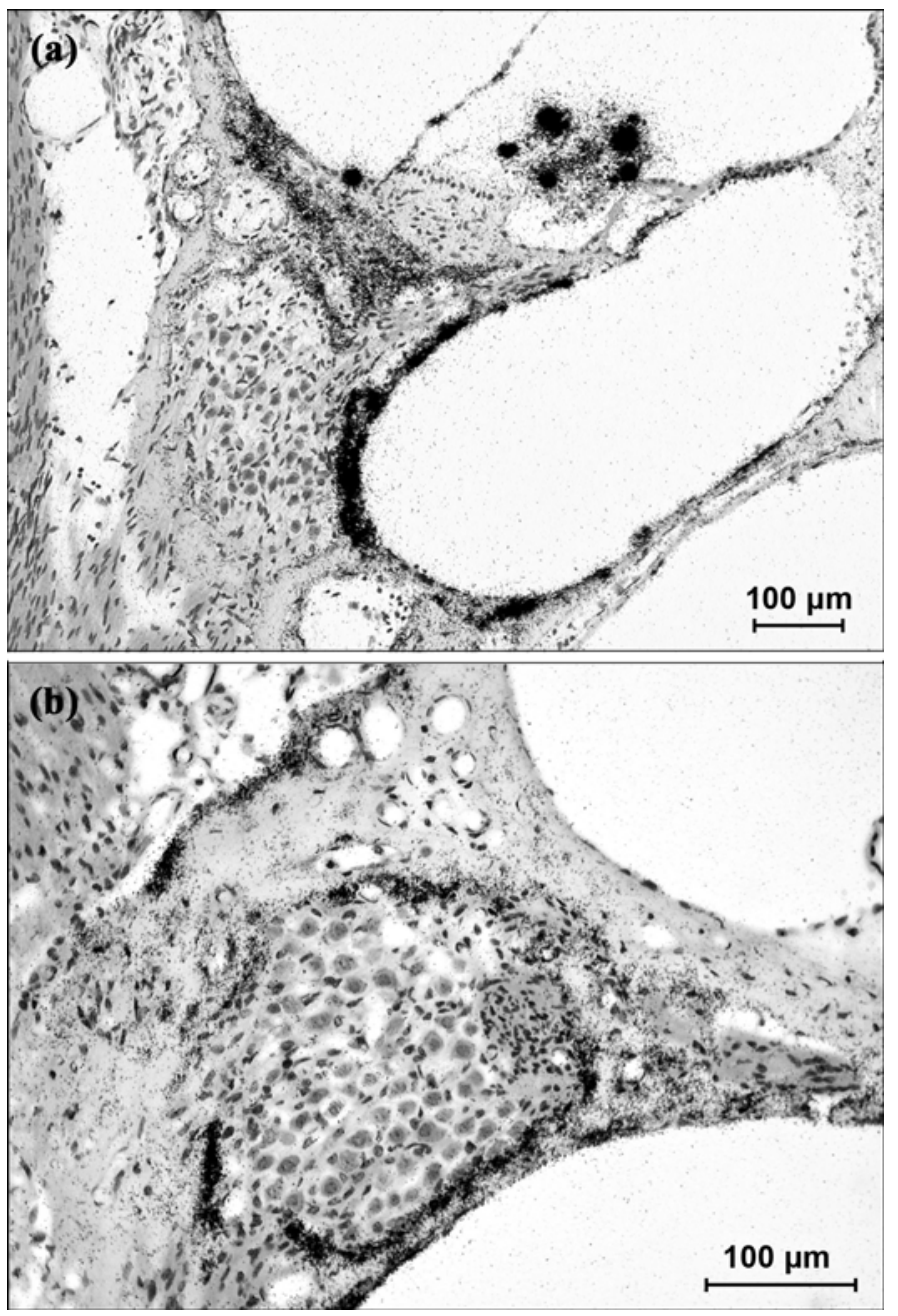

Figure 42.

Autoradiographs of cross section of guinea pig cochlea showing distribution of radio iodine-labeled neurotrophin 3 (NT-3). (a) Spiral ganglion and (b) spiral ganglion, basilar membrane, and organ of Corti. Courtesy of R. Richardson, The Bionic Ear Institute (East Melbourne, Australia).

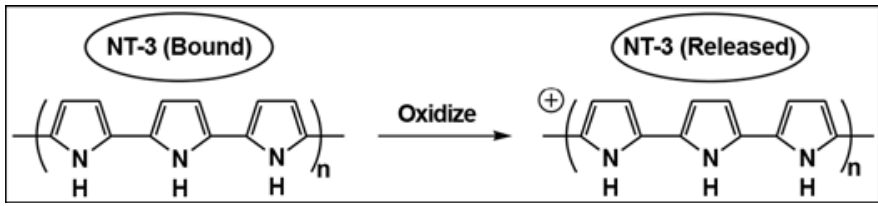

Figure 43.

Oxidation of pyrrole and binding of neurotrophin 3 (NT-3). $\mathrm{H}=$ hydrogen, $\mathrm{N}=$ nitrogen, $\mathrm{n}=$ number.

loss. In Figure 49(a), hearing thresholds of an average 70 $\mathrm{dB}$ speech spectrum for suitable hybrid implant patients are plotted against frequency. This array had a mean $9 \mathrm{~dB}$ loss

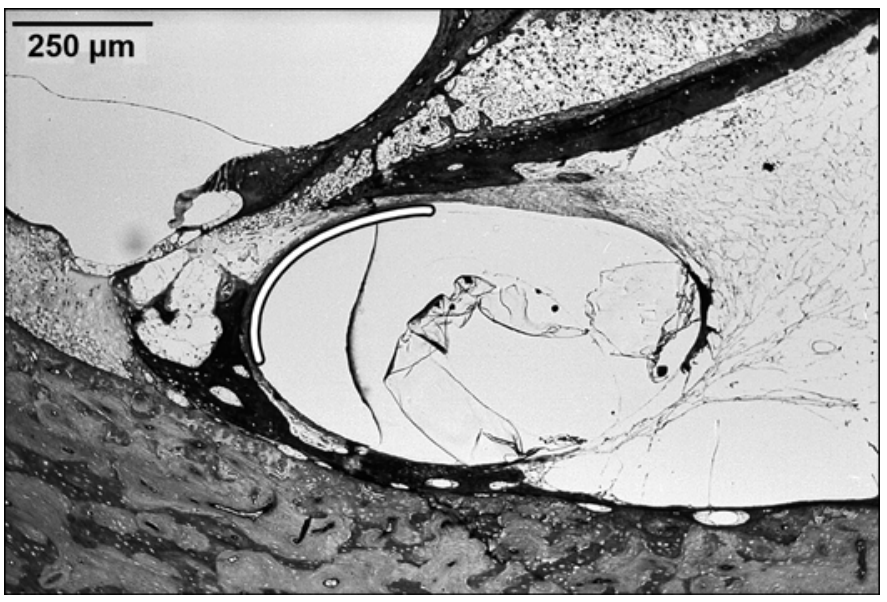

Figure 44.

Electrode bundle placed in cat cochlea beneath basilar membrane illustrates where polymer array with neurotrophin would lie.

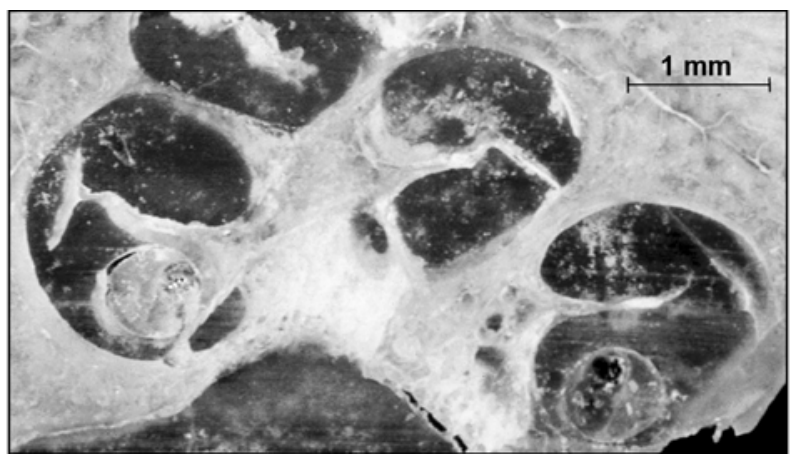

Figure 45.

Contour electrode (periomodiolar) array in section of human cochlea. Reprinted by permission of Springer Science+Business Media, (C) 2003, from Clark GM. Cochlear implants: Fundamentals and applications. Berlin (Germany): Springer-Verlag; 2003.

3 months postoperatively for the frequencies 125,500 and $1,000 \mathrm{~Hz}$. Figure 49(b) shows a short electrode lying opposite the high frequencies. With this electrode and a hearing aid, the results for open sets of CNC words were better than for the latest implant strategies.

\section{Electrophonic Speech Processing}

An alternative to an implant and a hearing aid is direct electrical stimulation of the auditory nerve plus electrophonic hearing. Electrophonic hearing is due to indirect stimulation of hair cells by an electrical stimulus 


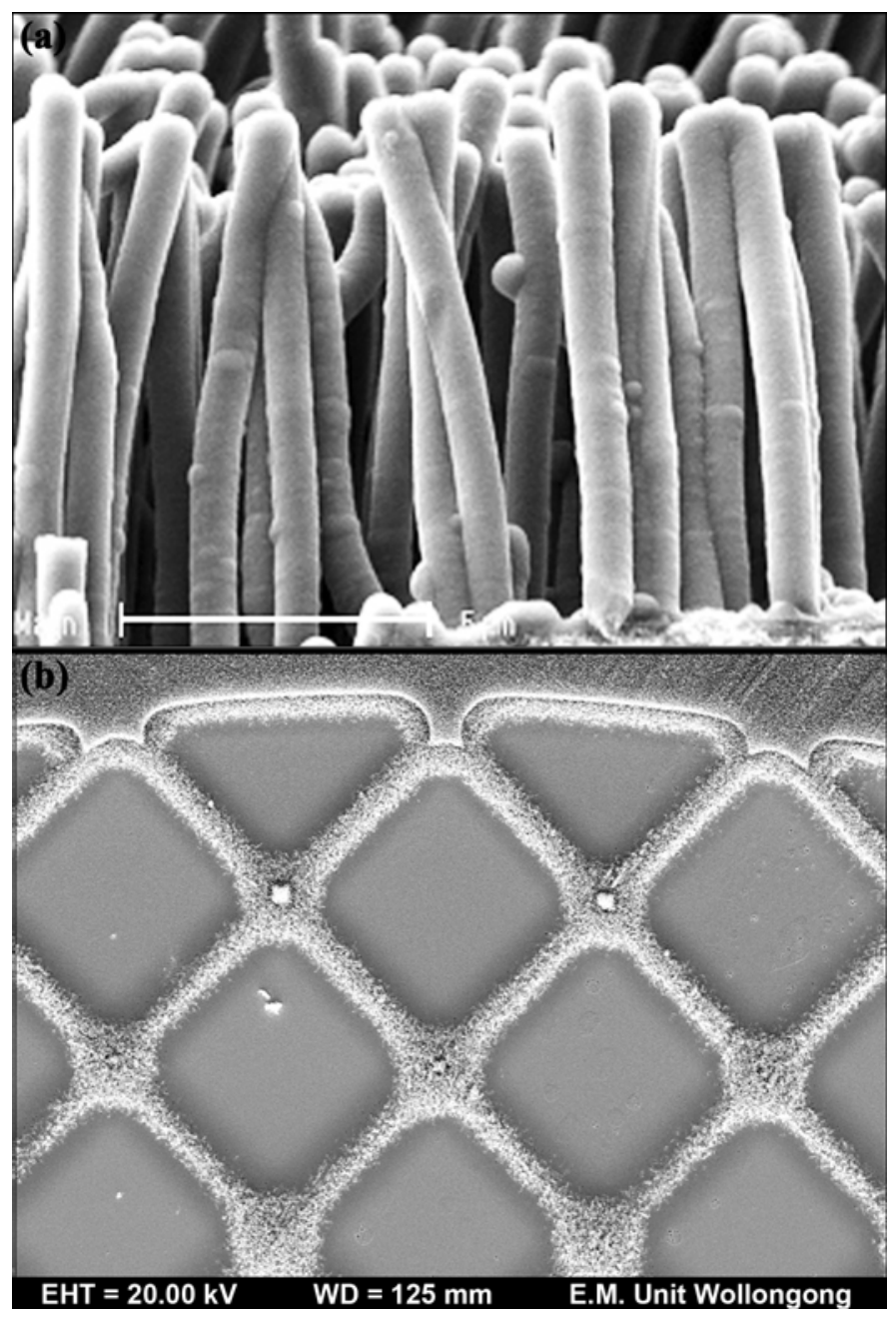

Figure 46.

(a) Forest of carbon nanotubes with coating of polypyrrole, (b) Patterned carbon nanotubes. Photographs courtesy of Australian Research Council Centre of Excellence for Electromaterials Science, Canberra, Australia.

that induces a vibration and traveling wave in the basilar membrane. Researchers have studied it in the experimental animal by stimulating the inner ear with a burst of electrical pulses and using it to mask acoustic probe frequencies. The frequency of the probe indicates the distance along the cochlea where maximal excitation occurs and the level of masking indicates the spread of current (Figure 50) [190].

Figure 51 shows an example in which a burst of electrical pulses at $1,000 \mathrm{~Hz}$ was maximally masked by a probe tone of $1,000 \mathrm{~Hz}$; that is, the current produced a traveling wave to the site of maximal excitation at the same frequency. From the compound action potential data in this study, the level of energy propagated to the

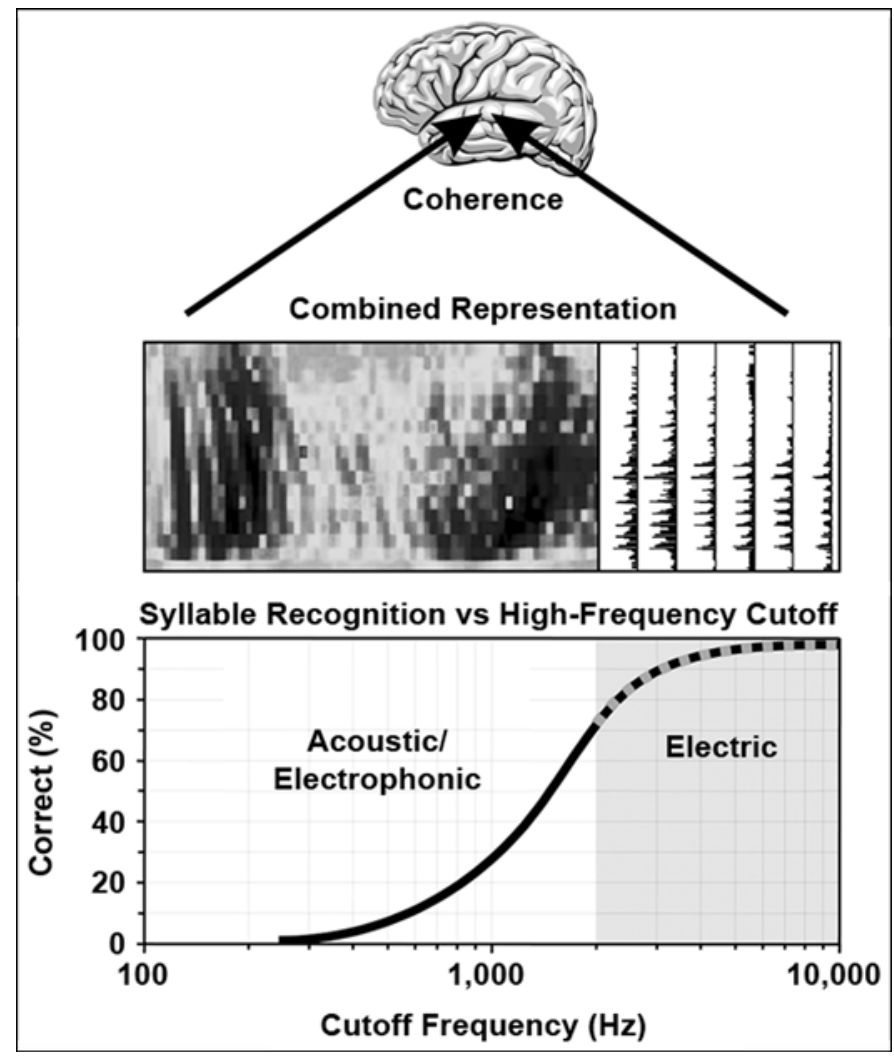

Figure 47.

Combined sensory hair cell excitation and electrical stimulation of auditory nerves.

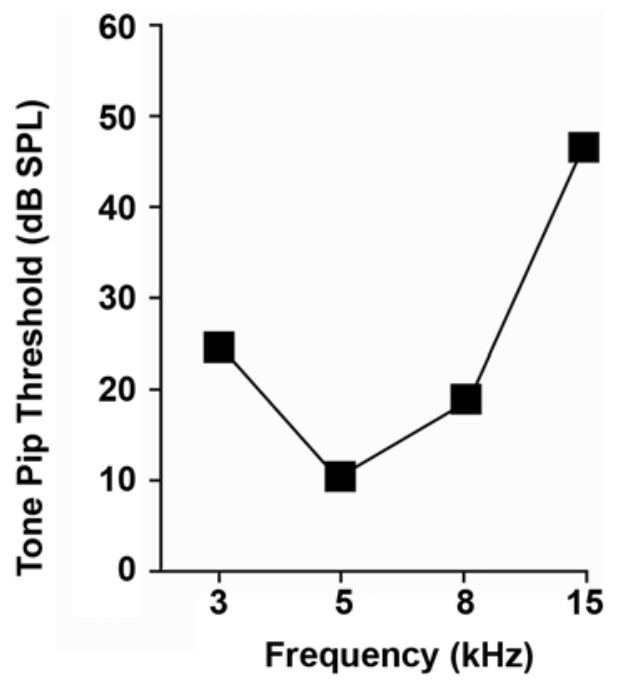

Figure 48.

Visual detection threshold of brainstem response for tone pips (short bursts). SPL = sound pressure level. Adapted from Black RC, Clark GM, O’Leary SJ, Walters CW. Intracochlear electrical stimulation of normal and deaf cats investigated using brainstem response audiometry. Acta Otolaryngol Suppl. 1983;399:5-17. [PMID: 6316713] 


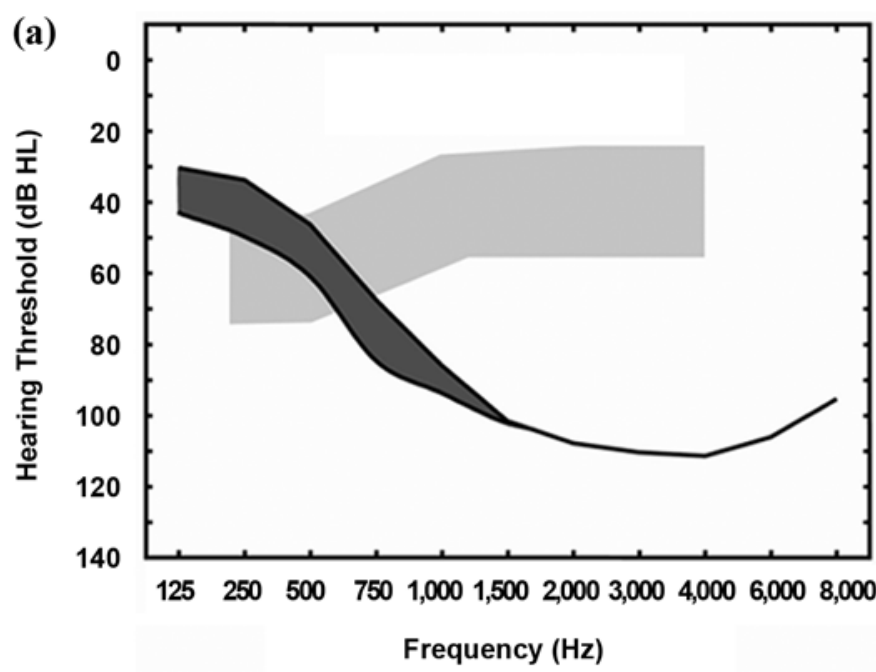

(b)

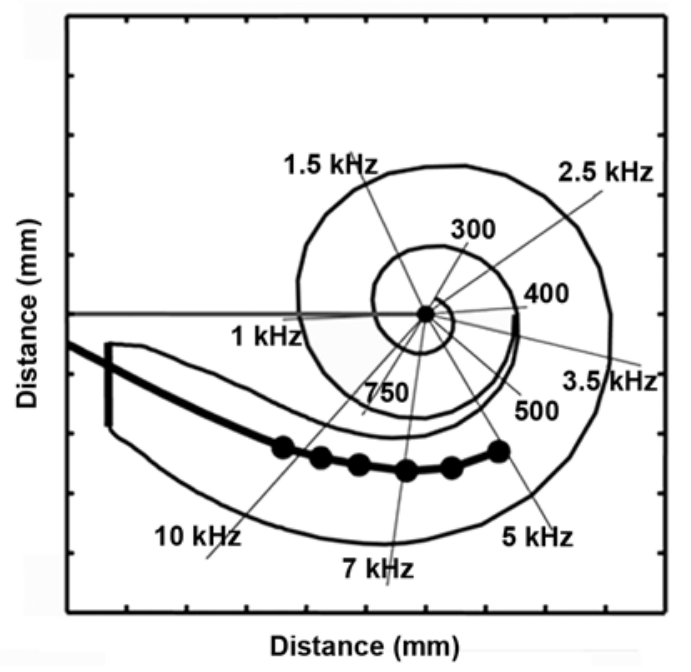

Figure 49.

(a) Audiogram of average $70 \mathrm{~dB}$ speech spectrum of hearing thresholds plotted against frequency for patients suitable for hybrid implant. (b) Short electrode array and neighboring frequency region. $\mathrm{HL}=$ hearing level.

frequency regions below $1,000 \mathrm{~Hz}$ was difficult to assess. However, stimulating the lower frequencies was of the greatest importance in applying electrophonic stimulation to people with residual hearing, where hearing is better preserved for low frequencies. These problems were overcome by recording action potentials. In addition, a very effective transmission of energy to the lower frequency region as low as 500 or even $250 \mathrm{~Hz}$ was found to exist, and this energy can be transmitted with biphasic pulses. Furthermore, a sine wave is not necessary

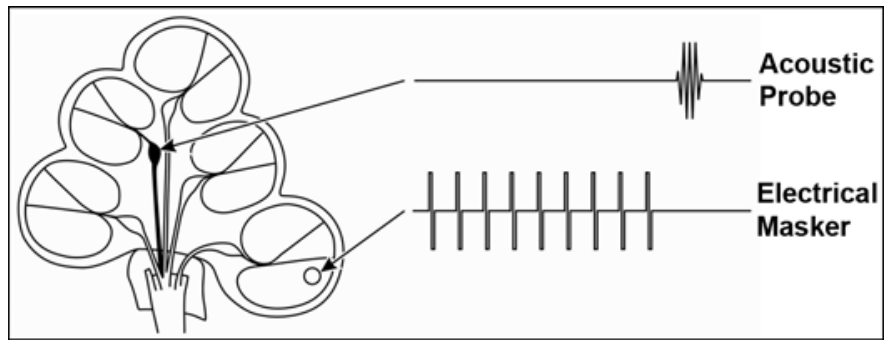

Figure 50.

Electrical masker and acoustic probe to determine spread of electrophonic excitation in cochlea. Adapted from McAnally KI, Clark GM. Stimulation of residual hearing in the cat by pulsatile electrical stimulation of the cochlea. Acta Otolaryngol. 1994;114(4): 366-72. [PMID: 7976307]

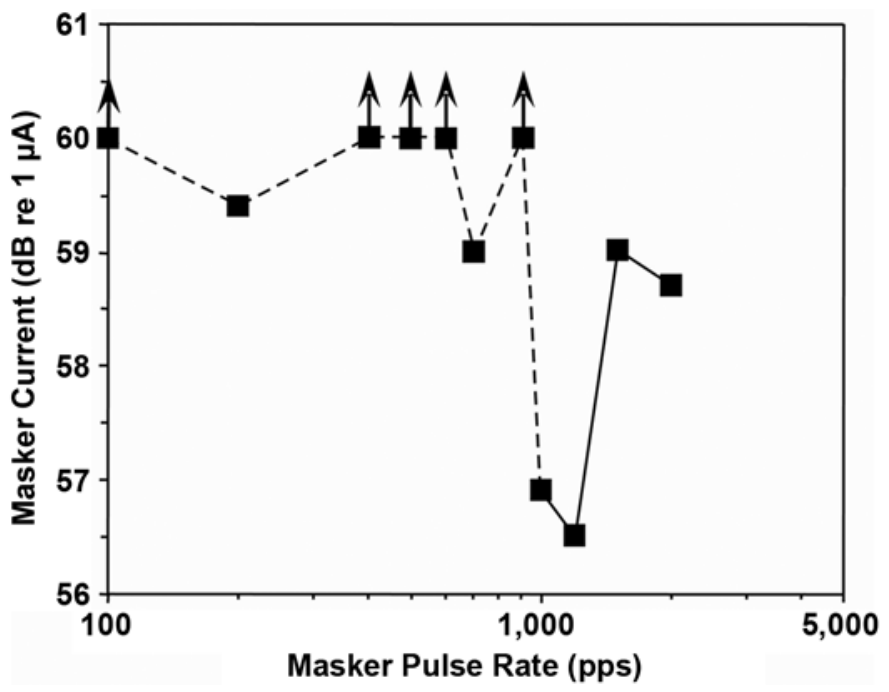

Figure 51.

Masking of 1,000 Hz probe tone with masker pulses. Adapted from McAnally KI, Clark GM. Stimulation of residual hearing in the cat by pulsatile electrical stimulation of the cochlea. Acta Otolaryngol. 1994; 114(4):366-72. [PMID: 7976307]

because a biphasic pulse leads to a similar spread of energy [191-192].

As a result, Grayden and I have been developing a speech processing strategy that will enable the electrical stimuli to not only excite the nerves in the basilar area but also electrically excite the residual hair cells in the lower frequency region. This strategy would provide a better overall timing control than the use of electrical stimulation together with a hearing aid, and for speech processing strategies of the future, this strategy is promising if the current can be focused along the scala tympani and be less influenced by pathology near the round window, as for a hearing aid. 


\section{CONCLUSIONS}

The multichannel cochlear implant illustrates the success of bionics for engineering devices that model brain mechanisms. Advances in electronics, nanotechnology, micromechanics, polymer chemistry, and molecular biology should lead to cochlear implants that give high-fidelity sound. The research is the basis for a new discipline that I have called medical bionics, which should also contribute to spinal cord repair and the relief of blindness.

\section{ACKNOWLEDGMENTS}

I am indebted to Dr. David Lawrence for his attention to the preparation of the figures in particular and to Ms. Naomi Morter for her administrative assistance. The research would not have been possible without the support of the University of Melbourne, University of Sydney, Bionic Ear Institute, Royal Victorian Eye and Ear Hospital, National Health and Medical Research Council of Australia, ARC, U.S. National Institutes of Health (NIH), Lions Clubs International, and many trusts and foundations. However, taking the research to many thousands internationally has required an outstanding level of cooperation with Cochlear Ltd.

This material was based on work supported by the ATV0 Nerve Deafness Telethon; Australian Government's Public Interest Grant Scheme; National Health and Medical Research Council of Australia; ARC; U.S. NIH grants 1-DC-9-2400, 1-NS-7-2342 (studies on pediatric auditory prostheses implants), and 1-NS-5-2388 (speech processors for auditory prostheses); Deafness Foundation of Victoria; and trusts and foundations.

Until 2006, Dr. Graeme Clark received an inventor's share of royalties from Cochlear Ltd.

\section{REFERENCES}

1. Clark GM. Cochlear implants: Fundamentals and applications. Berlin (Germany): Springer-Verlag; 2003.

2. Simmons FB. Cochlear implants. Arch Otolaryngol.1969; 89(1):61-69. [PMID: 5782683]

3. Wever EG, Bray CW. Auditory nerve impulses. Science. 1930;71(1834):215. [PMID: 17818230]

4. Stevens SS, Jones RC. The mechanisms of hearing by electrical stimulation. J Acoust Soc Am. 1939;10:261-69.
5. Jones RC, Stevens SS, Lurie MH. Three mechanisms of hearing by electrical stimulation. J Acoust Soc Am. 1940; 12(2):281-90.

6. Djourno A, Eyries C. Prosthèse auditive par excitation electrique à distance du nerf sensoriel a l'aide d'un bobinage includ a demeure [Auditory prosthesis for electrical excitation at a distance from a sensory nerve with the help of an embedded electrical coil]. Presse Medicale. 1957; 35:14-17. French.

7. Simmons FB, Epley JM, Lummis RC, Guttman N, Frishkopf LS, Harmon LD, Zwicker E. Auditory nerve: Electrical stimulation in man. Science. 1965;148:104-6. [PMID: 14258725]

8. Simmons FB. Electrical stimulation of the auditory nerve in man. Arch Otolaryngol. 1966;84:2-54.

9. Clark GM. Middle ear and neural mechanisms in hearing and the management of deafness [PhD thesis]. Sydney (Australia): University of Sydney; 1970.

10. Clark GM. Cochlear implants: Historical perspectives. In: Plant G, Spens K-E, editors. Profound deafness and communication. London (England): Whurr; 1995. p. 165-218.

11. Simmons FB. Permanent intracochlear electrodes in cats, tissue tolerance and cochlear microphonics. Laryngoscope. 1967;77(2):171-86. [PMID: 6018791]

12. Lawrence M. Direct stimulation of auditory nerve fibers. Arch Otolaryngol. 1964;80:367-68. [PMID: 14198698]

13. Rose JE, Brugge JF, Anderson DJ, Hind JE. Phase-locked response to low-frequency tones in single auditory nerve fibers of the squirrel monkey. J Neurophysiol. 1967;30(4): 769-93. [PMID: 4962851]

14. Clark GM. The multiple-channel cochlear implant: the interface between sound and the central nervous system for hearing, speech, and language in deaf people-a personal perspective. Philos Trans R Soc Lond B Biol Sci. 2006;361(1469):791-810. [PMID: 16627295]

15. Michelson RP. Electrical stimulation of the human cochlea. A preliminary report. Arch Otolaryngol. 1971;93(3):317-23. [PMID: 5100631]

16. Danley MJ, Fretz RJ. Design and functioning of the singleelectrode cochlear implant. Ann Otol Rhinol Laryngol Suppl. 1982;91(2 Pt 3):21-26. [PMID: 6805393]

17. Hochmair ES. An implantable current source for electrical nerve stimulation. IEEE Trans Biomed Eng. 1980;27(5): 278-80. [PMID: 7380445]

18. Fourcin AJ, Rosen SM, Moore BC, Douek EE, Clarke GP, Dodson H, Bannister LH. External electrical stimulation of the cochlea: clinical, psychophysical, speech-perceptual and histological findings. Br J Audiol. 1979;13(3):85-107. [PMID: 314825]

19. Clark GM. Responses of cells in the superior olivary complex of the cat to electrical stimulation of the auditory nerve. Exp Neurol. 1969;24(1):124-36. [PMID: 5771101] 
20. Clark GM, Dunlop CW. Response patterns in the superior olivary complex of the cat. Aust J Exp Biol Med Res. 1969;47:5.

21. Goldberg JM, Neff WD. Frequency discrimination after bilateral section of the brachium of the inferior colliculus. J Comp Neurol. 1961;116:265-90. [PMID: 13706458]

22. Moxon EC. Electric stimulation of the cat's cochlea: A study of discharge rates in single auditory nerve fibers [master's thesis]. Cambridge (MA): Massachusetts Institute of Technology; 1967.

23. Clark GM, Kranz HG, Nathar JM. Behavioural responses in the cat to electrical stimulation of the cochlea and auditory neural pathways. Aust J Exp Biol Med Res. 1972;3: 202.

24. Clark GM, Kranz HG, Minas H. Behavioral thresholds in the cat to frequency modulated sound and electrical stimulation of the auditory nerve. Exp Neurol. 1973;41(1):190-200. [PMID: 4743485]

25. Williams AJ, Clark GM, Stanley GV. Pitch discrimination in the cat through electrical stimulation of the terminal auditory nerve fibers. Physiol Psychol. 1976;4:23-27.

26. Clark GM, Nathar JM, Kranz HG, Maritz JS. A behavioral study on electrical stimulation of the cochlea and central auditory pathways of the cat. Exp Neurol. 1972; 36(2):350-61. [PMID: 5053357]

27. Clark GM, Tong YC, Bailey QR, Black RC, Martin LF, Millar JB, O’Loughlin BJ, Patrick JF, Pyman BC. A multiple-electrode cochlear implant. J Oto-Laryngol Soc Aust. 1978;4:208-12.

28. Tong YC, Black RC, Clark GM, Forster IC, Millar JB, O'Loughlin BJ, Patrick JF. A preliminary report on a multiple-channel cochlear implant operation. J Laryngol Otol. 1979;93(7):679-95. [PMID: 469398]

29. Hochmair-Desoyer IJ, Hochmair ES, Burian K, Fischer RE. Four years of experience with cochlear prostheses. Med Prog Technol. 1981;8(3):107-19. [PMID: 6895542]

30. Rose JE, Galambos R, Hughes JR. Microelectrode studies of the cochlear nuclei of the cat. Bull Johns Hopkins Hosp. 1959;104(5):211-51. [PMID: 13651831]

31. Kiang NY-S. Stimulus coding in the auditory nerve and cochlear nucleus. Acta Otolaryngol. 1965;59(2-6):186-200.

32. Clark GM. Electrical stimulation of the auditory nerve: the coding of frequency, the perception of pitch and the development of cochlear implant speech processing strategies for profoundly deaf people. Clin Exp Pharmacol Physiol. 1996;23(9):766-76. [PMID: 8911712]

33. Merzenich MM, Michelson RP, Pettit CR, Schindler RA, Reid M. Neural encoding of sound sensation evoked by electrical stimulation of the acoustic nerve. Ann Otol Rhino Laryngol. 1973;82(4):486-503. [PMID: 4721185]
34. Merzenich MM, Reid MD. Representation of the cochlea within the inferior colliculus of the cat. Brain Res. 1974; 77(3):397-415. [PMID: 4854119]

35. Wilson BS, Finley CC, Lawson DT, Wolford RD. Speech processors for cochlear prostheses. Proc IEEE. 1988;76(9): 1143-54.

36. Black RC, Clark GM. Electrical transmission line properties of the cat cochlea. Proc Aust Physiol Pharmacol Soc. 1977;8:137.

37. Black RC, Clark GM. Electrical network properties and distribution of potentials in the cat cochlea. Proc Aust Physiol Pharmacol Soc. 1978;9:71P.

38. Black RC, Clark GM. Differential electrical excitation of the auditory nerve. J Acoust Soc Am. 1980;67(3):868-74. [PMID: 6892642]

39. Von Békésy G. The coarse pattern of the electrical resistance in the cochlea of the guinea pig (electroanatomy of the cochlea). J Acoust Soc Am. 1951;23(1):18-28.

40. Johnstone BM, Johnstone JR, Pugsley ID. Membrane resistance in endolymphatic walls of the first turn of the guineapig cochlea. J Acoust Soc Am. 1966;40(6):1398-1404. [PMID: 5975575$]$

41. Busby PA, Whitford LA, Blamey PJ, Richardson LM, Clark GM. Pitch perception for different modes of stimulation using the cochlear multiple-electrode prosthesis. J Acoust Soc Am.1994;95(5 Pt 1):2658-69. [PMID: 8207139]

42. Moxon EC. Neural and mechanical responses to electrical stimulation of the cat's inner ear [PhD thesis]. Cambridge (MA): Massachusetts Institute of Technology; 1971.

43. Kiang NY, Moxon EC. Physiological considerations in artificial stimulation of the inner ear. Ann Otol Rhinol Laryngol. 1972;81(5):714-30. [PMID: 4651114]

44. Kiang NY, Pfeiffer RR, Warr WB, Backus AS. Stimulus coding in the cochlear nucleus. Trans Am Otol Soc. 1965; 53:35-58. [PMID: 5834666$]$

45. Clark GM, Kranz HG, Minas H, Nathar JM. Histopathological findings in cochlear implants in cats. J Laryngol Otol. 1975;89(5):495-504. [PMID: 1097552]

46. Clark GM. An evaluation of per-scalar cochlear electrode implantation techniques. An histopathological study in cats. J Laryngol Otol. 1977;91(3):185-99. [PMID: 850098]

47. Clark GM, Hallworth RJ, Zdanius K. A cochlear implant electrode. J Laryngol Otol. 1975;89(8):787-92. [PMID: 1185061]

48. Clark GM, Patrick JF, Bailey Q. A cochlear implant round window electrode array. J Laryngol Otol. 1979;93(2): 107-9. [PMID: 429893]

49. Shepherd RK, Clark GM, Pyman BC, Webb RL. Banded intracochlear electrode array: evaluation of insertion trauma in human temporal bones. Ann Otol Rhinol Laryngol. 1985;94(1 Pt 1):55-59. [PMID: 3838226$]$ 
50. Franz BK-HG, Clark GM. Refined surgical technique for insertion of banded electrode array. Ann Otol Rhinol Laryngol. 1987;96:15-16.

51. Clark GM, Pyman BC, Webb RL, Franz BK-HG, Redhead TJ, Shepherd RK. Surgery for safe the insertion and reinsertion of the banded electrode array. Ann Otol Rhinol Laryngol. 1987;96:10-12.

52. Kha HN, Chen BK, Clark GM. 3D finite element analyses of insertion of the Nucleus standard straight and the Contour electrode arrays into the human cochlea. J Biomech. 2007;40(12):2796-2805. [PMID: 17408675]

53. Chen BK, Clark GM, Jones R. Evaluation of trajectories and contact pressures for the straight nucleus cochlear implant electrode array — a two-dimensional application of finite element analysis. Med Eng Phys. 2003;25(2): 141-47. [PMID: 12538068$]$

54. Kha HN, Chen BK, Clark GM, Jones R. Stiffness properties for Nucleus standard straight and Contour electrode arrays. Med Eng Phys. 2004;26(8):677-85. [PMID: 15471696]

55. Xu J, Stevenson AW, Gao D, Tykocinski M, Lawrence D, Wilkins SW, Clark GM, Saunders E, Cowan RS. The role of radiographic phase-contrast imaging in the development of intracochlear electrode arrays. Otol Neurotol. 2001; 22(6):862-68. [PMID: 11698810]

56. Roland JT Jr. A model for cochlear implant electrode insertion and force evaluation: results with a new electrode design and insertion technique. Laryngoscope. 2005; 115(8):1325-39. [PMID: 16094101]

57. Patrick JF, Busby PA, Gibson PJ. The development of the Nucleus Freedom Cochlear implant system. Trends Amplif. 2006;10(4):175-200. [PMID: 17172547]

58. Clark GM, Shepherd RK, Patrick JF, Black RC, Tong YC. Design and fabrication of the banded electrode array. Ann N Y Acad Sci. 1983;405:191-201. [PMID: 6575644$]$

59. Clark GM, Blamey PJ, Brown AM, Gusby PA, Dowell RC, Franz, BKH, Pyman BC, Shepherd RK, Tong YC, Webb RL, Hirshorn MS, Kuzma J, Mecklenburg DJ, Money DK, Patrick JF, Seligman PM. The University of Melbourne-Nucleus multi-electrode cochlear implant. New York (NY): Karger; 1987. p. 38.

60. McCreery DB, Agnew WF. Changes in extracellular potassium and calcium concentration and neural activity during prolonged electrical stimulation of the cat cerebral cortex at defined charge densities. Exp Neurol. 1983; 79(2):371-96. [PMID: 6822270]

61. Agnew WF, Yuen TG, Pudenz RH, Bullara LA. Neuropathological effects of intracerebral platinum salt injections. J Neuropathol Exp Neurol. 1977;36(3):533-46.

[PMID: 870625$]$

62. Shepherd RK, Clark GM, Black RC, Patrick JF. Chronic electrical stimulation of the auditory nerve in cats. Proc Aust Physiol Pharmacol Soc. 1982;13:211P.
63. Shepherd RK, Clark GM, Black RC. Chronic electrical stimulation of the auditory nerve in cats. Physiological and histopathological results. Acta Otolaryngol Suppl. 1983;399:19-31. [PMID: 6316712]

64. Clark GM, Shepherd RK, Franz BK, Dowell RC, Tong YC, Blamey PJ, Webb RL, Pyman BC, McNaughtan J, Bloom DM, Kakulas BA, Siejka S. The histopathology of the human temporal bone and auditory central nervous system following cochlear implantation in a patient. Correlation with psychophysics and speech perception results. Acta Otolaryngol Suppl. 1988;448:1-65. [PMID: 3176974]

65. Clark GM, Shepherd RK, Franz BK-HG, Bloom D. Intracochlear electrode implantation. Round window membrane sealing procedures and permeability studies. Acta Otolaryngol Suppl. 1984;410:5-15.

66. Clark G, Tong YC, Patrick JF. Cochlear prostheses. Edinburgh (Scotland): Churchill Livingstone; 1990.

67. Clark G. Cochlear implants in children: safety as well as speech and language. Int J Pediatr Orthinolaryngol. 2003; 67 Suppl 1:S7-20. [PMID: 14662167]

68. Franz BK, Clark GM, Bloom D. Permeability of the implanted round window membrane in the cat-An investigation using horseradish peroxidase. Acta Otolaryngol Suppl. 1984;410:17-23.

69. Cranswick NE, Franz BK-HG, Clark GM, Shepherd RK. Middle ear infection postimplantation: response of the round window membrane to streptococcus pyogenes. Ann Otol Rhinol Laryngol. 1987;96:53-54.

70. Berkowitz RG, Franz BK-HG, Shepherd RK, Clark GM, Bloom D. Pneumococcal middle ear infection and cochlear implantation. Ann Otol Rhinol Laryngol. 1987; 96(Suppl 128):55-56.

71. Dahm MC, Clark GM, Franz BK, Shepherd RK, Burton MJ, Robins-Browne R. Cochlear implantation in children: labyrinthitis following pneumococcal otitis media in unimplanted and implanted cat cochleas. Acta Otolaryngol. 1994;114(6):620-25. [PMID: 7879619]

72. Imani P. Prevention of cochlear infection and meningitis post cochlear implantation [master's thesis]. Melbourne (Australia): The University of Melbourne; 2003. p. 286.

73. Wei BP, Shepherd RK, Robbins-Browne RM, Clark GM, O'Leary SJ. Pneumococcal meningitis threshold model: A potential tool to assess infectious risk of new or existing inner ear surgical interventions. Otol Neurotol. 2006; 27(8):1152-61. [PMID: 16980916]

74. Wei B, Shepherd RK, Robbins-Browne RM, Clark GM, O'Leary SJ. Pneumococcal meningitis: development of an animal model. Otol Neurotol. 2006;27(6):844-54. [PMID: 16936571]

75. Wei BP, Robins-Browne RM, Shepherd RK, Azzopardi K, Clark GM, O'Leary SJ. Protective effects of local administration of ciprofloxacin on the risk of pneumococcal 
meningitis after cochlear implantation. Laryngoscope. 2006; 116(12):2138-44. [PMID: 17146386$]$

76. Wei BP, Shepherd RK, Robbins-Browne RM, Clark GM, O'Leary SJ. Effects of inner ear trauma on the risk of pneumococcal meningitis. Arch Otolaryngol Head Neck Surg. 2007;133(3):250-59. [PMID: 17372082]

77. Dahm M, Xu J, Tykocinski M, Shepherd RK, Clark GM. Intracochlear damage following insertion of the Nucleus 22 standard electrode array: A post mortem study of 14 implant patients. Proceedings of the 6th International Cochlear Implant Conference; 2000 Feb; Miami Beach, Florida. Florida: University of Miami School of Medicine; 2000. p. 149.

78. Dahm MC, Shepherd RK, Clark GM. The postnatal growth of the temporal bone and its implications for cochlear implantation in children. Acta Otolaryngol Suppl. 1993;505:1-39. [PMID: 8379315]

79. O’Donoghue GM, Jackler RK, Jenkins WM, Schindler RA. Cochlear implantation in children: the problem of head growth. Otolaryngol Head Neck Surg. 1986;94(1): 78-81. [PMID: 3081861]

80. Xu J, Shepherd RK, Xu SA, Seldon HL, Clark GM. Pediatric cochlear implantation. Radiologic observations of skull growth. Arch Otolaryngol Head Neck Surg. 1993; 119(5):525-34. [PMID: 8484942]

81. Burton MJ, Shepherd RK, Xu SA, Xu J, Franz BK, Clark GM. Cochlear implantation in young children: histological studies on head growth, leadwire design, and electrode fixation in the monkey model. Laryngoscope. 1994; 104(2):167-75. [PMID: 8302119]

82. Minas H. Acoustic and electric stimulation of the cochlea in the cat: A behavioural study [bachelor's thesis]. Melbourne (Australia): University of Melbourne; 1972.

83. Forster IC, Patrick JF, Tong YC, Black RC, Clark GM, inventors; University of Melbourne, assignee. Improvements in prostheses. Australian patent application PC8094/76. 1976 Nov 1.

84. Clark GM, Black RC, Dewhurst DJ, Forster IC, Patrick JF, Tong YC. A multiple-electrode hearing prosthesis for cochlear implantation in deaf patients. Med Prog Technol. 1977;5:127-40.

85. Clark GM, Tong YC, Black R, Forster IC, Patrick JF, Dewhurst DJ. A multiple electrode cochlear implant. J Laryngol Otol. 1977;91(11):935-45. [PMID: 591780]

86. Clark GM, O’Laughlin BJ, Rickards FW, Tong YC, Williams AJ. The clinical assessment of cochlear implant patients. J Laryngol Otol. 1977;91(8):697-708. [PMID: 894122]

87. Clark GM, Pyman BC, Bailey QR. The surgery for multipleelectrode cochlear implantations. J Laryngol Otol. 1979; 93(3):215-23. [PMID: 429901]
88. Clark GM, Kranz HG, Minas HJ. Response thresholds to frequency modulated sound and electrical stimulation of the auditory nerve in cats. Proc Aust Physiol Pharmacol Soc. 1973;4:134.

89. Clark GM, Busby PA, Roberts SA, Dowell RC, Tong YC, Blamey PJ, Nienhuys TG, Mecklenburg DJ, Webb RL, Pyman BC, Franz BK. Preliminary results for the cochlear corporation multi-electrode intracochlear implants on six prelingually deaf patients. Am J Otol. 1987;8(3):234-39. [PMID: 3631226$]$

90. Hill FJ, McRae LP, McClellan RP. Speech recognition as a function of channel capacity in a discrete set of channels. J Acoust Soc Am. 1968;44(1):13-18. [PMID: 5659828$]$

91. Laird RK. The bioengineering development of a sound encoder for an implantable hearing prosthesis for the profoundly deaf [master's thesis]. Melbourne (Australia): The University of Melbourne; 1979.

92. Tong YC, Clark GM. Speech comprehension with multiplechannel electrical stimulation of human auditory nerve fibres. Proc Aust Physiol Pharmacol Soc. 1980;11:201P.

93. Tong YC, Clark GM, Seligman PM, Patrick JF. Speech processing for a multiple-electrode cochlear implant hearing prosthesis. J Acoust Soc Am. 1980;68(6):1897-98. [PMID: 6893993]

94. Clark GM, Tong YC, Martin LF, Busby PA. A multiplechannel cochlear implant. An evaluation using an openset word test. Acta Otolaryngol. 1981;91(3-4):173-75. [PMID: 6894818]

95. Clark GM, Tong YC, Martin LF. A multiple-channel cochlear implant: an evaluation using open-set CID sentences. Laryngoscope. 1981;91(4):628-34. [PMID: 7219008 ]

96. Tong YC, Seligman PM, Clark GM, Patrick JF, Millar JB, inventors; University of Melbourne, assignee. Speech processor. Australian patent application PD8973/79. 1979 May 28.

97. Clark GM, Tong YC. A multiple-channel cochlear implant. A summary of results for two patients. Arch Otolaryngol. 1982;108(4):214-17. [PMID: 6896141]

98. Clark GM, Tong YC, Martin LF, Busby PA, Dowell RC, Seligman PM, Patrick JF. A multiple-channel cochlear implant: An evaluation using nonsense syllables. Ann Otol Rhinol Laryngol. 1981;90(3 Pt 1):227-30. [PMID: 6895008]

99. Dowell RC, Mecklenburg DJ, Clark GM. Speech recognition for 40 patients receiving multichannel cochlear implants. Arch Otolaryngol Head Neck Surg. 1986; 112(10):1054-59. [PMID: 3755975]

100. Eddington DK, Dobelle WH, Brackmann DE, Mladejovsky MG, Parkin J. Place and periodicity pitch by stimulation of multiple scala tympani electrodes in deaf volunteers. Trans Am Soc Artif Intern Organs. 1978;24:1-5. [PMID: 715981] 
101. Eddington DK. Speech recognition in deaf subjects with multichannel intracochlear electrodes. Ann N Y Acad Sci. 1983;405:241-58. [PMID: 6575648]

102. Merzenich MM, Byers C, White M. Scala tympani electrode arrays. Bethesda (MD): National Institutes of Health (US); 1984 Fifth Quarterly Progress Report, Contract No. NO1-NS9-2353. p. 1-11.

103. Tong YC, Millar JB, Clark GM, Martin LF, Busby PA, Patrick JF. Psychophysical and speech perception studies on two multiple channel cochlear implant patients. J Laryngol Otol. 1980;94(4):1241-56. [PMID: 6893715]

104. Clark GM, Tong YC, Dowell RC. Comparison of two cochlear implant speech-processing strategies. Ann Otol Rhinol Laryngol. 1984;93(2 Pt 1):127-31. [PMID: 6546846]

105. Tong YC, Clark GM, Blamey PJ, Busby PA, Dowell RC. Psychophysical studies for two multiple-channel cochlear implant patients. J Acoust Soc Am. 1982;71(1):153-60. [PMID: 6895638]

106. Tong YC, Blamey PJ, Dowell RC, Clark GM. Psychophysical studies evaluating the feasibility of a speech processing strategy for a multiple-channel cochlear implant. J Acoust Soc Am. 1983;74(1):73-80. [PMID: 6688434]

107. Tong YC, Clark GM. Percepts from scala tympani stimulation. Ann N Y Acad Sci. 1983;405:264-67. [PMID: 6575650]

108. Tong YC, Dowell RC, Blamey PJ, Clark GM. Twocomponent hearing sensations produced by two-electrode stimulation in the cochlea of a deaf patient. Science. 1983; 219(4587):993-94. [PMID: 6823564]

109. Tong YC, Clark GM. Loudness summation, masking, and temporal interaction for sensations produced by electric stimulation of two sites in the human cochlea. J Acoust Soc Am. 1986;79(6):1958-66. [PMID: 3722606]

110. Blamey PJ, Dowell RC, Tong YC, Clark GM. An acoustic model of a multiple-channel cochlear implant. J Acoust Soc Am. 1984;76(1):97-103. [PMID: 6547735]

111. Blamey PJ, Martin LF, Clark GM. A comparison of three speech coding strategies using an acoustic model of a cochlear implant. J Acoust Soc Am. 1985;77(1):209-17. [PMID: 3838322]

112. McKay CM, McDermott HJ, Carlyon RP. Place and temporal cues in pitch perception: Are they truly independent? Acoust Res Lett Online. 2000;1(1):25-30.

113. Blamey PJ, Dooley GJ, Parisi ES, Clark GM. Pitch comparisons of acoustically and electrically evoked auditory sensations. Hear Res. 1996;99(1-2):139-50. [PMID: 8970822]

114. Dowell RC, Seligman PM, Blamey PJ, Clark GM. Evaluation of a two-formant speech-processing strategy for a multichannel cochlear prosthesis. Ann Otol Rhinol Laryngol. 1987;96 Suppl 128:132-34.

115. Dowell RC, Seligman PM, Blamey PJ, Clark GM. Speech perception using a two-formant 22-electrode cochlear prosthesis in quiet and in noise. Acta Otolaryngol. 1987; 104(5-6):439-46. [PMID: 3434265]

116. Dowell RC, Whitford LA, Seligman PM, Franz BK-HG, Clark GM. Preliminary results with a miniature speech processor for the 22-electrode/cochlear hearing prosthesis. In: Sacristan T, Alvarez-Vicent JJ, Bartual J, Antoli-Cantela F, editors. Proceedings of the XIV World Congress of Otorhinolaryngology, Head and Neck Surgery; 1990; Amsterdam, the Netherlands. Amsterdam (Netherlands): Kugler and Ghedini; 1990. p. 1167-73.

117. Cohen NL, Waltzman SB, Fisher SG. A prospective, randomized study of cochlear implants. The Department of Veterans Affairs Cochlear Implant Study Group. New Engl J Med. 1993;328(4):233-37. [PMID: 8418403]

118. Eddington DK. Speech discrimination in deaf subjects with cochlear implants. J Acoust Soc Am. 1980;68(3): 885-91. [PMID: 6893461]

119. Wilson BS, Finley CC, Farmer JC Jr, Lawson DT, Weber BA, Wolford RD, Kenan PD, White MW, Merzenich MM, Schindler RA. Comparative studies of speech processing strategies for cochlear implants. Laryngoscope. 1988;98(10):1069-77. [PMID: 3172953]

120. Wilson BS. Strategies for representing speech information with cochlear implants. In: Niparko JK, Kirk KI, Mellon NK, Robbins AM, Tucci DL, Wilson BS, editors. Cochlear implants: principles and practices. Philadelphia (PA): Lippincott Williams \& Wilkins; 2000. p. 129-70.

121. McDermott HJ, McKay CM, Vandali AE. A new portable sound processor for the University of Melbourne/Nucleus Limited multielectrode cochlear implant. J Acoust Soc Am. 1992;91(6):3367-71. [PMID: 1619114$]$

122. Clark GM. Cochlear implants. Diseases of the ear. 6th ed. Ludman H, Wright T. London (England): Edward Arnold; 1998. p. 149-163.

123. Tong YC, Van Hoesel R, Lai WK, Vandali A, Harrison JM, Clark GM. Speech processors for auditory prostheses. Sixth quarterly progress report. NIH Contract NO1-DC-92400. 1990 .

124. Tong YC, Vandali A, Busby PA, Harrison M, Van Hoesel R, Clark GM. Speech processors for auditory prostheses. Seventh quarterly progress report. NIH Contract NO1DC-9-2400. 1990.

125. McKay CM, McDermott HJ, Vandali AE, Clark GM. Preliminary results with a six spectral maxima speech processor for The University of Melbourne/Nucleus multiple electrode cochlear implant. J Otolaryngol Soc Aust. 1991; 6:354-59.

126. McKay CM, McDermott HJ, Vandali AE, Clark GM. A comparison of speech perception of cochlear implantees using the Spectral Maxima Sound Processor (SMSP) and the MSP (MULTIPEAK) processor. Acta Otolaryngol. 1992;112(5):752-61. [PMID: 1456029] 
127. Skinner MW, Holden LK, Whitford LA, Plant KL, Psarros C, Holden TA. Speech recognition with the Nucleus 24 SPEAK, ACE, and CIS speech coding strategies in newly implanted adults. Ear Hear. 2002;23(3):207-23. [PMID: 12072613]

128. Kessler DK, Loeb GE, Barker MJ. Distribution of speech recognition results with the Clarion cochlear prosthesis. Ann Otol Rhinol Laryngol Suppl. 1995;166:283-85. [PMID: 7668672]

129. Tykocinski M, Shepherd RK, Clark GM. Reduction in excitability of the auditory nerve following electrical stimulation at high stimulus rates. Hear Res. 1995;88(1-2):124-42. [PMID: 8575988]

130. Xu J, Shepherd RK, Millard RE, Clark GM. Chronic electrical stimulation of the auditory nerve at high stimulus rates: a physiological and histopathological study. Hear Res. 1997;105(1-2):1-29. [PMID: 9083801]

131. Vandali AE, Harrison JM, Huigen JM, Plant K, Clark GM. Multichannel cochlear implant speech processing: further variations of the spectral maxima sound processor strategy. Ann Otol Rhinol Laryngol Suppl. 1995;166: 378-81. [PMID: 7668714]

132. Grayden DB, Clark GM. The effect of rate stimulation of the auditory nerve on phoneme recognition. In: Barlow M, editor. Proceedings of the Eighth Australian International Conference on Speech Science and Technology; 2000 Dec 4-7; Canberra, Australia. Canberra (Australia): Australian Speech Science and Technology Association, Inc; 2001. p. 356-61.

133. Grayden DB, Clark GM, inventors; University of Melbourne, assignee. Improved sound processor for cochlear implants. International patent application PCT/AU00/ 01038. 2001.

134. Clark GM. Editorial. Cochlear implants: climbing new mountains. The Graham Fraser Memorial Lecture 2001. Cochlear Implants Int. 2001;2(2):75-97.

135. Bruce IC, Irlicht LS, White MW, O’Leary SJ, Clark GM. Renewal-process approximation of a stochastic threshold model for electrical neural stimulation. J Comput Neurosci. 2000;9(2):119-32. [PMID: 11030517]

136. Grayden DB, Tari S, Hollow RD. Differential-rate sound processing for cochlear implants. In: Warren P, Watson CI, editors. Proceedings of the Eleventh Australian International Conference on Speech Science and Technology; 2006 Dec 6-8; Auckland, New Zealand. Auckland (New Zealand): University of Auckland; 2006. p. 323-28.

137. Vandali AE. Emphasis of short-duration acoustic speech cues for cochlear implant users. J Acoust Soc Am. 2001; 109(5 Pt 1):2049-61. [PMID: 11386557]

138. Kennedy E, Levitt H, Neuman AC, Weiss W. Consonantvowel intensity ratios for maximizing consonant recogni- tion by hearing-impaired listeners. J Acoust Soc Am. 1998;103(2):1098-1114. [PMID: 9479764$]$

139. Sammeth CA, Dorman MF, Stearns CJ. The role of consonant-vowel amplitude ratio in the recognition of voiceless stop consonants by listeners with hearing impairment. J Speech Lang Hear Res. 1999;42(1):42-55. [PMID: 10025542]

140. Martin LFA, James C, Blamey PJ, MacFarlane D, Swanson B, Just Y, Galvin KL. Adaptive dynamic range optimisation for cochlear implants. Aust J Audiol. 2000;22 Suppl:64.

141. Martin LFA, Blamey PJ, James C, Galvin KL, MacFarlane D. Adaptive range of optimisation for hearing aids. In: Barlow M, Rose P, editors. Proceedings of the Eighth Australian International Conference on Speech Science and Technology; 2000 Dec 4-7; Canberra, Australia. Canberra (Australia): Australian Speech Science and Technology Association, Inc; 2001. p. 373-78.

142. Müller-Deile J, Schmidt BJ, Rudert H. Effects of noise on speech discrimination in cochlear implant patients. Ann Otol Rhinol Laryngol Suppl. 1995;166:303-6. [PMID: 7668681]

143. Skinner MW, Holden LK, Holden TA, Demorest ME, Fourakis MS. Speech recognition at simulated soft, conversational, and raised-to-loud vocal efforts by adults with cochlear implants. J Acoust Soc Am. 1997;101(6):3766-82. [PMID: 9193063]

144. Van Hoesel RJ, Clark GM. Evaluation of a portable twomicrophone adaptive beamforming speech processor with cochlear implant patients. J Acoust Soc Am. 1995;97(4): 2498-2503. [PMID: 7714267]

145. Van Hoesel RJ, Clark GM. Manikin and cochlear implant patient test results with a portable adaptive beamforming processor to suppress the effects of noise. Ann Otol Rhinol Laryngol Suppl. 1995;166:144-46. [PMID: 7668608]

146. Skinner MW, Clark GM, Whitford LA, Seligman PM, Staller SJ, Shipp DB, Shallop JK, Everingham C, Menapace CM, Arndt P, Antogenelli T, Brimacombe JA, Daniels P, McDermott HJ, Beiter AL. Evaluation of a new spectral peak coding strategy for the Nucleus 22 Channel Cochlear Implant System. Am J Otol. 1994;15 Suppl 2: 15-27. [PMID: 8572106]

147. Van Hoesel RJ, Tong YC, Hollow RD, Clark GM. Psychophysical and speech perception studies: a case report on a binaural cochlear implant subject. J Acoust Soc Am. 1993; 94(6):3178-89. [PMID: 8300953]

148. Van Hoesel RJM, Tong YC, Hollow RD, Huigen JM, Clark GM. Preliminary studies on a bilateral cochlear implant user. J Acoust Soc Am. 1990;88(S1):S193.

149. Geers AE, Moog JS. Effectiveness of cochlear implants and tactile aids for deaf children: A report of the CID sensory aids study. The Volta Review. 1994;96(5):1-231. 
150. Geers AE, Tobey EA. Longitudinal comparison of the benefits of cochlear implants and tactile aids in a controlled educational setting. Ann Otol Rhinol Laryngol Suppl. 1995;166:328-29. [PMID: 7668691]

151. Dooley GJ, Blamey PJ, Seligman PM, Alcantara JI, Clark GM, Shallop JK, Arndt P, Heller JW, Menapace CM. Combined electrical and acoustical stimulation using a bimodal prosthesis. Arch Otolaryngol Head Neck Surg. 1993;119(1):55-60. [PMID: 8417744]

152. Van Hoesel RJ, Tong YC. A pitch perception study for a cochlear implant user with residual hearing in the contralateral ear. J Acoust Soc Am. 1989;86(S1):S81.

153. Van Hoesel RJ, Clark GM. Fusion and lateralization study with two binaural cochlear implant patients. Ann Otol Rhinol Laryngol Suppl. 1995;166:233-35. [PMID: 7668650]

154. Van Hoesel RJM, Clark GM. Psychophysical studies with two binaural cochlear implant subjects. J Acoust Soc Am. 1997;102(1):495-507. [PMID: 9228813]

155. Van Hoesel RJM, Tyler RS. Speech perception, localization, and lateralization with bilateral cochlear implants. J Acoust Soc Am. 2003;113(3):1617-30. [PMID: 12656396]

156. Van Hoesel RJM, Clark GM. Speech results with a bilateral multi-channel cochlear implant subject for spatially separated signal and noise. Aust J Audiol. 1999;21:23-28.

157. Ching TY, Incerti P, Hill M. Binaural benefits for adults who use hearing aids and cochlear implants in opposite ears. Ear Hear. 2004;25(1):9-21. [PMID: 14770014]

158. Tong YC, Busby PA, Clark GM. Perceptual studies on cochlear implant patients with early onset of profound hearing impairment prior to normal development of auditory, speech, and language skills. J Acoust Soc Am. 1988; 84(3):951-62. [PMID: 3183213]

159. Clark GM, Blamey PJ, Busby PA, Dowell RC, Franz BK, Musgrave GN, Nienhuys TG, Pyman BC, Roberts SA, Tong YC, Webb RL, Kuzma JA, Money DK, Patrick JF, Seligman PM. A multiple-electrode intracochlear implant for children. Arch Otolaryngol Head Neck Surg. 1987; 113(8):825-28. [PMID: 3620142]

160. Dawson PW, Blamey PJ, Clark GM, Busby PA, Rowland LC, Dettman SJ, Brown AM, Dowell RC, Rickards FW, Alcantara JI. Results in children using the 22-electrode cochlear implant. J Acoust Soc Am. 1989;86 Suppl 1:S81.

161. Dowell RC, Dawson PW, Dettman SJ, Shepherd RK, Whitford LA, Seligman PM, Clark GM. Multichannel cochlear implantation in children: a summary of current work at the University of Melbourne. Am J Otol. 1991;12 Suppl:137-43. [PMID: 2069174]

162. Dawson PW, Blamey PJ, Rowland LC, Dettman SJ, Clark GM, Busby PA, Brown AM, Dowell RC, Rickards FW. Cochlear implants in children, adolescents and prelinguistically deafened adults: speech perception. J Speech Hear Res. 1992;35(2):401-17. [PMID: 1573879$]$
163. Staller SJ, Dowell RC, Beiter AL, Brimacombe JA. Perceptual abilities of children with the Nucleus 22-channel cochlear implant. Ear Hear. 1991;12(4 Suppl):34S-47S. [PMID: 1955089]

164. Dowell RC, Blamey PJ, Clark GM. Potential and limitations of cochlear implants in children. Ann Otol Rhinol Laryngol Suppl. 1995;166:324-27. [PMID: 7668690]

165. Dettman SJ, Pinder D, Briggs RJS, Dowell RC, Leigh JR. Communication development in children who receive the cochlear implant younger than 12 months: risks versus benefits. Ear Hear. 2007;28 Suppl:11S-18S. [PMID: 17496638]

166. Busby PA, Clark GM. Electrode discrimination by earlydeafened subjects using the cochlear limited multipleelectrode cochlear implant. Ear Hear. 2000;21(4):291-304. [PMID: 10981605]

167. Busby PA, Tong YC, Clark GM. Electrode position, repetition rate, and speech perception by early- and latedeafened cochlear implant patients. J Acoust Soc Am. 1993;93(2):1058-67. [PMID: 8445117]

168. Clark GM. Learning to hear and the cochlear implant. In: Fahle M, Poggio T, editors. Text book of perceptual learning. Cambridge (MA): MIT Press; 2002. p. 147-60.

169. Rickards FW, Clark GM. Steady-state evoked potentials to amplitude-modulated tones. In: Nodar RH, Barber C, editors. Evoked potentials II: The Second International Evoked Potentials Symposium. Boston (MA): Butterworth Publishers; 1984. p. 163-68.

170. Stapells DR, Linden D, Suffield JB, Hamel G, Picton TW. Human auditory steady state potentials. Ear Hear. 1984; 5(2):105-13. [PMID: 6724170]

171. McGurk H, MacDonald J. Hearing lips and seeing voices. Nature. 1976;264(5588):746-48. [PMID: 1012311]

172. Surowiecki V, Grayden DB, Dowell RC, Clark GM, Maruff P. The role of visual cues in the auditory perception of synthetic stimuli by children using a cochlear implant and children with normal hearing. In: Bow C, editor. Proceedings of the 9th Australian International Conference on Speech Science and Technology; 2002 Dec 14; Melbourne, Australia. Melbourne (Australia): Australian Speech Science and Technology Association, Inc; 2002.

173. Pijl S, Schwarz DW. Melody recognition and musical interval perception by deaf subjects stimulated with electrical pulse trains through single cochlear implant electrodes. J Acoust Soc Am. 1995;98(2 Pt 1):886-95. [PMID: 7642827]

174. Pijl S. Pulse rate matching by cochlear implant patients: effects of loudness randomization and electrode position. Ear Hear. 1997;18(4):316-25. [PMID: 9288477]

175. Clark GM. The bionic ear in the second and third millennia. Proc Aust Neurosci Soc. 1999;10:4.

176. Clark GM. Research advances for cochlear implants. Auris Nasus Larynx. 1998;25(1):73-87. [PMID: 9512798$]$ 
177. Paolini AG, Clark GM. The effect of pulsatile intracochlear electrical stimulation on intracellularly recorded cochlear nucleus neurons. In: Clark GM, editor. Cochlear implants. XVI World Congress of Otorhinolaryngology Head and Neck Surgery; 1997 Mar 2-7, Sydney, Australia. Bologna (Italy): Monduzzi Editore; 1997. p. 119-24.

178. Wise AK, Richardson R, Hardman J, Clark G, O’Leary S. Resprouting and survival of guinea pig cochlear neurons in response to the administration of the neurotrophins brain-derived neurotrophic factor and neurotrophin-3. J Comp Neurol. 2005;487(2):147-65. [PMID: 15880560]

179. Neely ST, Kim DO. A model for active elements in cochlear biomechanics. J Acoust Soc Am. 1986;79(5): 1472-80. [PMID: 3711446]

180. Au D, Bruce I, Irlicht L, Clark GM. Cross-fiber interspike interval probability distribution in acoustic stimulation: a computer modeling study. Ann Otol Rhinol Laryngol Suppl. 1995;166:346-49. [PMID: 7668700]

181. Clark GM. Cochlear implants in the Third Millennium. Am J Otol. 1999;20(1):4-8. [PMID: 9918163]

182. Paolini AG, FitzGerald JV, Burkitt AN, Clark GM. Temporal processing from the auditory nerve to the medial nucleus of the trapezoid body in the rat. Hearing Res. 2001;159(1-2):101-16. [PMID: 11520638]

183. Kuhlmann L, Burkitt AN, Paolini AG, Clark GM. Summation of spatiotemporal input patterns in leaky integrate-andfire neurons: application to neurons in the cochlear nucleus receiving converging auditory nerve fiber input. J Comput Neurosci. 2002;12(1):55-73. [PMID: 11932560]

184. Marzella PL, Clark GM, Shepherd RK, Bartlett PF, Kilpatrick TJ. Synergy between TGF-beta 3 and NT-3 to promote the survival of spiral ganglia neurons in vitro. Neurosci Lett. 1998;240(2):77-80. [PMID: 9486476]

185. Shepherd RK, Coco A, Epp SB, Crook JM. Chronic depolarization enhances the trophic effects of brain-derived neurotrophic factor in rescuing auditory neurons follow- ing a sensorineural hearing loss. J Comp Neurol. 2005; 486(2):145-58. [PMID: 15844207]

186. Richardson RT, Wise A, O’Leary S, Hardman J, Casley D, Clark G. Tracing neurotrophin-3 diffusion and uptake in the guinea pig cochlea. Hear Res. 2004;198(1-2):25-35. [PMID: 15567599]

187. Black RC, Clark GM, O’Leary SJ, Walters CW. Intracochlear electrical stimulation of normal and deaf cats investigated using brainstem response audiometry. Acta Otolaryngol Suppl. 1983;399:5-17. [PMID: 6316713]

188. Clark GM, Shute SA, Shepherd RK, Carter TD. Cochlear implantation: osteogenesis, electrode-tissue impedance, and residual hearing. Ann Otol Rhinol Laryngol. 1995;104: 40-42. [PMID: 7668722]

189. Chow JK, Seldon HL, Clark GM. Experimental animal model of intracochlear ossification in relation to cochlear implantation. Ann Otol Rhinol Laryngol Suppl. 1995;166: 42-45. [PMID: 7668732]

190. McAnally KI, Clark GM. Stimulation of residual hearing in the cat by pulsatile electrical stimulation of the cochlea. Acta Otolaryngol. 1994;114(4):366-72. [PMID: 7976307]

191. Morrison NA, Brown M, Clark GM. Electrophonically driven single unit responses of the anteroventral cochlear nucleus in the cat. Proceedings of the Australian Neuroscience Society Seventh Annual Meeting; 1996; Bedford Park, South Australia. Bedford Park (South Australia): Australian Neuroscience Society; 1996. p. 226.

192. Morrison NA. Single unit responses in the anteroventral cochlear nucleus to electrophonic excitation of the cochlea (bachelor's thesis). Melbourne (Australia): University of Melbourne; 1995.

Submitted for publication May 2, 2007. Accepted in revised form August 13, 2007. 